

375

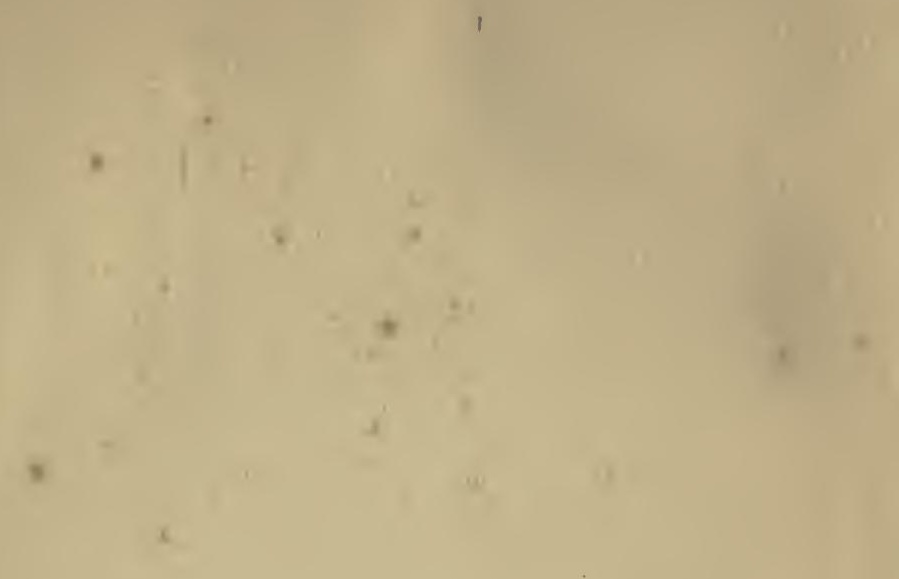

in

*

n

$$
1
$$


Digitized by the Internet Archive in 2007 with funding from Microsoft Corporation 


\section{HOW TO KEEP BEES FOR PROFIT}




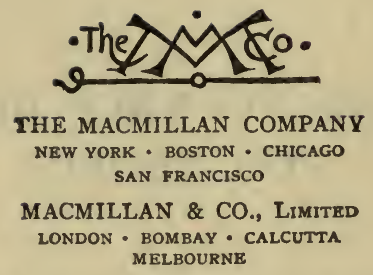

THE MACMILLAN CO. OF CANADA, LtD. TORONTO 
7
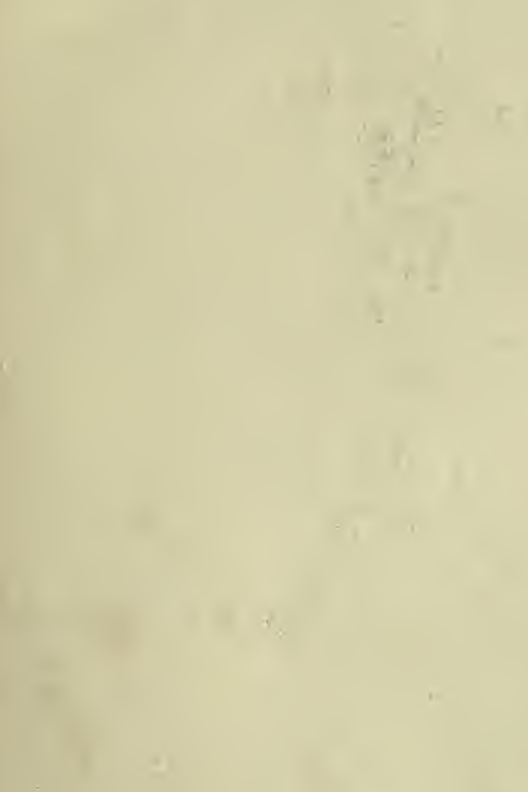

$x$
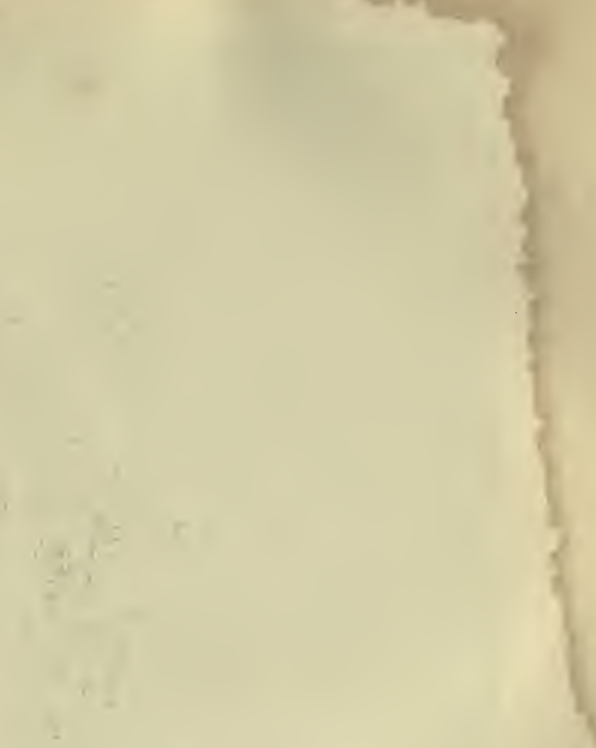


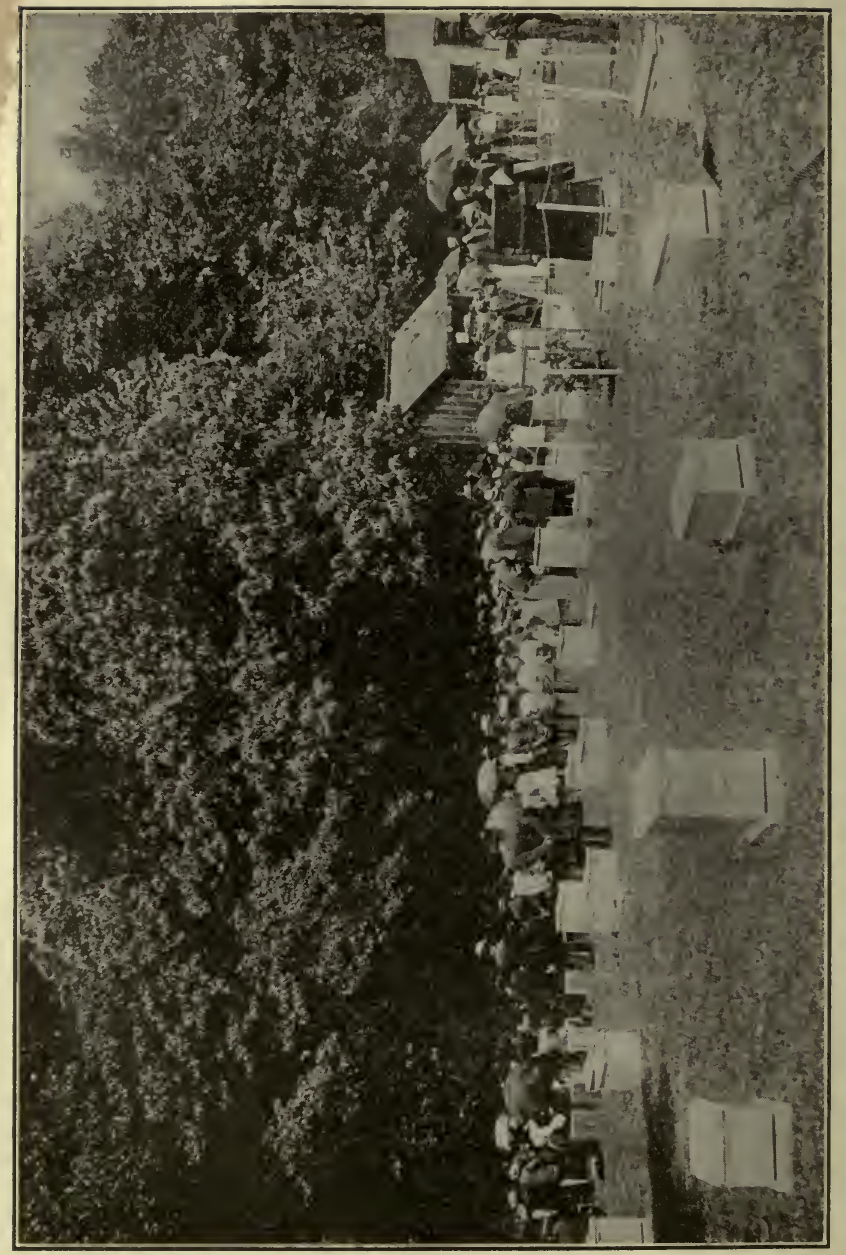

हूँ
है
हूँ
है

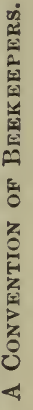




\title{
HOW TO KEEP BEES FOR PROFIT
}

\author{
BY \\ D. EveretT LYON, Ph.D.
}

WITH FRONTISPIECE

Torew 19atk

THE MACMILLAN COMPANY

1920

All rights reserved 


\section{Univ. Library, UC Santa Cruz 1997}

Coptright, 1910,

BY THE MACMILLAN COMPANY.

Set up and electrotyped. Published May, rgro 


\section{SF 523 48}

\section{INTRODUCTION}

As far back as the dawn of history the honey bee was regarded as a benefactor to man, and it is not surprising, therefore, that on the ancient monuments of Egypt, in the classic writings of Rome and Greece, we find many references to the bee, which, with the exception of the silkworm, has the distinction of being the only insect kept by man in a semi-domestic state for his benefit. The interest of our forefathers in these busy little people was due to the fact that honey was practically the only sweet which they could readily obtain.

The bees were hunted in their native habitat in the cleft of the rocks, in the heart of the trees of the forest, and such other places where they were accustomed to build their combs. In securing their golden stores the 
hunters were compelled to smoke and destroy the bees, thus creating in them a fear of smoke that has been inbred for centuries.

So deeply ingrained is this fear that the modern beekeeper has but to puff a little smoke into the entrances of their hives to render them tractable and permit of their easy handling, and that without any serious interference with their multiform labors.

We do not have to search the records of the past to find evidences of the brutal and needless destruction of bees to secure their honey; for it is still the custom of a large number of ignorant beekeepers to brimstone their faithful little workers, when the adoption of modern hives and methods, neither expensive nor intricate, would render it unnecessary.

During the last few centuries there have been naturalists of note who have given much time to the study of the habits of the honey bee, and the literature of the world has been greatly enriched by the observations of Jan Swammerdam, born at Amsterdam in 1637; 
Huber, the blind Swiss, who was ably assisted by a devoted wife and faithful manservant; as well as a host of others equally well known.

No less great a personage than Pliny has recorded his observations of the honey bee, and Shakespeare also frequently mentions it.

Of modern writers, Dzierzon in Germany, Cheshire and Cowan in England, Langstroth, Quinby, and Root in America, have added to the rich store of knowledge we have on Apis mellifera.

The Belgian Maeterlinck is not to be taken seriously in his interesting little book, "The Life of the Bee"; for however attractive it may be from a literary standpoint, it teaches the rankest heresy concerning the habits of these wonderful little people, and shows but a superficial knowledge of them.

The late Lorenzo Lorraine Langstroth, known as the Father of American Bee-keeping, was the inventor of the hive which bears his name, and its almost universal adoption in this country has wrought a revolution in bee- 


\section{N T R O D U C T I O N}

keeping both from the commercial standpoint and in the ease with which the life work of the bees may be studied.

It is the purpose of this volume to give the reader an insight into the life history of the bee family, and point out the various methods by which they may be made of increased interest and profit. 


\section{CONTENTS}

\section{INTRODUCTION}

OHAPTER

I. Bees-Fruit - Honey and Money • - 1

II. Physiology of the Honey Bee • - 11

III. RACES of BeEs • • • • • • 18

IV. The Home of the Bees • • • - 28

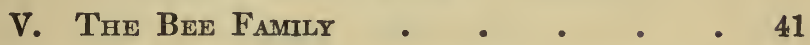

VI. How to start BeEkeEping - Hives and Tools - Transferring Bees • • 55

VII. How to quiet and handle Bees-How to AVoid Stings - Remedies . 73

VIII. Why Bees Swarm - How to hive a Swarm 一 How to control Swarming • $\quad 83$

IX. Raising Queen Bees-How to introduce

A QUEEN • • • • • • 97

X. How to produce Comb Honey - • . 117

XI. How to proddce Extracted Honey. • 133

XII. How to make Increase • • • • 152

XIII. Location of the Apiary - Out Apiaries

-Moving Bees . • • • • . 172 ix 


\section{CONTENTS}

OHAPTER

XIV. Diseases and Enemies of Bees • 187

XV. Marketing the Honey Crop • • - 202

XVI. BeEswax - Its Uses - How to Render It 217

XVII. Honey as a Food And Medicine • 230

XVIII. Robber Bees - How to prevent Robbing 258

XIX. Feeding • • • • • • • • 269

XX. How to winter Bees Successfully • 283

XXI. SOURces OF HoNeY . • • • . 297 


\section{HOW TO KEEP BEES FOR PROFIT}





\section{HOW TO KEEP BEES FOR PROFIT}

\section{CHAPTER I}

\section{BEES - FRUIT - HONEY AND MONEY}

A HIVE of bees nestling in the grass in A the orchard is neither artistic nor ornamental in the eyes of most people, and the sentiment it inspires may even be one of fear.

But when we consider that within its narrow confines there is housed a teeming population of over thirty thousand of the busiest little folk in the world, the feeling changes from fear to amazement at the wonderful work that is there going on.

Judging from the size of the population, we should naturally infer that pandemonium would reign; and this belief would be strengthened by the constant bustle and hum that 
accompany the bees as they come and go from their humble home to the fields in quest of nature's sweets.

Instead of chaos being the order of things, the very reverse is true; and each denizen of the hive has its allotted task which it busily and joyfully performs, and that with clocklike precision.

The young bees for the first few days of their existence spend their time in taking care of their developing brothers and sisters, feeding the larvæ a food made of a mixture of honey, pollen, water, and a secretion from the glands of the head and chyle-stomach, and only varying this task by an occasional play spell of flying in front of the hive during the early part of the afternoon. Other bees, fully matured, are afield in quest of pollen from the flowers, while others are gathering propolis, or bee-glue, with which to firmly fasten the lids and bottom boards of their homes. Others still are carriers of water, while the main force of field bees are busily 
BEES-FRUIT-HONEY AND MONEY

engaged in sipping from the flowers the nectar awaiting them.

At the entrance of each hive is a number of sentinel bees, armed with their sharpened spears, ready to repel robber bees from strange hives, or whatever else may threaten to disturb them. No bee returning from the field can pass the vigilant sentinels without the proper countersign, and that countersign is the distinctive odor of the colony to which it belongs, for this is the only means of identification the bees possess; and so powerful are their organs of sense, that a strange bee seldom passes by them. These sentinels are relieved from time to time, but at all times, during the genial days of spring, summer, and early fall, the entrance to their little homes is fully guarded.

With a mother queen to rule them and provide the offspring to take the place of the old bees that are constantly dying (for the average life of a worker bee is only about five weeks), the work of rearing the young, the building 
HOW TO KEEP BEES FOR PROFIT of comb, and the storing of honey against a rainy day goes steadily on.

With a knowledge of these facts does not the aspect of the hive change from a commonplace-looking box to a veritable kingdom, presided over by royalty, which challenges our interest and admiration, and at once inspires in us the purpose to become the better acquainted with it?

Another thing we should not overlook - and we are liable to do so if we look at the hive only from the standpoint of the number of pounds of honey it is likely to produce - is, that bees bear a close and vital relation to the matter of fruit production in the neighborhood. The real mission of the honey bee after all is not the production of honey, for that is only incidental, but rather to insure the proper pollination of our fruit blossoms, and were it not for their active agency in this department of agricultural life, the fruit output of the country would be astonishingly small.

A careful examination of the body of a 
BEES-FR UIT-HONEY AND MONEY

worker bee will reveal that nature has clothed it in a coat of fuzzy down, and as the little fellow enters the blossom in search for its hidden sweets, the particles of pollen adhere to the down, so that as the bee goes from flower to flower, it unconsciously performs the work of cross pollination.

It is a remarkable fact that nature gives the nectar-secreting organs only to those blossoms whose fruit demands the pollination of their seeds.

There have been certain sections of the country, where soil and climatic conditions were in every respect favorable to fruit production, yet there was a surprising lack of fruit, and careful examination has shown that bees were not present in the neighborhood.

Horticulturists were thus led to import bees from a distance, with almost immediate benefit to the orchards. So, if for no other reason than that of securing a good quantity and quality of fruit, bees have proved a real blessing to the farmer and the suburbanite. 
The phase of bee-keeping, however, that most appeals to the average man or woman, is that of honey production, and in this respect it is an unusually safe undertaking.

It is surprising how locations, apparently most unpromising, will often produce a crop of honey from sources hitherto unsuspected, and yet it is a fact that the bees by their mar vellous industry, and long flights of as much as five miles from home, will year after year richly reward their owners by a substantial surplus.

There are possibly not over two hundred persons of all classes, including many professional men and women, in the United States who make bee-keeping a sole means of livelihood, and though the possibilities of profit are almost infinite, the majority of people are contented to keep from two to twenty-five hives of bees as a side line. Some of the most successful beekeepers are women, their deft fingers making them particularly adapted to the rapid handling of bees, especially in 
BEES-FR UIT-HONEY AND MONEY

commercial queen-rearing, of which we shall speak later on. Smokers with which to subdue the colonies, veils for the faces, and gloves for the hands will enable the most timid to keep bees with perfect safety, and to go through the entire season without experiencing the slightest annoyance from stings.

How much honey a single hive of bees will produce in a single season, and how profitable bees may become, are questions that are frequently asked by the prospective beekeeper, and in answer it may be said that results will depend upon the flora of the locality, the amount of care given to the bees, and the conditions under which they have been wintered.

It is an undisputed fact that bees are the most profitable of stock that can be kept, as their keeping involves little outlay beyond the initial expense of the proper outfit, and a small amount of time given them.

There is a large number of business men who have suburban homes, and keep a few colonies of bees, giving to their care only the 
time remaining after they return home late in the afternoon, or in the early morning before going to business, yet who have made a marked profit from the keeping of their few hives. The writer has had individual colonies that have given as high as one hundred and twenty pounds of comb honey each, which was sold to the neighbors for twenty-five cents a pound, leaving a net profit of over $\$ 25$ a hive; this, however, was exceptional, though I have known a number of people who have kept a few hives of bees to average this and more from every hive.

It should be remembered that when a large number of hives are kept in a limited territory, the output per hive will diminish in proportion to the number of hives kept in the home yard, as there will be more bees for the blossoms to support, but where not more than seventy-five hives are kept in a fairly large section, there should be little difficulty in reaping a profit close on to $\$ 5$ or $\$ 6$ per hive. Unless one is located in the buckwheat or alfalfa 
BEES-FRUIT-HONEY AND MONEY

section of the country, the better plan would be not to overstock the home yard, but rather resort to a system of outyards, placing fifty to sixty hives of bees in, say, three yards, one at the home and the others three miles from the home in opposite directions, all of them being easy of access. In this way the possession of, say, one hundred and fifty hives of bees in the hands of an experienced person should provide a fair income, especially if the product is sold in the neighborhood at retail prices.

There is a large number of people who keep only three or four hives of bees to supply their own table, and an occasional gift of honey to a friend, who get great pleasure from keeping them, and who like to point with pride to the comb of immaculately white honey on the table as the product of their busy bees.

When it comes to a production of honey which runs up into tons, then the placing of the product comes under the heading of How to Dispose of the Crop, of which we will speak in a later chapter. 
HOW TO KEEP BEES FOR PROFIT

By all means get some bees, and be sure that you will never regret it; for the writer, after fifteen years' experience in the keeping of bees, is as enthusiastic as when, many years ago, he became the proud possessor of an oldfashioned hive, and acquired the "Bee Fever," from which he has never recovered, and never expects to recover. 


\section{CHAPTER II}

\section{PHYSIOLOGY OF THE HONEY BEE}

T $\mathbf{T}$ would be impossible to minutely de1 scribe the physiology of the honey bee within the narrow confines of a single chapter, nevertheless in the keeping of bees it is necessary to understand the most important of their physical characteristics. A more thorough and extensive discussion of their various organs can be found in works by Cheshire and others, who devote whole chapters to a single organ or function of A pis melifera.

The honey or hive bee belongs to the order Hymenoptera, perhaps the most comprehensive order of insects, most of which are remarkable for social traits and quality of instinct.

As we look into the brood nest of a colony of bees, we find that they have built a number 
HOW TO KEEP BEES FOR PROFIT of accurately spaced combs, in the cells of which they store their honey and pollen, and rear their

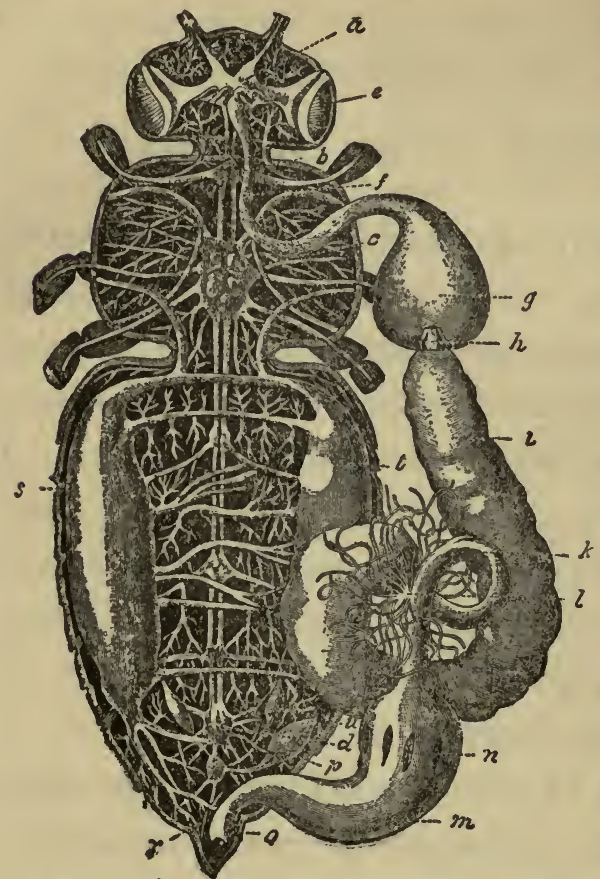

young. The combs are made of beeswax, and are composed of worker and drone cells, hexagonal in shape and as thin as paper. In these cells the queen deposits her eggs, which the clustering bees

Honey bee dissected. After Witzgall. maintain at a proper temperature, varying the kind of food according to the cell and the kind of egg that reposes in it. The eggs will hatch in from sixteen to twenty-four days, a worker egg taking 
PHYSIOLOGY OF THE HONEY BEE

twenty-one days, a drone twenty-four, while a queen cell requires but sixteen days.

The laying powers of the queen bee are remarkable, as she will lay anywhere from two thousand to five thousand eggs in a given twenty-four hours. She does not, however, lay at this rate during the entire year, but does her best during the breeding season, during the summer and spring months. She is the only perfectly developed female in the hive, whereas the workers are imperfectly developed females; their lack of development being due to the smaller cells in which they are reared and the absence of royal jelly in the food that is given the egg and larvæ.

The drones are perfectly developed males, and their sole function is the fertilization of the virgin queens, an act taking place while in flight, and resulting in the immediate death of the drone.

Unlike mammals, the bees have no skeleton as a framework for support, but have a framework mostly external, composed of a horny 
bonelike substance called chitine. The body of the bee is made up of three distinct parts, the head, the thorax, and the abdomen, all closely related.

Extending from the head on each side are the antennæ, most delicate organs, in which are located the senses of hearing and smelling, and an unknown sense by which they can communicate their desires one to another.

There are also located in the head of the honey bees two sets of eyes, five in number; the three convex eyes, or ocelli, are microscopic in power and are used by the bees while working in the dark recesses of their hives.

The two large compound eyes are composed of thousands of little eyes or facets arranged over the front and sides of the head, thus enabling the bee to see in many directions when in flight.

Projecting from the head and mouth of the honey bee is another wonderful and delicate organ, the tongue, marvellously adapted to the work for which it is intended. In the 
PHYSIOLOGY OF THE HONEY BEE

first place, it is not round like a tube, but is in reality a flexible trough, the edges of which can be brought together to enable the busy worker to extract the last drop of nectar from the yielding blossoms.

By various experiments in breeding, the tongue of some strains of bees has been lengthened considerably, thus enabling them to extract the nectar from the red clover, whose corolla is so deep that its hidden sweets are beyond the reach of the ordinary bee.

The thorax is the intermediate part of the body of the bee, and in it are located the organs of locomotion, consisting of six legs and four wings. The posterior legs are the most interesting, as they have on them the little receptacles for pollen in which the bees carry the pollen from the flowers to their hives; sometimes they are so heavily loaded as to be seriously impeded in their flight.

The honey sac is located in the abdomen, and is a false or secondary stomach, and is the vessel in which the bee carries the nectar from 
the field to its hive. The heart of the honey bee is made up of five elongated sections, resembling in appearance a clinical thermometer; beginning in the head, it extends through the thorax clear to the extremity of the abdomen.

The blood of the bee is colorless, and is oxygenated by the air coming in contact with it through the many trachex, or breathingholes, with which the outer shell of the bee is pierced.

Extending from the lower extremity of the abdomen of the bee is its sting. It is barbed like a spear, so that the bee can seldom withdraw it when once it is inserted, and it is the tearing away of its sting that so mutilates and cripples the bee that it usually dies after stinging. The poison of the sting is similar to that of the bite of the rattlesnake, and it is estimated that if a person should be stung by five hundred bees at a time the poison injected into the system would be about the same in quantity as that from the bite of a rattlesnake. The drones have no stings, and the queen 
PHYSIOLOGY OF THE HONEY BEE seldom uses hers except to aid in depositing her eggs.

As we stated at the beginning of this chapter, it is impossible to give more than a casual glance at the physiology of the bee and merely call attention to some of its organs, for to do full justice to the intricate and delicately adjusted machinery of these wonderful little creatures would require a work three times the size of the present one. The nature student who is interested solely in the natural history of the honey bee, and to whom the commercial and profitable part of bee-keeping does not appeal, we would refer to the excellent books by Cowan, Cheshire, Cook, Langstroth, Burroughs, and others who have gone into a detailed and elaborate discussion of the subject of bee physiology.

The organs and various functions outlined are practically the same in all varieties of bees, and it is the possession and use of these various powers that enables them to carry on their laborious and profitable work. 


\section{CHAPTER III}

RACES OF BEES

THERE are many races of bees, as many, 1 in fact, as there are different races of the human family, and each race has its distinctive racial characteristics. Among them are the Common Blacks, the Italians, the Carniolans, the Caucasians, the Cyprians, the Banats, the Holy Lands, as well as many others which it would be useless to describe, as the majority of beekeepers keep either the Italians or the Blacks.

The Blacks are widely distributed throughout the United States, having been brought over by the early settlers, while the Italians are of quite recent importation. The Blacks, while fairly good honey gatherers, and builders of the whitest combs, a thing much desired 


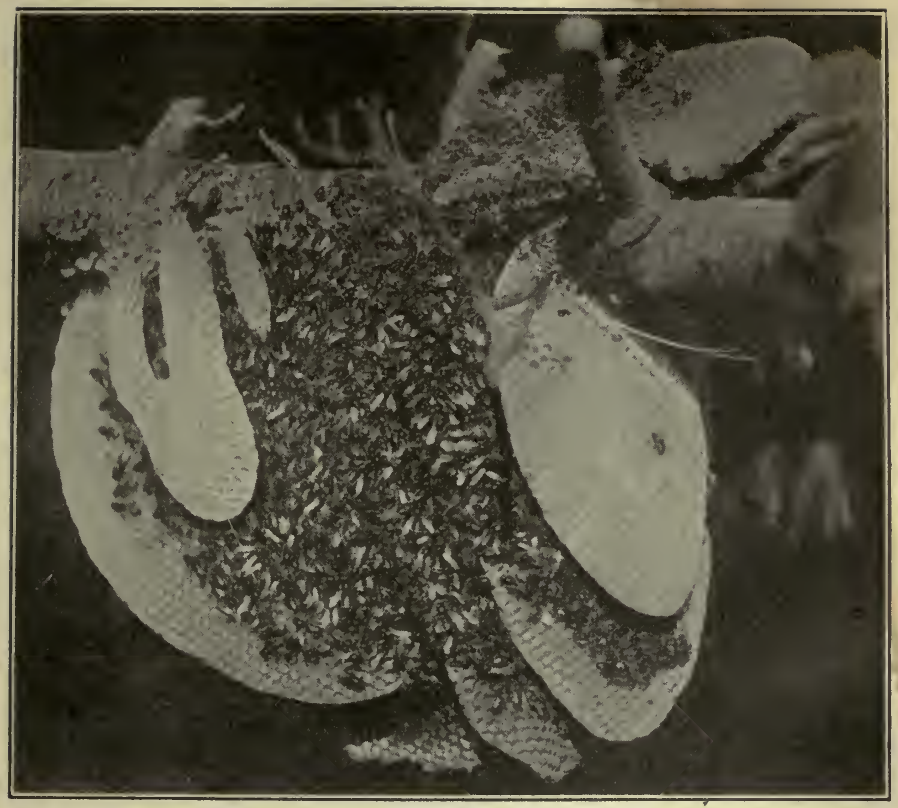

Bees living on Combs built in the Open Air.

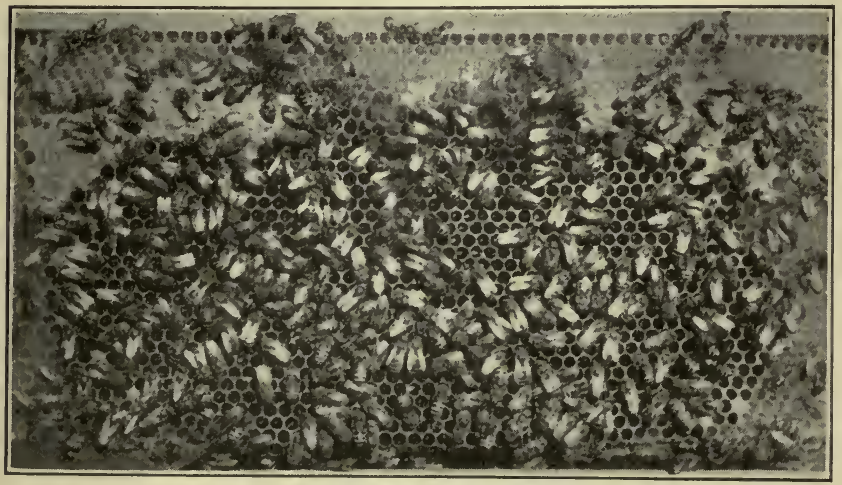

A Frame of Bees. 



\section{RACES OF BEES}

by the producer of comb honey, are seldom if ever kept by the progressive beekeeper, owing to certain undesirable traits of character.

They are of a very nervous temperament, and are apt to rush all over their combs when being manipulated, which renders the finding of the queen a hard task; they will also gather in great clusters on the ends of their frames and fall to the ground, to the annoyance and discomfort of the person handling them. They are very irritable, and will often fly from their hives and attack the passerby with no provocation whatever. Whether they are naturally lazy or quickly disheartened, the fact remains that they do not seem able to resist disease and enemies as vigorously as the Italians. Again and again have I seen a strong colony of Blacks completely destroyed through the ravages of the bee moth or from disease, which a weak colony of Italians seem able to resist.

One thing is certain, the Blacks become 
discouraged and quit working upon the first indication of a cessation of the honey flow, and thus leave a lot of unfinished sections in their supers, while other races will continue working right up to the close of the flow.

These undesirable traits have induced the majority of beekeepers to discard them, though some beekeepers prefer a hybrid race of Italians and Blacks, as they claim they get in such a mixture of blood the gentleness and hustling qualities of the Italians and the superior comb-building qualities of the Blacks. However, any one who has kept Hybrids can vouch for the fact that what is gained is more than offset by the viciousness of the Hybrid, as they seem possessed of an incurable propensity to sting.

The Cyprians have been extensively kept; they are natives of the Island of Cyprus, and as honey-gatherers are without an equal.

They are good defenders of their hives, and will repel the attacks of diseases and robber bees better than any other known 


\section{RACES OF BEES}

race, and are most excellent winterers. As workers they are indefatigable, gathering honey from every available quarter even after other races have quit, but they have the habit of filling their cells completely full, so that the combs have a watery appearance, which renders its sale difficult, hence the few beekeepers who stick to them run them mostly for extracted honey. While this race has all of the desirable qualities attributed to them, their dispositions are so vicious, that there is hardly a beekeeper in the land who keeps an absolutely pure strain of Cyprians. By no means should the novice ever think of keeping Cyprians, as they are extremely sensitive, and resent the slightest jarring of their hives, and when once aroused no amount of smoke will subdue them, in fact, it seems to infuriate them the more.

The Carniolans are large gray bees from the Alpine regions of Carniola in Austria, and with the exception of the Caucasians are the gentlest race known. Coming originally from 
HOW TO KEEP BEES FOR PROFIT

a cold country, the Carniolans are the hardiest race we know, and not being so sensitive to cold as other races, will begin to go afield earlier in the morning, and work later in the day than others, and for this reason, they winter unusually well. Their comb honey is the best produced, as they do not, like the Cyprians, fill their cells completely full, and thus they produce comb honey of snowy whiteness.

To handle them is a delight, as they seldom sting, and I have worked with them day in and day out without any protection for the face or hands, and for weeks at a time have gone without being stung.

But the great objection to the Carniolans, and one that has led most beekeepers to discard them, is their proneness to frequent and excessive swarming, which means a loss of bees and a loss of honey. The Caucasians are in appearance not unlike the Carniolans, and certain strains of them are hardly distinguishable from the Blacks, but in dis- 
position they are in a class by themselves, as their gentleness is simply marvellous. Again and again I have tried to anger them without success; in fact, I have kicked their hives, shaken their frames, blown my breath on them, and, whereas other races would have attacked me at once, the Caucasians would offer no retaliation. It might be inferred from this that they are not good defenders of their hives; but such is not the case, for there have been times when I have been abusing them, when they would sally forth and fight to the death robber bees that tried to take advantage of their hives being opened out of season, to rob them of their stores.

They are good winterers, and builders of choice white combs, and not given to excessive swarming, but they have an unpleasant habit of plastering balls of propolis, or beeglue, all over their frames and at the entrances of their hives.

The main objection to this otherwise most excellent race is the fact that they so closely 


\section{HOW TO KEEP BEES FOR PROFIT}

resemble the Blacks that only an expert can distinguish the difference, and if one is not careful, before long the entire apiary will be made up of Blacks.

The Banats are a race of bees from Hungary, in appearance similar to the Caucasians, remarkably gentle, and, best of all, are great breeders in the early spring, so when the honey flow comes on they have a great force to gather it. They build beautiful white combs and gather little propolis, and are so little given to swarming that some beekeepers have claimed that they are a non-swarming race. However, their introduction is so recent that the beginner will do well to pass them by until a thorough test shall have firmly established their good qualities.

On the whole it may be said that fully 75 per cent of the professional beekeepers prefer the Italians, as this race seems to have more desirable traits and fewer disagreeable ones than any other. These bees came originally from Italy, the first successful importation of 
queens being about 1861, and at once leaped into favor, maintaining their precedence to the present time. In appearance they are very handsome, varying in color from a leatherbrown to the most lustrous gold, and, as compared with the Blacks, are remarkable for their gentleness. They rarely get nervous when they are handled, and it is very easy to find their queens. I have frequently opened their hives after nine o'clock in the evening, and have often brought a comb of bees into the house and passed it around for visitors to examine, and I have yet to know of an occasion where those so examining them have been stung, though they will sting if sufficiently provoked.

They are energetic workers, not easily discouraged, and, having originally come from a warm climate, they are alert for enemies and seem to have no trouble in repelling the bee moth.

It has been said that the Italian bees are more prone to rob than other races, but this 
is an evidence of their honey-gathering qualities. It may be likewise said that when precautionary methods are taken they soon cease to rob, a thing that cannot be said of some of the other races when the habit has once been formed. After many years of experience with almost every known race of bees, I have been compelled to come back to the Italians as the best general-purpose bee in existence.

Of late years there has been a tendency toward golden-all-over Italians on the part of some beekeepers, and this demand has led some breeders in their anxiety to quickly produce them to use a Cyprian cross because of their bright golden color, with the result that some strains of Italians are as vicious as the pure Cyprians. For this reason the beginner will do well to select Italians of a leather color, as they are more certain to be of a pure strain, and experience has proved that they winter much better than the golden ones.

In selecting Italian bees it would be a wise 


\section{RACES OF BEES}

thing to secure from some reputable breeder queens of the red clover strain, as these bees will visit and secure a rich harvest from red clover, whereas ordinary Italian bees will seldom visit it, as their tongues are not sufficiently long to reach down into the deep corolla of the blossom. 


\section{CHAPTER IV}

\section{THE HOME OF THE BEES}

THE natural home of the honey bee 1 before it became domesticated was in the heart of a forest tree, or in the cleft of a rock, sheltered from the wind and rain, and more or less protected from the cold.

That the remembrance of their early homes still remains is shown by the fact that when a swarm is not hived, and gets away before its owner can care for it, they are apt to seek the interior of a partially decayed tree, entering and emerging through a knothole. It is not uncommon to find a tree thus tenanted by a vagrant swarm. I have also found many swarms that have made their homes under the weather boards of a house or under the eaves of a garret; only a few years ago I 


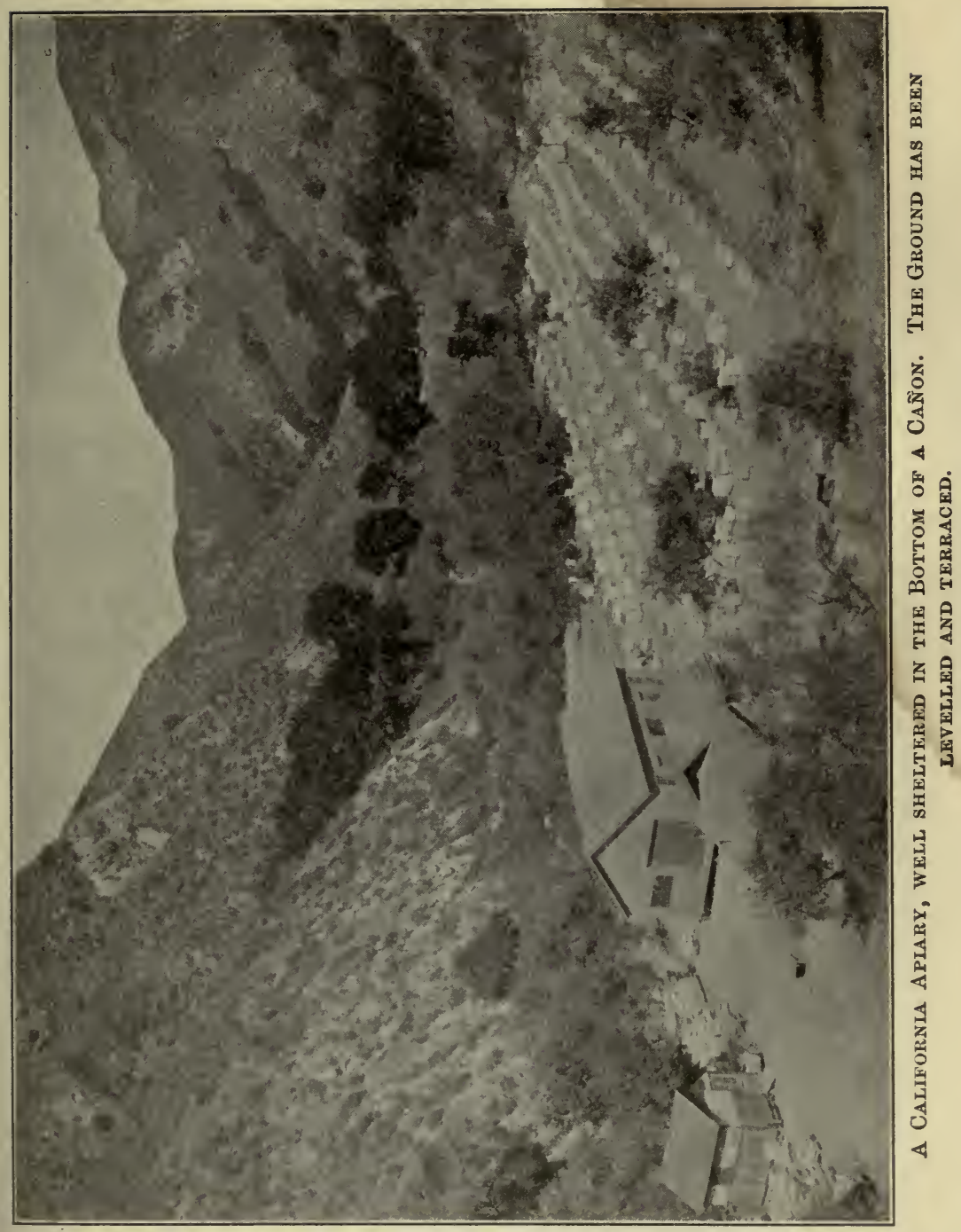





\section{THE HOME OF THE BEES}

removed a swarm of bees from a bird box, where the bees had driven the birds from their homes and taken complete possession.

Whether a swarm finds its home in a modern hive or in the heart of an old tree, the first thing they proceed to do is to remove all trash and render it scrupulously clean, for they are the most cleanly little creatures in existence. Again and again have I seen bee trees where the process of decay had already begun, but no sooner had a swarm of bees taken possession than they at once removed all decayed wood, and so completely varnished its interior with propolis, or bee-glue, that future decay was impossible.

We are, however, more interested in the modern home, or hive, of the bee. Lifting its lid and glancing within, we find a set of eight or ten irames of comb, according to the size of the hive. We say "frames" of combs, for no up-to-date beekeeper would think of throwing a swarm of bees into an empty hive and permitting them to build their combs in 
every direction, as this would render manipula. tion of the hive an impossibility. The late Lorenzo Langstroth was the inventor of the movable frame hive with bee space, and his invention has revolutionized the industry. These frames fit the hive bodies and have a bee space all around them so as to leave no space for the bees to build bur and brace combs, which would make it impossible to lift them out to examine the brood, find the queen, and do such other work as from time to time is essential.

By the use of frames it is possible to lift out a single frame of comb at a time without tearing each comb from the sides of the hive, as each comb is nicely built in the frame and bound on all sides by wood. To insure straight combs and a large proportion of worker cells, all progressive beekeepers piace in each frame before the time of hiving the swarm a large sheet of wax foundation, which nearly fits the frames, and on which have been stamped the rudiments of cells. These sheets of foun- 


\section{THE HOME OF THE BEES}

dation are wired in, so that when the combs are built out from them each comb is held securely in place and no danger of the comb breaking loose from the frame is possible in handling or when extracting the honey. This foundation must of necessity be pure beeswax melted and moulded, as the bees will not accept or work on any substitute that has been found, so that, the foundation being pure beeswax like the comb that is built on it, the honey is in no sense adulterated.

Many thousands of pounds of foundation are used annually by beekeepers, and this has given rise to the popular notion that it is possible to make artificial combs, fill them with glucose, cap them, and sell them as pure honey. It might be said here that there never yet has been produced a pound of artificial comb honey, and so determined are the beekeepers to stop the lie that the National Beekeepers' Association offers a standing reward of $\$ 1000$ for the first pound of artificial comb honey that shall be produced. 
Looking down into the home of the bees, we find a number of frames of comb running from front to back of the hive and covered by clustering bees. These combs constitute the furniture of the bees, for in the cells of the combs they rear their young and store their honey. The bees usually begin at the tops of their frames and build their combs downward until every frame is nicely filled.

These combs are made of wax, which the bees manufacture from the honey with which they have filled their stomachs. Hanging in clusters, they produce small pentagonal disks of wax from the little wax scales or pouches on the under side of the abdomen of the worker bee. The work of wax-building, like that of feeding the eggs, is done mostly by the young bees, as the older bees seem to have lost the wax-producing power with old age. It usually takes the bees about twentyfour hours to produce wax after having gorged themselves with honey, and they will consume from nine to ten pounds of honey to produce 
THE HOME OF THE BEES

a pound of wax. Sometimes, but not often, a colony will use pieces of old comb in waxbuilding, but generally they prefer the fresh disks, as being more pliable.

Their cells are hexagonal in shape, thus conforming to one of the main principles of mathematics, in the matter of occupying all available space and also of securing the greatest structural strength. The cells are not horizontal, but incline from their opening to their bottom, so as to be filled with honey the more easily by the bees and to prevent their running over.

The comb is a trifle over an inch in thickness, with cells on each side, and in their natural state the bees space their combs about $\frac{7}{16}$ of an inch apart, so that they may travel with comfort between them. These combs when first built are a beautiful white, but they soon become discolored, and when old will be almost black, but this does $n c t$ impair their usefulness, as they will last for several years. Being non-conductors of heat and cold, they 
become a perfect medium for keeping the bees warm, and likewise usually prevent the honey from granulating.

The cells in which the workers are reared are much smaller than those in which they rear their drones. While it cannot be said that all cells are mathematically correct, it can be generally stated that there are about twentyfive cells to a square inch.

It cannot be said that the bees act with intelligence in the matter of cell-building, first building worker and then drone cells, for recent experiments seem to prove that they are simply reflex machines, obeying without violation a law of nature.

Besides the combs we will find that the bees have used some propolis, or bee-glue, with which they have stopped the cracks of their hive and rendered it rain and wind proof. For some reason the bees cannot tolerate any foreign object in their homes, and should a piece of wood or other movable substance be thrown into their hives, they will immediately proceed 
THE HOME OF THE BEES

to tightly propolize or glue it in place. I have known of instances where squirrels, snakes, mice, and even toads, have invaded a hive and been stung to death, and the bees, being unable to remove the carcass, have covered it with a thick coating of propolis until it has been literally embalmed or mummified. The propolis is secured from resinous trees, and when first gathered is so sticky that the bees smear it over their hives at once. Certain races of bees gather more propolis than others, the Caucasians particularly being generous, in fact too generous, in its use. There is no doubt that while propolis is troublesome when prying off the lids of hives, and taking out the frames, it is nevertheless a preservative to the wood of the hives and adds to their life and usefulness.

It was their love for propolis or glue that led to the wide publication some years ago of the story of the funeral of a German beekeeper, whose coffin, as it was carried from the house to the hearse, was covered by 
the bees, who clustered upon it as a token of their esteem for their departed keeper. The truth was, the bees were securing some of the fresh varnish with which the coffin was polished, and were perfectly oblivious of the fact that their owner had left them. A superstitious custom is still practised in some parts of Europe on the death of a beekeeper of draping the hives with black; a relative of the dead man then whispers into the entrance of each hive the sad intelligence that their owner is no more. It is believed by many such people that if this is not done the bees will leave the hives and will not return.

As we examine the combs in the home of the bees, we shall find some of the cells containing honey, others pollen, while nestling in still others we find the developing brood. In taking care of the brood as well as maintaining themselves, the bees require water, pollen, and honey; thus we find it present in their homes at all times.

Honey is not a product of the bees in that 36 


\section{THE HOME OF THE BEES}

they manufacture it, though it undergoes a chemical change in their honey-sacs, but is a nectar gathered from various blossoms, and, together with pollen and water, constitutes their principal food.

When first gathered, this honey or nectar is very thin and may easily be shaken from the combs like so much sweetened water, and in fact it contains a large percentage of water, but after the bees have evaporated the water by fanning it after it has been stored in the cells, it becomes thick and ripe.

It is generally thought also that the bees mix with it a small percentage of formic acid to act as a preservative, and the sour taste of some honey while in process of evaporation seems to prove this.

Honey, being gathered from many sources, has distinctive flavors, and even a novice can distinguish the difference between buckwheat, basswood, and clover honey. While we may have our individual preferences as to flavor, yet the bees seem willing to extract nectar 
HOW TO KEEP BEES FOR PROFIT

from any available source, though there are times when they will hardly notice any other flowers if they have access to basswood.

Ripe honey sealed in the comb seldom granulates unless exposed to extreme cold, as each cell is practically air-tight.

Honey, pollen, and water are mixed with chyle, a secretion of the chyle-stomach of the nurse bees, and fed the worker larvæ for about three days, when the chyle is withdrawn and more honey and pollen substituted.

During the winter months and early spring, more or less water is secured from the condensation of moisture in the hives, but as the season advances the bees make frequent visits to neighboring streams and pools, and at times are so plentiful around the drinking-troughs of stock as to become a nuisance.

The pollen is gathered from the various flowers and is carried to their homes by the bees in the little pollen baskets on their legs.

In the early spring, when the bees are active and the pollen scarce, a good substitute can be 


\section{THE HOME OF THE BEES}

found in rye flour, and when a box containing a quantity of it is placed in the bee yard, it is astonishing to see how readily they will accept it and carry it away to their hives.

The hardest work a bee has to perform is that of pollen-gathering, and only the strongest bees in the colony engage in this work, while others are constantly gathering propolis, water, and honey. The young or nurse bees have all they can do to feed the larvæ, and to maintain a proper temperature of about ninety-eight degrees in the hive, without which the eggs will not hatch. About ten thousand bees are required in the hive to keep the incubator at work, for the hive is literally an incubator. The honey-gathering force of the hive is composed of all bees above this number, so the advantage of having large colonies at the time of the honey flow is manifest.

Thus we have seen that the things present in the home of the bees are combs, honey, propolis, pollen, with a little silk used for lining the cells for the larvæ, besides the bees and larvæ. 


\section{CHAPTER V}

\section{THE BEE FAMILY}

WhateVER the race of bees kept, we find at the beginning of the season that there are but three kinds of bees present in a hive, - the queen, the drones, and the workers.

With very rare exceptions there is usually but one queen present, a limited number of drones for propagation, and about thirty thousand workers, or about six quarts of bees by measure.

The queen is the mother of the entire colony, and under average conditions will lay from three thousand to five thousand eggs in twenty-four hours, doing her best during the spring and early summer. She is revered by the workers and tenderly cared for, not because of any regal traits she possesses or royal 
prerogatives she exercises, but rather because she is the sole reproducer of workers, and her death usually means the extinction of the swarm unless the workers have means of replacing her. Their solicitude for her is founded upon the law of self-preservation, and not because she rules them as a monarch.

When hatched from a queen cell she is a virgin, and of no use in the matter of reproduction until she takes her matrimonial flight, which usually occurs a few days after she is born, and mates with a drone. Many times a virgin is lost to a colony while seeking to be impregnated, as a bird may catch her in flight, and during her absence the bees are greatly agitated until she returns with evidences of having accomplished her purpose. The mating occurs outside of the hive while the queen is on the wing, and may take place within a hundred yards of the hive or a mile or so away, the distance depending upon the presence of drones in the vicinity.

If it were possible to mate our queens in the 
hive, we could in every sense control it and be certain that she was purely mated to a drone of the same race, but, the mating occurring in the air, somewhat remote from her hive, we can never be certain that she has mated properly until after some of her eggs have hatched, when the markings of the worker offspring will tell the tale.

This uncertainty has been the bane of queenraisers, and to overcome it they have found it economy to seek out all owners of bees in a radius of three miles and to Italianize their colonies free of charge, by the introduction of pure queens, so as to be reasonably certain of the fact that none but pure drones are present in the immediate neighborhood. Again and again have I had a choice virgin queen mated to the common black drones that may be near by; and as her offspring will be hybrids with more or less vicious dispositions, the only remedy has been to pinch off her head and try again. The presence of impure races, however, need not prove a serious bugbear, for in a little 
while the drones from our own apiaries will succeed in fertilizing the virgins from any common stock, until most of the neighboring bees will in time be of pure blood.

When about nine days old a virgin sallies forth, and high in the air is mated to a drone who inserts an amount of seminal fluid into her spermatheca, and the single impregnation is sufficient for her lifetime, during which she may lay nearly half a million eggs.

When a virgin sails forth she is usually beset by a large number of drones, and with these in pursuit she flies very rapidly, so that she is overtaken only by the strongest, nature thus insuring vigor in her offspring.

A strange fact concerning the mating of the queen is that the drone usually dies immediately after he has accomplished his purpose, as the end of his existence has been fulfilled, and the queen returns to the hive with the male organs still clinging to her; these in time are either pulled away by the workers or else shrivel and dry up. 
The queen is the only perfectly developed female in the hive, as the workers are imperfectly developed females; and though the bees may upon the death of the queen introduce a laying worker, as the head of the hive, yet the laying worker being imperfectly developed, and never having mated with a drone, will lay only drone eggs, so that in time the colony will be made up of drones and become extinct.

Sometimes a virgin with imperfect wing development is not able to accomplish a mating, and will lay nothing but drone eggs. This phenomenon is called parthenogenesis, or "generation from a virgin," and was first discovered by Dzierzon of Germany; it must be regarded as one of the most remarkable discoveries of science.

In appearance the queen is very easily distinguished by even the novice, for while she is not so bulky as the drones, she has a body considerably more elongated than the workers, and is decidedly waspish-looking. Usually she is slow in her movements, though 
she can move with astonishing rapidity, especially when locked in a death struggle with a rival. She is constantly attended by a retinue of young bees who feed her from time to time, for a queen will in twenty-four hours lay more than her own weight in eggs, and to do this must be abundantly fed, a function carried on by her attendants. The reverence the workers have for her, if such it can be called, is due to their knowledge
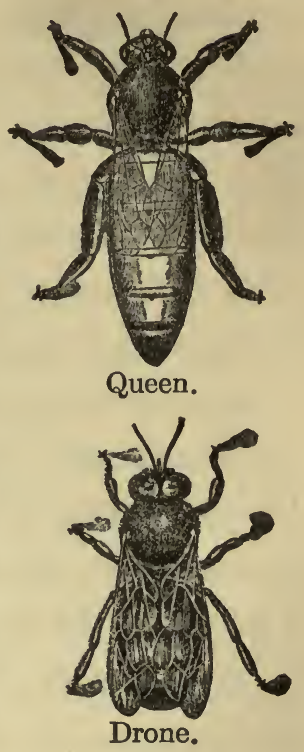

that without her presence in the hive the colony must eventually perish, as there will be no brood to develop into workers to take the place of the

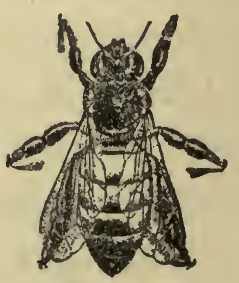

Worker. bees that are constantly dying off from old age. 
While the average age of a worker bee is about five weeks, queens have been known to live for a period of as many years, though as they grow older their powers of reproduction grow less. When the queen shows signs of failing the workers will rear another to supersede her, and under these conditions we often find two queens present for a limited time.

The cells in which the workers rear their queens are entirely different in shape from those in which they rear their workers and drones, and are very similar in appearance to a peanut hanging from the bottom of the brood comb.

The eggs from which the workers produce their queens are identically the same in character as those from which they raise the workers, but being deposited in the larger queen cells, and being fed a more stimulative food rich in royal jelly, the larva is enabled to expand to its proper size and permit the full development of its ovaries. In fifteen to sixteen days from the time the eggs were laid the matured virgin emerges, and is ready for mating in a few days. 
Usually a large number of cells are started by the workers at the swarming season. It must be remembered that when a swarm comes out seeking new quarters, the hive from which it emerges is left queenless for a few days, as the old queen accompanies the swarm, and the bees and brood that are left in the hive are dependent upon the hatching of one of the remaining queen cells for a queen.

If but one queen cell were left and that should fail to hatch, the hive would be hopelessly queenless, as at the time the cell should hatch the old queen would have been away so long that there would be no eggs present sufficiently young from which the remaining bees could rear another, as the egg must not be much over three days old to start it toward royalty. It is this possibility that prompts the bees to leave a large number of cells behind, often as many as fifty, so that provision is made for any emergency.

Usually as soon as a good virgin comes forth, the bees will proceed to tear down the re- 
HOW TO KEEP BEES FOR PROFIT

maining cells, though very frequently as many as a half dozen queens will hatch at nearly the same time, in which case the bees and the virgin first hatched will destroy the surplus.

Frequently the hatching of two or more queens at a time will result in the emergence of after-swarms, a thing not to be desired, as these swarms are at best very small and seldom amount to much, and the best thing to do in such a case is to throw them back into the hive and let them fight it out until but one queen is in charge.

About two days after mating, a queen will begin laying, usually in the centre of the brood nest, but as the season advances and the attending nurse bees increase, she will cover a much larger area of comb, until at times, in the case of a very vigorous queen, every comb will be more or less brooded.

The workers which constitute the main population of the hive are, as we have said, undeveloped females, and in size are smaller than either the queens or drones. The eggs 
from which they are reared are eggs that have been fertilized by a drone and are deposited in worker cells by the queen. These eggs when first laid look like a piece of cotton thread about a thirty-second of an inch long, and are attached to the bottom of the cell by a bluish white gelatinous secretion.

Although at the time it is deposited the egg retains an upright position, on the second day it inclines to an angle of about forty-five degrees, and by the third day it lies perfectly flat in its cell, containing in itself the vital germ of life.

On its fourth day it has developed into a tiny white grub, and is supplied with a sufficient amount of food, known as pap, which the nurse bees give to it as soon as it has developed past the egg stage.

The food fed to the larvæ is produced by the chyle-stomach of the nurse bees and is liberally given until the third day, when less is given, honey and pollen being added to the mass.

When the larva is about six days old, or 
HOW TO KEEP BEES FOR PROFIT

about ten days from the time the egg was deposited by the queen, the bees close up the cells with a substance made of bee bread and wax, which under the microscope is seen to be porous so as to enable the developing bee to secure the necessary air, and in twentyone days from the time the egg was laid the fully developed worker bites through the cap of the cell, and at once heads for a cell filled with honey, from which she sips a liberal supply. In about four days she is ready for her duties as a nurse bee, and about two weeks after birth is ready to begin her work as a field bee.

It is an interesting sight to watch a lot of young bees having a play spell in front of their hive. They will fly back and forth in front of the entrance, seldom flying more than three feet away, but as they become older they become self-reliant, and in a few days they may be seen returning to their homes heavily laden with propolis, pollen, and nectar.

Their life is short, only about five weeks, 
as they work themselves to death, and it has been estimated that a dessert-spoonful of honey represents the life-work of each field bee.

The drones are reared from infertile eggs, and are the male or father bees, and during the early spring and breeding season are present in large numbers. It takes about twenty-four days for the drone egg to develop into a fully matured bee, and though the cappings to their cells are raised much higher than those of the worker cells, they are porous and made of the same material.

They are in every sense of the word gentlemen of leisure, as all of the work of gathering pollen, propolis, honey, nursing the larvæ, as well as defending the hives, devolves upon the workers. As sentinels the drones would be useless, as they have no stings, and can be handled with ease; it is perhaps this lack of defence that makes them manifest signs of fright when we take them in our hands. While the drones do no work and are large consumers of honey, yet their presence in the hive 
is more or less beneficial, as they doubtless help to conserve the heat of the hive and indirectly aid thereby in the development of the brood. When flying to and from their hives the drones are big noisy fellows, and one unacquainted with their history may be frightened by their buzzing, but they are perfectly harmless and can be picked up and carried about, as they have no stings with which to defend themselves.

It has not been definitely determined whether in laying an infertile egg from which springs the drone, the queen lays it through choice, or is compelled to owing to the increased size of the drone cell. The fact remains, however, that in depositing the drone egg, the enlarged size of the cell permits the queen to spread her limbs farther apart, and thus the egg slips out without coming in contact with the fertilizing fluid as does the worker egg in the case of the smaller cell, which compels the queen to keep her limbs closer together. 
It is a remarkable fact that the drone is produced from an unimpregnated egg, and even to this day there are many who doubt it, but careful experiments have proved it to be true. A microscopical examination of the eggs for worker bees reveals the fact that spermatozoa are always present in numbers of from one to five, but in the case of the drone egg, none are present. This fact is further proved when we find that laying workers incapable of mating will also produce drones, though such drones are much smaller in size than those produced by a queen. It may be that the size of the drone reared from the egg of a laying worker is influenced by its being laid in a worker cell.

Having no stings, nor suitable proboscis with which to gather honey, nor baskets on their legs to gather and carry pollen, nor wax scales with which to secrete wax, nature has restricted them to their sole function in the hive; namely, the fecundation of the virgin queens. 
HOW TO KEEP BEES FOR PROFIT

During the breeding season the drones are permitted to roam as they please through the hive and are fed a pap by the workers, who seem to know that the drones are needed for breeding purposes, but when the honey flow begins to show signs of ending, and especially in the early fall, the workers withhold from them the strengthening pap and drive them from the hives.

It is interesting and even pathetic at this time to find them clustered on the bottom board of the hive after the workers have driven them from the combs and life for them becomes a problem. Again and again I have seen a little worker tugging at a big drone to hustle him out of the hive, and though he plead in the language of the bees to be readmitted, the workers are inexorable in their decision that out he must go, for, being a heavy consumer of honey, and the days of his usefulness over, the decree for his exclusion has been issued and the hand of every worker is turned against him. 


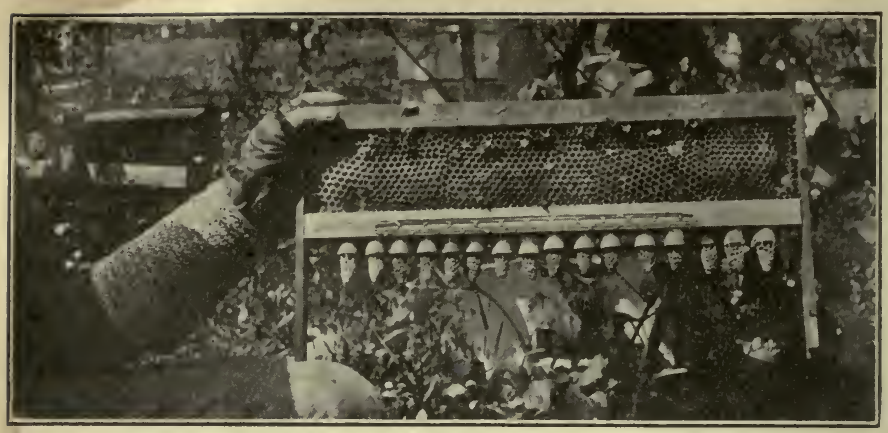

Fully completed Queen Cells, Bult on Wooden Cell-Holders.
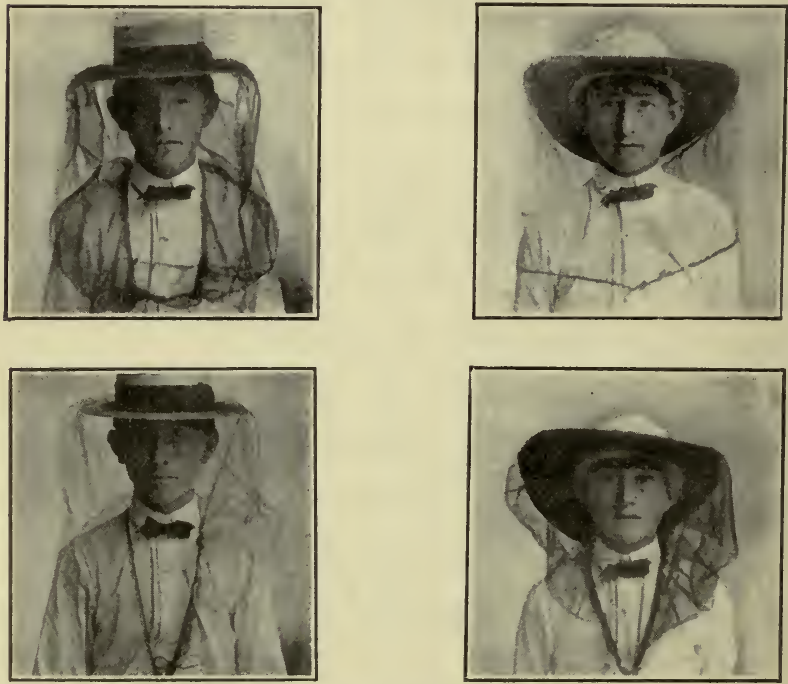

Right and Wrong Way to Fasten a BeE-veil, having a RUBBER CORD INSERTED IN BOTTOM. 


\section{CHAPTER VI}

HOW TO START BEE-KEEPING - HIVES AND TOOLS - TRANSFERRING BEES

T $T$ is a mistake to imagine that bee-keeping 1 can be carried on successfully in the remote country districts alone, for a large percentage of those engaged in this profitable and interesting work reside in suburban towns, and in some instances dwellers in large cities have successful apiaries located on the roofs of office buildings.

Another popular fallacy is the idea that only those sections of the country are suitable where some specific honey-producing blossom abounds in large numbers, such as alfalfa, sweet clover, basswood, and buckwheat. While it is true that those beekeepers who are located in such favorable sections are reason- 


\section{HOW TO KEEP BEES FOR PROFIT}

ably sure of a good crop of honey, in fact, of even obtaining record crops, yet the bees have such wonderful ability to adapt themselves to almost any locality, that it is astonishing how often they produce a goodly surplus for their owners when there are few evidences of large areas devoted to the cultivation of those plants of which they are most fond.

Even in the suburban districts it is surprising how much white and sweet clover are accessible to them, to say nothing of fruit blossoms and locust for the early flow. Again, there are many localities where the fall flow from goldenrod and the white and blue asters yields a supply that often surprises the incredulous. One of the most successful beekeepers in the profession, and one who for forty years has made bee-keeping a sole means of support, is Dr. C. C. Miller of Marengo, Illinois, who has again and again declared that his location is really below the average, showing how a little experience will enable the determined man to make good. Of course, 
if one is fortunate enough to be located in the buckwheat region of New York state, or the basswood sections of the Middle West, or in the heart of the alfalfa ranches of Colorado, Utah, and California, it is an easy matter to make money very rapidly; nevertheless, no one should be deterred from engaging in this interesting and profitable industry because he is located remote from these sources of supply.

Bees are wonderfully industrious little folk, and if properly cared for will extract tribute from unheard-of sources. For three years I owned an apiary located on the shores of Long Island Sound, where the flora appeared decidedly unfavorable, yet to my surprise and joy the bees did remarkably well. This led me to a more careful survey of the country by which I found that there was quite an abundance of locust trees, considerable fruit bloom, while the lawns abounded with clover.

While it is true that the beekeeper in the favored locations referred to has the advan- 
tage of being able to keep a great many hives in the home yard, yet the suburbanite can overcome this by resorting to a system of out apiaries, and by having two or more apiaries three or four miles from home be able to harvest crops. These out apiaries can be located so that they are accessible by buggy, trolley, or train, and the only difference in their management and the home yard is that their owner has to take a short trip to get to them. Indeed, the majority of large beekeepers prefer a system of out apiaries, as they claim they get larger crops without the danger of overstocking the home yard.

Having decided to get some bees, the question arises, "How and when shall I start?"

Spring is the best season of the year to begin, as such hives as will be purchased will not be heavy with honey and can be the more easily transported. Another advantage of starting 'n the spring is that the season is just beginning to open and the beginner will get experience in every phase of the industry, and should 
H O W TO START B E E-K E EPING

he make mistakes, he will have ample time in which to remedy them before the winter comes on.

It is the truest economy to purchase bees of a pure breed in modern hives from some reputable beekeeper in the neighborhood, and if none are located within a reasonable distance, there is a large number who advertise stock in the leading bee journals.

Oftentimes it will be more convenient to purchase a couple of colonies in old-fashioned box hives from a near-by beekeeper, though a beekeeper who keeps his colonies in such makeshifts is far behind the times and must of necessity have to kill his faithful wards in order to get their honey, - poor honey it is at that, as it generally is stored in old combs along with brood and even pollen from poisonous plants. These swarms can generally be purchased for from $\$ 1$ to $\$ 2$ a swarm, and all that is needed to put them in shape for shipping home by wagon or express is to wait until toward dark, when all the bees are in the 
HOW TO KEEP BEES FOR PROFIT

hive, and then quickly turn it upside down and tack a piece of mosquito wire net over the bottom, making sure that no openings are left for bees to escape and make trouble.

Keep the hive upside down, and in this position take them home or ship them by express. Under no circumstances allow the bottom to be closed up, as the bees will smother. When the journey is ended, by using a little smoke, to be described later on in this chapter, drive all the bees away from the screen, take it off, and set the hive in proper position on some boards or a large box.

Do not leave the bees in the old hive, but send away at once to a bee supply house and purchase a complete hive with full sheets of wax foundation wired in the frames, and as soon as it comes transfer the bees automatically.

The best way to transfer is to bore a large hole through the top of the old hive, making it no less than an inch in diameter, and over this is to be placed the new hive without its 


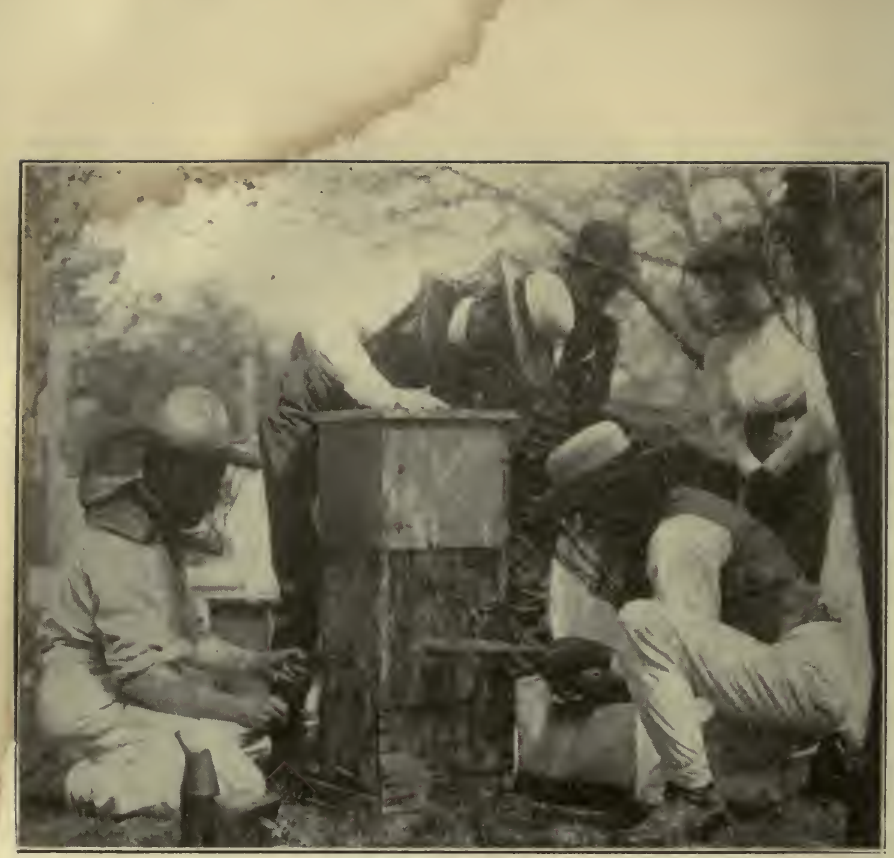

A BoX-HIVE TURNED UPSIDE-DOWN PREPARATORY TO DRUMMIYG THE BeEs OUt.

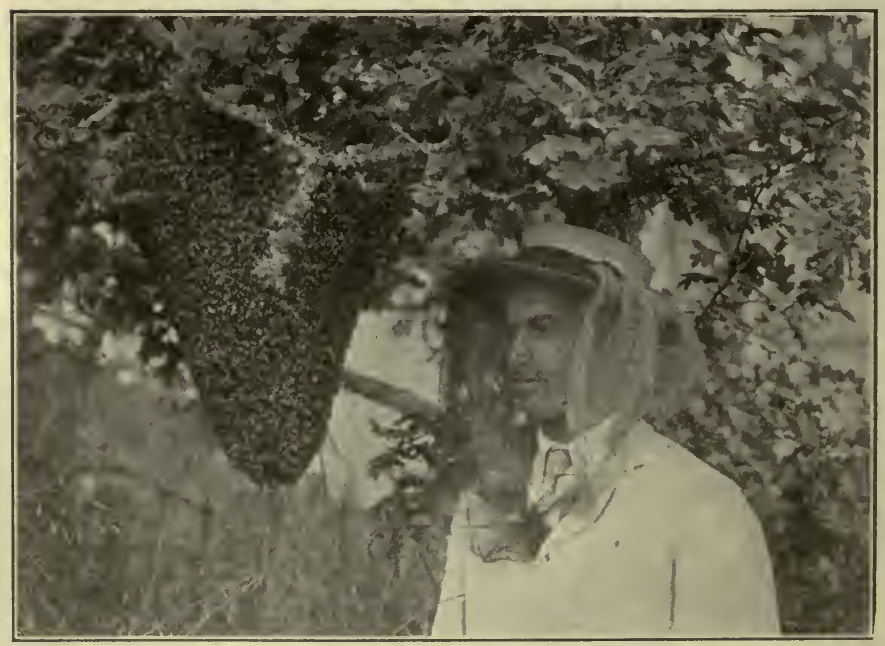

A Finf Symmetrical SWarm within Easy Reach. 
HOW TO START BEE-KEEPING

bottom board, but with its lid on and the frames all in place. Sometimes the outside bottom dimensions of the new hive will be larger than the top of the old hive, and special pains will have to be taken to keep the bees from coming out of the new hive when they are drummed upstairs. To prevent this it will be necessary to nail some cleats around the four edges of the top of the old box hive, or better still, take two boards and tack them together so that they can be set on top of the old box hive and project at least an inch outside of the bottom of the new hive on all sides.

With an auger bore one or two holes about an inch in diameter through the platform and old hive top near the centre, and place over it the new hive with its lid on, but no bottom board, for it must be remembered that we want no entrance to this double hive except the one at the bottom of the old box hive. Of course you should have your smoker going and your face and hands protected by veil and gloves.

Having everything in place, puff smoke in at 
the entrance of the old hive, and with a stick begin to pound on its sides.

Renew the smoke every four or five minutes, and keep up the drumming, and the bees will soon begin to go up into the new hive body, and in a half hour or so most of the bees will be up there, with the queen.

In a few days take off the lid of the new hive, and if you find that many of the bees are there and the queen has laid her eggs in the new combs, give the old box another smoking and pounding to drive up the rest, and in about a half hour you are ready to remove the new hive from the top, containing as it does the queen and most of the bees. To do this properly and to be sure of getting all the bees, lift the old hive to one side and, placing the bottom board of the new hive on the stand formerly occupied by the old hive, gently lift the new hive, bees and all, from the top of the old one and place it in position on the bottom board on the old stand. The old hive can be placed to one side of the new one not more 
than two feet away, and in about a week put it the same distance on the other side of the new hive, for by doing this all the bees that hatch from the brood that was left in the old hive will enter the new one and in a matter of three or four weeks all of the bees from the old hive will have entered the new one, whose work will be going on without interruption. After the bees have been transferred, the old combs in the old hive can be cut out without angering the bees, and may be melted up for beeswax. This method is certainly far superior to the old-fashioned way of tearing the old hive to pieces, and having to cut out a lot of sticky old combs and piece them together with strings in the new frames. It also has the advantage of putting the bees on frames whose combs will all be wired and making them more secure in handling and extracting.

Where the colonies are bought in modern hives there need be no transferring, and the only thing necessary to do to make them ready for moving will be to make a couple of frames 
of wood seven-eighths of an inch thick, cover them with wire netting, and nail a frame to the top and bottom of the hive after the lid and bottom board have been removed and the bees sent to their destination; where with the use of a little smoke the net frames can be removed, the hive body set in position on its bottom board, and the lid put on. The methods for transferring and moving bees are identically the same whether one or more hives are secured.

It is a waste of time, money, and patience for the beginner to attempt to make his own hives, as many a beekeeper has found to his sorrow, for the work as done by the hive manufacturers is so smooth and accurate, and the result of so many years of experience, that nothing made by the novice will equal them. Modern hives as made by a number of supply houses are of the best lumber planed smooth, and dovetailed at the corners to prevent warping.

Hives should conform to the habits of the bees, and there should be no more space in 
HOW TO START BEE-KEEPING

them than a bee space, or otherwise the bees will build brace-combs all around the frames and render their handling almost impossible,

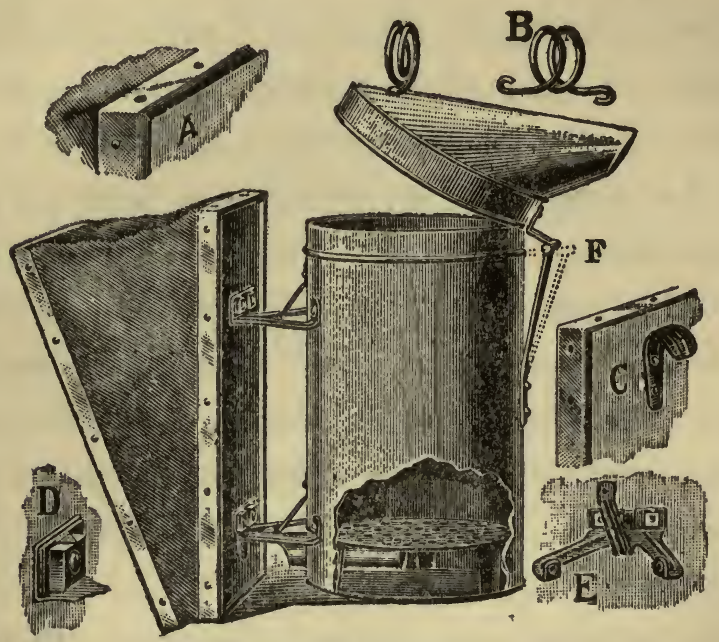

The Root Smoker.

A. Metal projection to aid the fingers in holding bellows.

B. Coiled wire handler. - C. Hook on back of bellows.

D. Locked nuts. - E. Stamped metal cap. - F. Flexible hinge.

to say nothing of the robbing that is sure to result from broken combs.

Before we take up the matter of the hives to be adopted, let me speak of the tools and implements necessary. The first thing essen. 
tial is a good smoker, one that has large fuel capacity, and a good strong bellows. After a thorough test of all the smokers on the market, I have no hesitancy in saying I prefer the Root Jumbo, a cold blast smoker, as it perfectly meets all the requirements. A good smoker can be purchased for $\$ 1.25$ and with proper care will last for years. Planer shavings, old rags, dried leaves, gunny bags soaked in a solution of saltpetre and dried in the sun, rotten wood, and dried pieces of apple branches all make excellent fuel, for what we want is plenty of smoke with little heat, and the beginner can take his pick.

I generally use planer shavings, though there are times when I want an enduring smoke I start a good fire with shavings; when I have about an inch of good red embers in the smoker I pile in rotten wood or apple wood, and a couple of replenishings of the fuel are sufficient for all day. As the fire gets low a few puffs of the bellows occasionally will bring it up so that it is ready whenever needed. 
H O W TO STAR T B E E-K E EP I N G

Another essential is a good veil, and after trying many I find that the Rauchfauss veil, a combination of muslin and wire net, is the best, as the cloth net veils seldom last over a season, - often not so long, - and the net may be blown by the wind so close to the face that the bees find no difficulty in stinging through it.

The Rauchfauss veil is made of stout muslin and ties around the crown of the straw hat. There is a circle of wire netting about a foot wide that comes just from below the brim of the hat and goes all around the head, permitting a current of air to enter and at the same time keeping out all the bees. From the bottom edge of the wire net there is another section of muslin with a drawing-string, so that all bees are excluded at its lower edge, and thus making a veil that is both durable and effective.

Such a veil can be bought for seventy-five cents, but can be made at home at a cost of about twenty-five cents.

Another essential is a hive tool for prying off the hive lids, lifting out the frames, and scrap- 


\section{HOW TO KEEP BEES FOR PROFIT}

ing propolis from the hives and frames, more or less of which is sure to be gathered by the bees.

There are a few other conveniences for the apiary which, though not essential, add to the comforts of working with the bees. A good market basket with stout handle is a handy thing for carrying the smoker, fuel, and hive tool, and as soon as one thing is used and set aside it can be dropped into the basket, which will save hunting around in the grass for it when wanted. A good wheelbarrow is also a great convenience, as it saves the back when it comes to carrying hives either filled or empty; the best one has removable sides. In preparing yourself to work among the bees, don't fail to close the ends of the trouser legs by using bicycle clips or by tying them with stout cords.

Though some of the most successful beekeepers are women, there has never yet been given in a bee journal a satisfactory bee dress for them. Some have advocated male attire, others bloomers, things the average woman detests, and yet there is available for women 
HOW TO START B E E-K E EPING

one of the most satisfactory and bee-proof dresses imaginable, and it is as follows.

A woman to prepare herself properly for work in the bee yard should first purchase a pair of men's overalls of proper length and in the bottom of each leg place a drawing-string.

The overalls should be put on just over the underwear, and when they are properly adjusted, tie the drawing-strings tightly about the ankles. Over this she may put her skirt, and in this attire she will suffer no annoyance whatever from the bees and yet be properly dressed. The drawing-strings at the bottoms of the legs of the overalls will effectively exclude the bees that may be in the grass, while the waist band of the skirt will keep out any bees that may adhere to the overalls. When the work is finished in the yard the skirt can be lifted and any adhering bees brushed off before entering the house.

After many years' experience I have found that by wearing a suit of white cotton material such as painters wear, consisting of overalls 
HOW TO KEEP BEES FOR PROFIT

and jumper, I am less liable to be stung than when I wear dark woollen clothes. Whether it is because they detect the animal scent in the woollen goods, or have a natural aversion to black, I am not able to say, but I do know that bees are more gentle and docile when I wear the light suit in preference to the dark.

I was visiting a few years ago the large apiary of Mr. Alexander at Delanson, New York.

He had a large flock of white wyandotte hens, which would wander all day among the hives, picking up drones. In the flock was one single black minorca hen, and strange to say the bees never troubled the white fowls at all, but again and again they would drive the black hen from their midst, which seemed to prove that they have a hatred for black.

"What hive shall I use?" is a question that is frequently asked, and its answer is the question, "What do you intend to produce, comb or extracted honey?"

If you intend to produce comb honey, by all means adopt a hive having a shallow brood 
HOW TO STAR T B E E-K E E P I N G

nest, as the shallow brood nest compels the bees to put the surplus up in the supers just where you want it, and not so much in the frames of the brood nest, which they are sure to do with the hives of regular depth.

'The brood nest is the hive body proper, in which the bees rear their brood, and must not be confused with the super or surplus chambers that are put on top of it at the beginning of the honey flow. In the case of bees in a comb-producing hive they are wintered in the brood body and the surplus supers are set away for the next season, as will be described later. At the beginning of the honey flow, the supers containing the little section boxes are set over the brood nest; each of these little boxes holds about a pound of honey, and there are usually twenty-four of them in a super chamber.

If comb honey is desired, purchase the shallow brood nest hive such as the Danzenbaker hive, or other shallow hive, of which a number of different kinds are on the market. Not 
less than four supers for each hive should be made ready for the flow. This phase of the subject will be more amply discussed in the chapter on How to Produce Comb Honey.

There are a large number of beekeepers who use the deep brood bodies even when producing comb honey, but their numbers are diminishing as the advantages of the shallow brood nest for comb honey production are becoming more and more manifest. The ordinary hive body should be adopted if extracted honey is to be the object, and a hive containing ten frames is the standard, though the tendency among certain producers of extracted honey is toward a larger hive such as the twelve-frame. In any case the standard self-spacing frame known as the Hoffman frame should be adopted, as it is the easiest frame to handle, and is made by all manufacturers of bee supplies. A careful reading of the catalogues of the leading supply houses will give the beginner much light and enable him to adopt the hive best suited to his purposes. 


\section{CHAPTER VII}

HOW TO QUIET AND HANDLE BEES - HOW TO AVOID STINGS - REMEDIES

REES are not naturally vicious, as many B suppose, but on the contrary are the most docile of creatures if we will but conform to their desires, and refrain from doing those things that irritate them.

Judging from the rough methods used by careless and ignorant beekeepers, it is surprising that stinging is not more frequent.

I have worked with my pets day after day without receiving a single sting, and this is due, not to the popular notion that bees know their keeper, but rather because I know there are some things the bees will not tolerate, such as jarring their hives, or mashing bees in taking out the frames, and it is these things I avoid. 
Bees also detest the odor of a horse or stable, so that I am careful to wash my hands thoroughly and change my clothing after driving a horse, and such a simple matter as this has wrought a remarkable change in the temper of the bees. I must confess that there have been times when in my eagerness to rush the work I have been careless, and in every instance the result has been a number of stings, but it has been entirely my own fault.

The ease with which some beekeepers open their hives and work among the bees has led a great many people to suppose that there was an acquaintance between the beekeeper and his pets, but there is absolutely no truth whatever in this belief. It seems strange, but somehow the confident and fearless manner in which the experienced beekeeper goes among the bees seems to awe them, whereas a timid person by his every move seems to make the bees aware of the fact that he fears them, and they are not slow to act when once this notion possesses them. 
HOW TO QUIET AND HANDLE BEES

The avoidance of stings, a thing greatly sought even by the veteran beekeeper, is largely a matter of care and the moderate use of the smoker.

The fear of smoke seems to be inbred in the bees, and the most savage of them are quickly subdued when given a whiff of it. It is not necessary to overwhelm them with it until they are completely dazed, but just enough to let them know that they are mastered, a lesson that they soon learn. Bees are easily frightened, and a little smoke blown in at the entrances of their hives, supplemented with a pounding on the lids, makes them panic-stricken and causes them to gorge themselves with honey, and it is this condition that renders them easy of manipulation. It is a physical impossibility for a bee to sting when it is full of honey, and this accounts for the easy manner in which they can be handled when they have swarmed. In order to sting, a bee must be able to bend its abdomen, and when it is filled with honey as it is at the time of swarming, and also when 
alarmed with smoke, it will be readily seen how easy it is even to handle them roughly at such a time.

Again, bees are more easily handled about the noon hour than earlier or later in the day, and that is because at this time of the day the old field bees are either abroad in the fields, or, if present in the hive, they are so loaded with the nectar they have brought in that they could not sting if they would.

The young bees for some reason are not given to stinging like the old ones, and can be handled and even abused without showing any signs of resentment.

Now that we have put on our veil and gloves and have the smoker well started, let us proceed to open a hive in a proper manner. Going to our first hive, we send in a couple of whiffs of smoke at the entrance, at the same time pounding a few times on the lid of the hive. We next take the hive tool and gently pry off the lid about one quarter of an inch and puff a little smoke in at the top, and drop it 


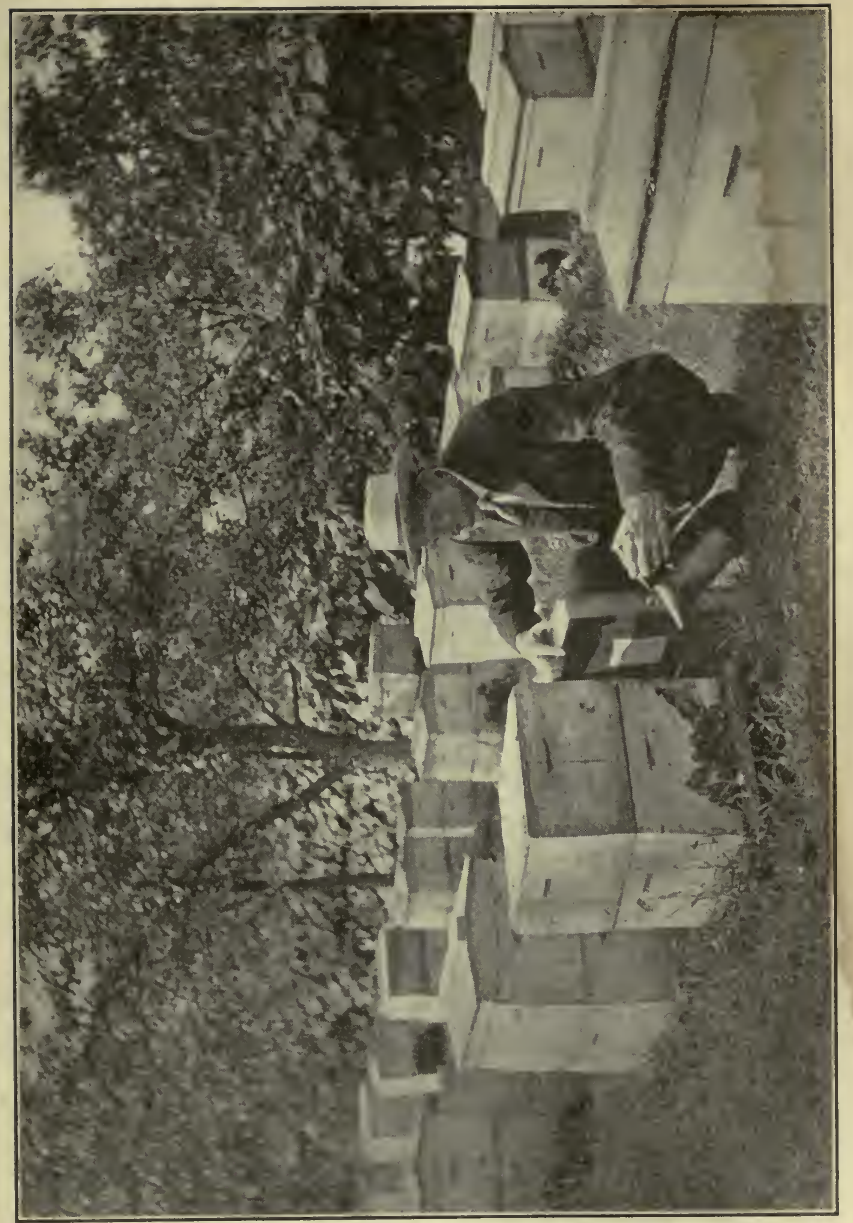

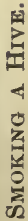



HOW TO QUIET AND HANDLE BEES

back in place for two or three minutes to give the bees time in which to fill up. I have frequently seen beekeepers who ought to have known better send a whiff of smoke in at the entrance, and, jerking the lid from the hive, send great volumes of smoke down over the frames and drive a horde of angry bees out of the hive in the proper frame of mind to sting most viciously. Had they sent just a puff or two of smoke in at the entrance and then a little under the lid and waited a minute or so, every bee would have been subdued and no stinging would have resulted. There are certain times in the season, when honey is coming in rapidly, when no smoke at all is necessary, and in such a case it is foolish to use it, as too much of it means a consumption of honey.

Lifting our lid we now find the bees as quiet as can be, and, supposing we want to find the queen, we with the aid of the hive tool pry apart a frame, for in all likelihood the frames are more or less glued together with propolis.

Using the hook end of the tool, we lift a 
frame from the brood nest with all adhering bees, and as the bees, if Italians, are very quiet, we can take our time in looking for the queen, for she is not hard to find. If she is not on the first frame, place it end up on the grass, letting it rest against the side of the hive while we remove another and look for her on it.

It may take a little more time to be careful so as not to mash any bees, and incidentally we might say that careless and too rapid handling not only mashes worker bees but often results in crushing a valuable queen; but in the end carefulness pays, as it makes the bees more gentle, and the next time we open their hives they seem to know that we mean them no harm.

One day I was examining a colony to find its queen in such a hurry that I mashed a number of bees, with the result that the colony was thrown into an uproar, and for days afterward every time I passed the hive the bees would rush out to sting me, while usually it was the gentlest colony in the yard. 
HOW TO QUIET AND HANDLE BEES

There is more danger of mashing bees when putting back the frames than when removing them; but a little time will enable us to accomplish it perfectly, and then working among our bees will be a positive delight.

If there are several colonies to be examined, it is a good plan to go down the line and smoke several of them before opening them, and by the time we get to the last one in the line we will find the first in splendid temper.

It may take the novice a couple of weeks to gain confidence in himself, but after he has learned the knack of the thing, as he will in an incredibly short time by actual work among the bees, he will be able to look through as many as forty or fifty hives in a single afternoon without slighting any.

As the beginner gains confidence he will discard his gloves, as he will find that in certain kinds of work, such as queen-raising, where eggs are to be grafted, etc., he can work much better barehanded than otherwise. He must not be surprised, however, if his 
HOW TO KEEP BEES FOR PROFIT

hands should receive an occasional sting, and the first few stings may cause a slight swelling; but, as his system becomes used to the poison, in time the stings will cause no swelling at all, and the only inconvenience is the slight pain, which after all is no more than that caused by a pin prick.

I have on rare occasions when working without a veil been stung under the eye, and it was quite painful for a minute or two, and although the eye closed up for a matter of twelve hours, the real pain was during the few minutes immediately following the sting.

The poison of the bee sting is formic acid. When the little bee injects its sting into our flesh, it usually in its endeavor to get away leaves the sting with its poison sac, and it is an easy matter to scrape it out. Never try to pull it out with the thumb and index finger, for in so doing you are sure to squeeze all of the poison out of the poison sac into the flesh and cause greater pain and swelling in the part stung, but take the sharp edge of the 
HOW TO QUIET AND IANDLE BEES

hive tool or the blade of a penknife, and if these are not handy use the thumb nail and scrape the sting out, and in a few minutes the pain will cease.

If, however, you find at the beginning that the part is swelling considerably, just pour a little household ammonia over it, and when your work among the bees is done soak a cloth in cold water and lay it over the spot, and in a short time the pain and swelling will be a thing of the past.

The gloves that are used are made of heavy muslin and treated with oil, having long gauntlets, that come well up over the arms and are described in the catalogues of the various supply houses.

Sometimes a bee or two will follow the beekeeper all over the yard and manifest every determination to sting as soon as there offers an opening. The only thing to do in such a case is to get a shingle or flat piece of wood and "swat" him. I carry a paddle in my basket for just such fellows. 
Be quiet in your movements, and manifest no signs of alarm, and the bees will soon learn that you are not afraid of them and will let you go your way in peace. If you are stung, then take my word for it that it is not nearly as painful or serious as is imagined, and not to be compared with the sting of the yellow jacket or hornet. There may be some satisfaction in the knowledge that the poor little bee pays its life as the forfeit for stinging, as it usually dies shortly after losing its sting. It may be well, however, that they do sting, as it is a guarantee that the business of beekeeping will never be overdone, and it also protects our hives from meddlers, both twoand four-footed ones. 



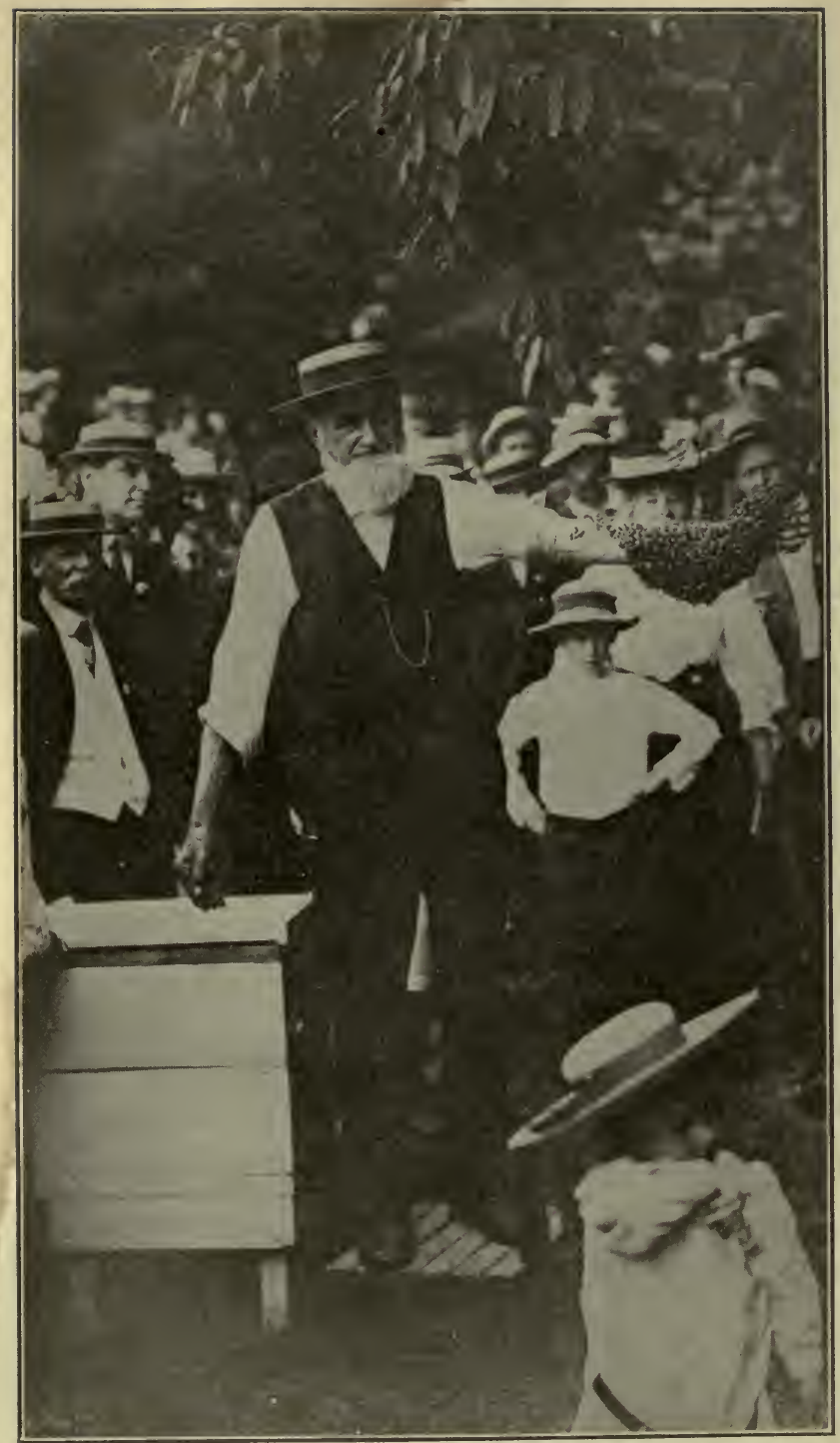

An Experienced Beekeeper handeing a Swarm of Bees. 


\section{CHAPTER VIII}

WHY BEES SWARM - HOW TO HIVE A SWARM - HOW TO CONTROL SWARMING

AL insects have some natural means of A reproducing themselves, and bees are no exception to the rule, their method being that of swarming. While swarming may be a perfectly natural act on their part, it cannot be said that beekeepers generally view it with any degree of pleasure, especially when they consider the possibility of losing valuable swarms that may emerge in their absence, which means a distinct loss of the entire working force of the hive and a consequent loss of honey.

Swarming usually occurs during the months of May and June, though they will frequently come out earlier and later than this, owing 
HOW TO KEEP BEES FOR PROFIT

to the season, and the reasons for swarming are as follows. Brood is present in large numbers in the hive, the blossoms in the field are yielding up a heavy tribute of nectar, and under these conditions the colony becomes overcrowded and makes preparations to decamp. An examination of the brood nest just before a colony swarms shows us practically every cell occupied with honey, pollen, and brood, and, realizing that no further work can be done in such crowded quarters, the colony decides that it is time to seek another home. In some mysterious way this idea is passed from one bee to another until all obey it.

Fortunately for the beekeeper, however, the colony usually gives some premonitory signs of its intention to swarm, and these if heeded will enable one to head them off and in many cases break up the fever entirely.

Often for several days before swarming the bees will cluster in large numbers on the front of the hive, and an examination of the brood 


\section{WHY BEES S WARM}

nest will reveal the presence of queen cells, and it is by taking advantage of these signs we can often prevent swarming by giving enlarged storage room. If we fail to forestall them, then we may look for a swarm to come forth some beautiful day in May or June, and the way the bees will come boiling out of the hive is a revelation to the tyro. Out they come literally by the thousands until the air is filled with them and their roar can be heard at a considerable distance.

The swarm is not, as is popularly supposed, made up of young bees, but is composed principally of the old bees and the old queen, and with the exception of the time she flies as a virgin to be mated, this is the only time that her majesty comes forth.

For several minutes the swarm will swirl about in the air, and with rare exceptions, will in a short time begin to cluster on the branch of a tree, and often at an inaccessible height, and will hang there probably for an extended period. 
The safest plan, however, is to hive the swarm as quickly as possible, for in all likelihood they have sent out their scouts to find a congenial home in the heart of an old tree or under the weatherboards of a house, and in some cases they often have their objective point picked out days in advance, and unless hived will eventually go away.

In the majority of cases the swarm will cluster on the lower limb of a tree or on a bush, and in fact I have had them cluster on a post, but in any case they are easily removed, and that without attendant danger of one's being stung, as every bee has filled its stomach with honey, realizing that it will be needed to build their combs within their new home, and it is this condition that renders them largely incapable of stinging, as they cannot bend the abdomen to do so.

If you are wise, you will have had your empty hive body with its frames of full foundation all ready for just such an emergency, and as soon as the swarm comes forth it will 


\section{WH Y BEES SWAM}

be the easiest thing in the world to set the hive in place, and if the swarm is on a tree or shrub, the branch to which they cling can be cut or sawed off and the swarm shaken in front of the empty hive, which they will be glad enough to enter.

If the swarm has clustered on a tree that you consider too valuable to cut, or on a fence or post, then take the new hive and place it under the cluster and shake the bees in front of it; or if on a post, brush them down with a brush or whisk broom, both of which are made for the purpose, and in a few minutes all of the bees will enter the hive.

Let them remain there until toward evening, when the hive can be gently lifted and placed on its permanent stand; and in the morning you will find that they have their sentinels posted, with the field bees going and coming to and from the fields.

In a few days one or more of the queen cells in the old hive will bring forth a virgin who in time will become mated, and thus you will 
HOW TO KEEP BEES FOR PROFIT

have two full colonies, each with a queen at its head.

Do not fail, however, to examine the old hive in about ten days and make certain that the virgin has mated, which can be quickly told by the presence of young eggs in the cells, and if for any reason she should have become lost in her matrimonial flight, give them another that you have reared or secured from some reputable breeder. The method of introducing her will be treated under the chapter on Queen Rearing.

It will occasionally happen that when one or more virgins hatch at the same time an after-swarm will also emerge, but as these are very small, and incapable of doing much in the way of building up for the winter, it is best to throw them back into the hive from which they emerged, and let the surplus virgins fight it out to the survival of the fittest.

The professional beekeeper looks upon natural swarming as a nuisance, especially if he is running a system of outyards, for it 
often happens that swarms will come out when he is not there to attend to them, and it seldom pays to keep a man watching for them.

This has led to a long-expressed desire for a race of non-swarming bees, but no such race is in sight, and beekeepers generally have taken up the next best thing, namely, preventive measures.

The dangers of losses from swarming have led a majority of beekeepers to devote their yards to the production of extracted honey, as by this plan the honey can be extracted as soon as the combs are nearly filled, and thus additional room can be given to the bees.

When the apiary is devoted to the production of comb honey, the problem becomes more serious, as the combs must of necessity be left on the hives until entirely sealed over, or else they will not be salable, and leaving them to be sealed impels the bees to swarm. To overcome this, a new plan was tried out some few years ago, and generally it has resulted in practically a complete control of swarming, 
even when the bees are kept for comb honey; it is known as the "Shook Swarm Plan."

About four days before the swarm is ready to come forth, - and their purpose can easily be told by the presence of queen cells and the actions of the bees, - the beekeeper lifts the hive to one side, say two feet, and in its place puts a new or empty hive in the frames of which only starter strips have been placed, not full sheets; and then lifting the frames from the hive about to swarm, all or nearly all of the bees are shaken at the entrance of the new hive, being sure of course to shake the queen. In some cases it may be best to put a queen-excluding piece of perforated zinc between the hive body of the new hive and its supers to restrict the queen to the lower chamber, and then the surplus bodies are removed from the old hive, bees and all, and placed on top of the new hive, as it would be the height of folly to leave them on the original hive, as the working force will be in the new hive. T'le question arises, What is to become of 
the old hive with its brood and few remaining bees? and the answer is that it can be left beside the new hive until its brood has hatched, when the bees can be shaken in with the bees in the new hive, and the combs can be removed and such honey as remains in them extracted, and the combs cut out and rendered into beeswax. It will be well in cutting out the combs to leave a strip of comb about an inch wide at the top of the frames, as such frames the following season will have starters of comb instead of foundation for colonies that may be shaken on them. By shaking the bees on starters only, we compel them to rush their honey up into the supers just where we want it, as they have no storage room below until the frames are filled with comb. Seldom will a colony swarm after it has been treated in this way, and this method has this apparent advantage over all others, namely, that the beekeeper swarms his bees at his own convenience and does away with all possibility of absconding swarms. 
Some men have said that the reason that the swarm shaken into the new hive seldom swarms again is because it has had the swarming impulse satisfied by being run into a new hive like a natural swarm, but the real reason is that a colony of bees will seldom desert a hive until it is completely filled with combs in the brood nest, and by the time the swarm will have filled its combs the honey flow is usually over and the cause of swarming a thing of the past.

There have been advertised from time to time a lot of automatic hivers, but he who invests his money in them but illustrates the old adage that "the fool and his money are soon parted." It is a good thing to go over the apiary and clip the wings of every queen after she has mated and has begun to lay; this will save many a swarm, as a swarm will never run off without its queen. If a swarm should come out with a clipped queen, it may cluster on a near-by tree, while the queen in her inability to fly will be found hopping about 
in the grass in her endeavor to join the swarm, and can be picked up with the bare fingers, as she will not sting, and removed to the house. A new hive being placed on the stand occupied by the one from which the swarm emerged, and the old swarm having returned and entered the new hive, the queen can be thrown in at the entrance; thus the hive swarm is hived without the owner having to handle it at all.

The "shook swarm" plan insures the beekeeper an abundance of beeswax after the combs have been rendered, and as this can be exchanged for sheets of foundation, it is an item worth considering.

The late Captain Hetherington of Cherry Valley, N.Y., one of the most extensive keepers of bees in his day, whose apiaries, scattered all over the country, numbered as many as three thousand colonies, had a plan of swarm control that he found satisfactory: the removal or caging of the queen during the swarming season. Some beemen contended that a swarm would not work as well with its queen 
removed or caged as one whose queen was present, to say nothing of the loss of brood during the period that the queen was caged, but the captain met this by the statement that any eggs she might lay would be so long in developing that the flow would be over before they were field bees.

The old-fashioned practice of ringing bells and banging on tin pans to cause a swarm to alight is really laughable, and as a matter of fact had no influence on the swarm whatever. That they did soon alight was only a coincidence, as they would sooner or later have done so. It has been said that the custom dates back to the days of Alfred the Great of England, who, in order to stop the disputes among his subjects as to the ownership of swarms that came forth, decreed that when a man's bees swarmed, he should ring a bell or make some other noise to notify his neighbors that the swarm was his. Another amusing custom still in vogue in some parts is the placing of empty hives in the woods as decoys 
for swarms to enter, and some have even resorted to the ridiculous practice of placing little red flags on top of them to flag the passing swarm and notify them that a welcome home awaits them. While it is true that a swarm has on rare occasion taken possession of some of these hives, yet it was a mere coincidence, and the flag, or the sprinkling of the hives with anise oil, had nothing whatever to do with it.

Before leaving the subject of swarming, it will be well to state that shade boards placed over a hive, and an extra current of air given them by elevating the entrance of the hive will be important factors in swarm control, but often, in spite of all that can be done, a swarm will come forth when the fever possesses them, and the only thing to do is to accept the situation philosophically and get them into a modern hive as soon as possible.

The proportion of swarming in comb honey production as compared with that of producing extracted honey is about two to one where 
HOW TO KEEP BEES FOR PROFIT

the "shook swarm" plan is not practised, as the free use of the extractor enables the beekeeper to remove the honey from the combs and give the colony additional storage room before the bees feel that they are crowded. 


\section{CHAPTER IX}

RAISING QUEEN BEES - HOW TO INTRODUCE

A QUEEN

TN the keeping of bees, there are many 1 occasions when extra queens are required, notably when colonies from one cause or another become queenless, or when increase is made, and the general practice is to send away to a queen-breeder for the same. While in the majority of cases queens arrive in good condition, and apparently none the worse for their journey, yet some beemen have contended that the queen is hurt more or less from her journey and is not as good as before.

Again, it costs a considerable sum to buy queens, especially if a large number are required, and, as they can be raised at home at a ridiculously low figure, the matter of expense has induced an ever increasing number H 
HOW TO KEEP BEES FOR PROFIT

of beekeepers to rear their own queens, as they are able to breed from only their best specimens, whose offspring have shown remarkable qualities of gentleness, and are great honey-gatherers. With the advent of a number of new systems of queen-rearing, which will be explained, one can easily see that this part of the profession is not so mysterious as some will suppose, and with a little experience the novice will soon be able to raise as good queens as the professional breeder, and not be compelled to pay from $\$ 1$ to $\$ 3$ apiece for them.

If left to follow their own natural impulses, the bees would build only a limited number of cells at the swarming time, but by the use of a few simple and inexpensive appliances, the beekeeper is able to rear them in almost unlimited numbers and thus always have them at hand when needed.

It is a known fact that in the breeding of all kinds of stock, the quality can be greatly improved by selection and restriction in the specimens that are to reproduce their kind, 
and bees are no exception to the rule. By breeding queens only from best mothers, the beekeeper will be able in a short time to secure a strain of bees in his apiaries that will be marvels of gentleness, to say nothing of gathering record crops of honey.

A good many apiarists advocate the requeening of all colonies with young queens of the season's breeding, as this insures every colony beginning the next season with vigorous young queens able to produce a large amount of brood, and such colonies are not so liable to swarm as those with old queens at their head.

There are three natural conditions under which colonies will of themselves raise queens, such as: at the time of swarming, when made queenless, and when about to supersede an old queen that is worn out. When about to swarm, the bees will begin to build a number of queen cells, usually at the bottoms of the combs, and in many instances the queen will deposit eggs in them for this purpose. While 
these cells are of the very best, yet the fact that they have to be cut out of the combs in order to isolate them in cages, has led to the adoption of little wooden cups in which eggs are grafted by the beekeeper, by which means they can the more easily be handled without the danger of injuring their occupants, as will be described later.

When a queen begins to show signs of failing through old age or injury, the colony will at once begin to build cells, and when the young queen begins to lay, the bees will usually kill the old one. If a colony has its queen taken from them, or should she be killed through the careless handling of the frames by the beekeeper, the colony will also build cells in order to replace her, and under the conditions outlined above will build from five to fifteen cells, though in the case of Carniolans and Cyprians colonies will often build as many as fifty cells at a time. While the cells reared by the bees under normal conditions are the very best, yet their production is 


\section{RAISING QUEEN BEES}

uncertain, and does not always occur when the beekeeper needs them, and this has led to the almost universal adoption of artificial methods. As far as is known, such queens are equal to those reared at the pleasure of the colony.

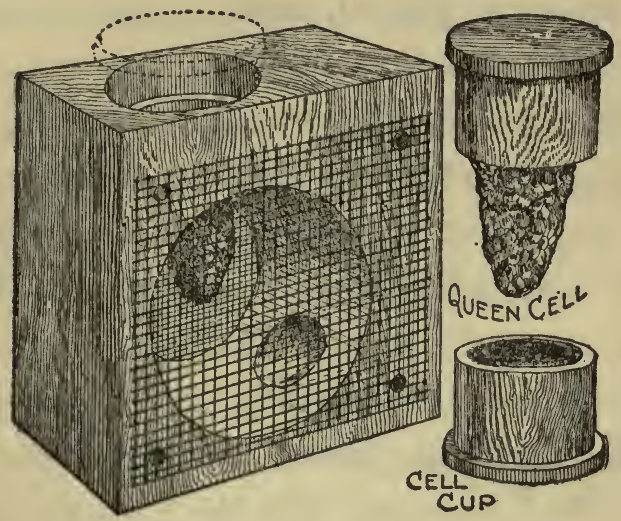

Nursery case for queens and virgins.

Perhaps the best system in vogue is the Swarthmore System, originated by the late E. R. Pratt of Swarthmore, Pennsylvania, and, with the few inexpensive appliances purchasable at almost any supply house, one can raise as many queens as are needed. This system requires a number of little wooden 
cell cups which are filled with melted beeswax, and with a small hand press made for the purpose, the rudimentary of the queen cell is made.

Into each one of these little cell cups a larva must be placed, and a small piece of wire is made for this purpose.

While a colony will accept these little cells, and supply the larvæ with the necessary food, yet it is best to make a colony queenless several days before the larvæ are grafted, and from the natural cells a small quantity of the royal jelly can be placed in each wooden cup with the grafted larvæ, as the bees more readily start on such cells than on those that are not so supplied.

The larva is taken from the worker cells of the colony from whose queen you desire to rear queens, and must be not more than about three days old, as such larvæ alone can be depended upon for good queens. If you secure a larva that is only a day old, so much the better, and in lifting it from the worker 
cell in the comb to the artificial cup, use great care not to bruise it, as it is very tender. The age of the larva can be easily determined by its size, and the smaller it is the better.

Before you are ready to graft cells, make your swarm box ready; the Swarthmore swarm box is a box that has the bottom side covered with wire gauze and holds just five frames of comb. About ten o'clock in the morning, gu to some strong colony, and, having previously placed in the box three combs filled with honey and pollen, but no brood, lift the lid from the box and shake into it the bees from three or four frames taken from the strong colony, put the lid on securely, and stop the entrance with a large cork or piece of wood. Remove the box, bees and all, to the house, and place it in a dark, quiet place, moderately warm, and wait until about four o'clock in the afternoon before you begin tc graft the larvæ.

During this time the imprisoned bees will discover that they are hopelessly queenless, 
as there is no brood present from which they can raise one, and it is this condition that induces them to accept the queen cups you give them and work on them at once.

The top of the swarm box is so cut out that

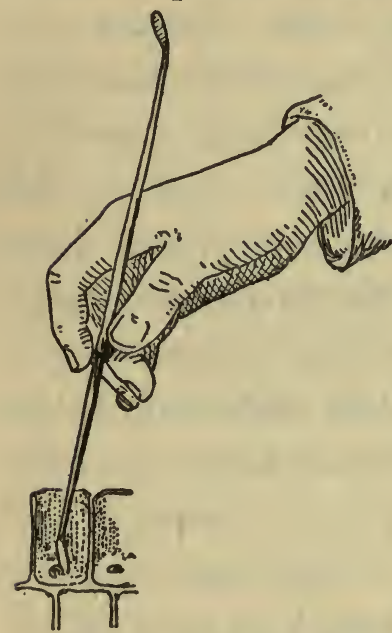

Lifting larva out of worker cell.

a couple of cell bars are fitted to it, and in each of these bars are sixteen little waxed cups which close the holes, and in which you will place the transferred larvæ, about four o'clock. At four o'clock, go to some colony whose queen is a choice one and lift out a frame that has a lot of larvæ not over three days old, shake off all the bees, and carry it to the house. See that the room in which you are to do the grafting is heated to at least eighty degrees so as not to chill the larvæ when grafted. Lift out one of the cell cups and place a dummy 


\section{RAISING QUEEN BEES}

cell cup in the hole it occupied in the cell bar. Cutting open a cell taken from the colony that was made queenless to rear them, transfer a little royal jelly to the base of the artificial cell, stir it a trifle with the little metal spoon, and then with the wire grafting needle, gently lift a tiny grub or larva from the frame of the brood at hand, place it in the bottom of the cup right in the midst of the royal jelly, and put it in the hole occupied by the dummy cup. Proceed in like manner with the other cups, and when all have been attended to, the frame of the brood can be returned to the colony from which it was taken.

Now cover the swarm box with a blanket for warmth, and leave it in a warm room until the following morning, and when, on the morrow, you lift out a cup to examine it, you will be surprised to find that the imprisoned bees will have accepted the majority of larvæ given them and will have fed them liberal allowances of royal jelly, and will have built down the cell to nearly an inch in length. 
As soon as the little cells have been started, they should be given to some strong colony to complete. Formerly, the custom was to make a colony queenless before grafting cells, and to give the started cells to that colony to complete, but since we now have the little incubating cages, and perforated zinc queenexcluders, we are able to give the started cells to a queenright colony for completion, as the zinc allows the workers free access to the cells, and at the same time excludes the queen from destroying them. If your colonies are occupying but one body for the brood nest, it will be necessary to use a holding frame fitted with an incubating cage in its top; this frame can be placed in the centre of any strong colony having a queen, the cell bar holding sixteen of the started cells can be slipped into the top of the cage, and the frame put in place in a strong colony. In about ten days the cells will be all sealed over and ready to be transferred to individual cages in which each virgin will hatch by herself and be safe from being de- 
stroyed, as would be the case if they were al permitted to hatch in one compartment. If the colony to which the cells have been given for completion is a strong one, and is occupying two brood bodies one above the other, it will be a very simple matter to place the queen down in the lower brood body, and between it and the upper story a queen-excluding zinc, which keeps her below; in this case as many as three bars of cells can be given to the upper story, each bar being put in the holding frame without the incubator cage.

When the cells are about twelve days old from the time the egg was laid, remove them, and put each one by itself in one of the little nursery cages. As many as forty-eight of these little cages can be secured firmly in an empty frame, and the frame given back to the strong colony to keep warm until the virgin queens shall hatch, which will be in sixteen days from the time the eggs were laid.

There is a little compartment in each of the nursery cages in which should be placed a 
HOW TO KEEP BEES FOR PROFIT

small quantity of candy made from mixing pulverized sugar with honey until it makes a stiff dough, so that the virgins will be provided with food when they emerge, in case the bees refuse to feed them through the wire netting, which they often do.

After the cells are completed, the only thing the bees do for the cell is to maintain the proper temperature of about ninety-eight degrees, and again and again I have hatched choice queens in an ordinary chicken incubator by keeping it at the required temperature. The cells taken care of by the bees, however, show a larger percentage of hatch, as the bees will gnaw the ends of the cells given to their care until they are as thin as paper, which is a great aid to the virgin in getting out.

Going back to the time of taking the cells from the swarm box, after the cells are removed, the imprisoned bees can be shaken at the entrance of the hive from which they were taken, and they are glad indeed to join their fellows. By the Doolittle Method, the 
breeder has to make his own cells by dipping a wooden rake tooth in melted wax, and sticking it to a bar of wood with more or less danger of its becoming detached, and it is difficult to handle such cells individually.

The Swarthmore System is superior to either the Alley or the Doolittle System, as they compel the queen-rearer to permit the bees to start the cells on a strip of brood comb under the Alley Method, and the objection to this is that there is more or less risk in injuring the queens when cutting the cells from the combs, to say nothing of the nuisance of having each cell all ragged at its top in handling.

The Swarthmore plan has every advantage, as each cell is fastened in a little wooden cup, and can even be handled roughly without fear of injury, and as for cell-starting, it is more convenient than any other system.

Now that your virgins have been hatched, the next thing is to mate them, and the small mating-box does this effectually, and does 
HOW TO KEEP BEES FOR PROFIT away with the old method of having to use a full colony for each queen mated. Virgiris may be given to a queenless colony and allowed to mate from them, but great care will have to be exercised in introducing them, as a colony will not accept them as readily as a queen that has mated and begun to lay. Then again if the beekeeper is rearing queens with which to supply the trade, the demand is for mated and laying queens, and it becomes a necessity to have them mated before being sold.

The best mating-box is the Root twin mating-box, which is so divided in the centre that each compartment contains two small combs that have been built in a strong colony; and as there are two small entrances to the box, each little nucleus of bees has the spirit of a colony.

When the virgins have hatched, take the small mating-boxes to a strong colony, and into each compartment of the mating-box brush about a teacupful of bees, being careful not to 
secure the queen; securely close the entrance of each compartment and remove the imprisoned bees to a shady place. About four in the afternoon run a virgin in at the entrance to each compartment, and if the bees were shaken in about ten o'clock in the morning, fully realizing their queenlessness, they will gladly accept her. Toward night, the entrance can be opened, and in the morning you will find that the miniature colony will have the spirit of a full colony, with their sentinels posted at the tiny entrance. In a few days the virgin will fly from this box and mate, and when you find that she has begun to lay, she can be used or sold as an untested queen.

An untested queen is one that has mated and begun to lay, and can be sold as a tested queen only after she has been kept laying long enough for some of her eggs to have hatched; and if the young bees prove by their markings that their mother has been purely mated, then she can be said to be a tested queen.

These little nuclei need encouraging, and 


\section{HOW TO KEEP BEES FOR PROFIT}

it will be necessary to feed them a small quantity of syrup every other day in the little feeders that are a part of the hive. The syrup should be made of equal parts of hot water and granulated sugar.

Many queen-rearers, when they put a virgin into the mating-boxes, also put another

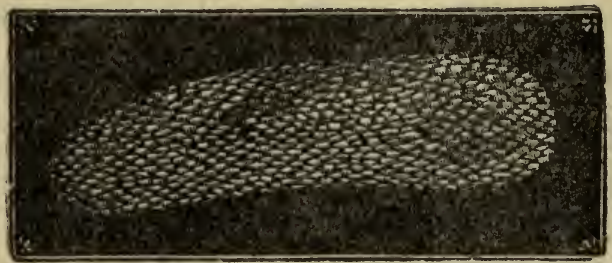

A queen's egg under the microscope.

in on its floor, imprisoned in its nursery cage so that it soon acquires the odor of the little nucleus. When the first virgin has mated and is removed, the caged virgin can be liberated at once, for the bees will accept her, as she bas the proper odor. This procedure can be carried on all through the season, a caged virgin being placed in each compartment as soon as a mated queen is sold and another virgin liberated. 


\section{RAISING QUEEN BEES}

At the close of the season these little swarms can be brushed into some weak colony that has been well smoked, or several of them can be united and given to a queenless colony and a queen provided, and the little boxes set away for use the following year.

Just a word of caution: Don't begin queen rearing too early in the season, or else you will fail. Wait until fruit bloom, when the weather is warm and the bees are flying nicely, and if you should need queens for your own use before it is time to rear them, remember that the better plan is to secure them by mail from some southern breeder whose warmer climate enables him to start breeding before it is possible in the North.

The next thing is to introduce a queen to a colony that needs one, and whether the queen to be introduced is one of your own raising or has come by mail from a distant breeder, the method is the same. The queen to be introduced is enclosed in a small introducing or mailing cage, and one end of the cage is filled 
with the honey dough previously described. Open the hive to which she is to be introduced, and after tearing away the little piece of wire or paper that covers the hole to the compartment where the dough is stored, pry apart a couple of frames in the centre of the queenless colony and slip the cage with the queen in it down between them with the candy side down, and leave the colony undisturbed for three or four days.

During this time the queen will be acquiring the odor of the colony, and the wall of candy will prevent the bees from getting at her to kill her, which they would do if they could the first day or so, but by the time the bees have eaten their way through to her and made a passage for her to get out, she will usually have become so impregnated with the odor of the colony that they will accept her.

In rare cases, however, they will destroy her, and sometimes even if they do not do this, they are sullen about accepting her, and will upon your opening the hive "ball her," in which case 


\section{RAISING QUEEN B EES}

you will find a large ball of angry bees, try. ing to kill her; but this can be broken up at once by filling the smoker with tobacco and sending clouds of tobacco smoke through the hive and at the cluster, and this seems to have the effect of making them all smell alike, thus averting all further trouble.

Every colony has its distinctive odor, and it is by this the bees recognize each other, as well as their queen, and the reason we cannot liberate a strange queen at once is that she has an odor from the hive or mating box from which she was taken; for this reason we are compelled to let her hang in the colony to which she is introduced for a few days until she has the odor of her new home. It may seem strange, but you can take a laying queen from her bees and hold her in your hand for a few minutes, and, when you will put her back in her regular hive the bees will ball her at once, thinking she is a strange queen simply because of her contact with your hand, and the odor she derives from it. 
HOW TO KEEP BEES FOR PROFIT

Whether you keep few colonies or many, make it a point to raise some queens if only for the fun of the thing, for it is intensely interesting work; and should you need a large number of queens as your colonies increase, it will prove a considerable saving to raise them yourself.

Those of us who keep a large number of colonies know that every year or so we find that we have a queen of rare worth, whose offspring are beautifully marked, remarkably gentle, and as honey-gatherers are hustlers, and it pays to breed from this queen, and in time make all the bees of this strain. 


\section{CHAPTER X}

HOW TO PRODUCE COMB HONEY

TONEY is marketed in two forms, either

11 as comb honey, in the individual onepound sections in which the bees store it, or as extracted honey, this being extracted from the large brood combs used in an upper story above the brood nest, the queen being prevented from laying her eggs in the extractingcombs by means of a perforated zinc board, which confines her below, at the same time giving the workers access to them for storing.

Whether the beekeeper proposes to produce comb or extracted honey, it is very necessary that the colonies shall be strong at the time of the honey flow, and this can only be brought about by seeing that every colony put into winter quarters is strong, supplied with ample stores, and, if wintered outdoors, is fully protected. 
HOW TO KEEP BEES FOR PROFIT

When the old-fashioned box hives were the thing, the principal way the surplus was gathered was by brimstoning the bees, a barbarous method to say the least, and when the bees were killed, the combs were cut out and set aside for use.

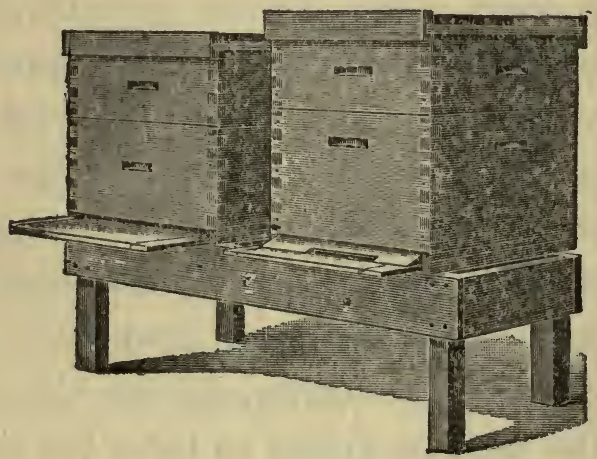

American hive, Langstroth type.

At best, this is an untidy method, and the combs secured are often more or less filled with brood and pollen, and such honey seldom finds a ready sale.

With the advent of the modern hive, it is possible to secure comb honey of snowy whiteness, in little boxes containing about a pound 
HOW TO PRODUCE COMB HONEY.

each, and, best of all, the colony does not have to be sacrificed, but is still in possession of the brood nest, with ample stores for winter, and ready for the next season's work.

In the production of comb honey under obsolete methods, twenty-five to thirty pounds was considered a good yield per colony, but with the modern hives with section box supers it is possible to produce three and four times that amount of the choicest honey imaginable.

While it is possible to secure a good surplus from any strong colony in an average season, with the ordinary hives having the full depth brood frames, such as the Hoffman SelfSpacing frames, yet a good many progressive beekeepers are adopting a shallower hive, as tests have proved that the shallower brood nest compels the bees to store more of their honey up in the sections where the comb-honey producer wants it. For the production of comb honey, there are no better hives on the market than the Danzenbaker and sinnilar hives, several kinds of which are manufactured, all 
HOW TO KEEP BEES FOR PROFIT

having a brood nest about four inches shal. lower than the ordinary hive.

Let us suppose that the winter is past and that the spring has come, and that with the first warm days of April, each and every colony has been looked over, and those that were found to be queenless were given queens, and those that were weak have been strengthened by giving them frames of sealed brood and bees from the stronger hives, so that things are generally equalized.

In transferring frames of bees and brood to the weaker colonies, be sure that you do not take from the stronger colonies the frame containing their queen, or else you will needlessly sacrifice her, since the colony to which she is given will destroy her, while the colony from which she was taken will be made needlessly queenless and will lose time and honey in having to rear a new one.

As fruit bloom comes on, examine the brood frames of a few colonies, and if the cells near the top bars are sealed with nice new white 


\section{HOW TO PRODUCE COMB HONEY}

cappings, indicating that the flow is well under way, then make haste to have the super cases

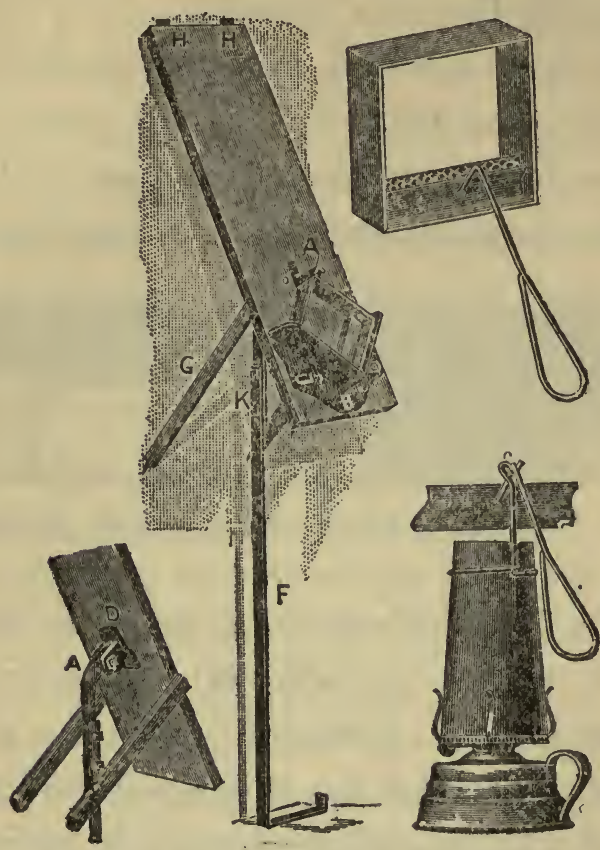

Foundation-fastener and section-holder.

all filled with the little section boxes with a full sheet of thin comb foundation in each box.

It is a good thing, if many sections are to be put together, to attend to this work during the 
HOW TO KEEP BEES FOR PROFIT

slack winter months, and thus have them all in readiness for the flow, as a good deal of worry will be saved thereby.

The little section boxes are made of white basswood and are grooved at the places where they are to be bent to put together, and before putting them together it is an excellent thing

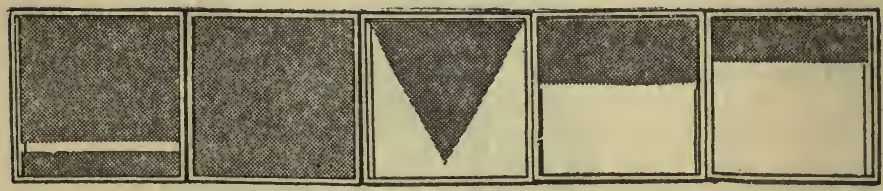

Different methods of cutting foundations for the sections.

to lay a lot of them on a table, so that the grooves will all coincide, and then pour a little hot water from a teakettle over the grooves, as this will make the wood soft and flexible and save the breaking of many a section.

The foundation should be cut in strips just long enough to almost fill the section boxes, leaving a space of about a half inch at the bottom and about a sixteenth of an inch space at the sides, as it is necessary only to secure 
HOW TO PRODUCE COMB HONEY

the sheet of foundation to the top of the section box.

While there are many methods of fastening the foundation to the tops of the section boxes, perhaps the best is the Dainy Foundation fastener, which works with a slight foot pressure, and, with a little heat supplied from the lamp that goes with it, securely fastens the foundation in place.

The average super case holds about twentyfour of these little sections, and each row of sections is held in place by a section-holder, with bee space fences or spaces between each row to prevent the bees from sticking the combs together, or causing some to bulge. Have no less than three super cases for each hive, and if possible four, and long before the fruit bloom have every super ready to place on the hives. When the brood combs reveal the fact that the colony is gathering new honey from fruit bloom, lift off its lid and on top of the brood body place a super filled with section boxes, and on top of this place the lid. 


\section{HOW TO KEEP BEES FOR PROFIT}

All the strong colonies should be treated alike, and by the time the clover honey begins to come in the bees will be at work in a state of great activity in the sections, and when an examination $=:$ the supers shows that the sections are nearly all drawn out and filled, it is time to give the colony another super case of sections. Instead, however, of putting the

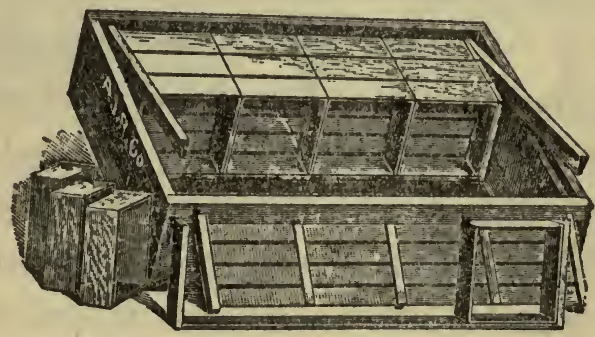

Supers for plain sections.

additional one on top, it must be slipped in between the super in which the bees are already working and the brood body, as tests have proved that the bees will more readily accept it and start to work in it than if it were placed on top.

By doing this, the bees that are working in 
HOW TO PRODUCE COMB HONEY

the super on top are compelled to pass through the empty one in order to get to the one in which they are working, and thus become familiar with it, and, being near the brood nest, it is accepted.

When it is found that the colony has pretty nearly filled the second one, and the field indications are that the flow is to continue, a third super can be placed beneath the upper two, and so on, one at a time, until sometimes as many as four or five may be placed on the hive. This is called tiering.

Tiering, however, should be carried on with caution, and no more supers given to each colony than it is able to take care of, and if the honey flow shows any signs of a cessation, no more supers should be given, or else there will be a lot of unfinished and unsalable sections on hand; whereas if the colony had only been given as many as they could take care of, and finish a nice surplus of, nearly all finished sections will be secured. No rule can be laid down; the beekeeper must be governed by the 
condition of the colony, and the local flora, and, using his best judgment, give to each colony individual treaı́ment.

As I look out over my own apiary, I find that some colonies have but one super, others have two, while a goodly number have as many as three and four, varying according to the rapidity with which each colony fills its sections.

Sometimes the bees will sulk and refuse to enter the supers, preferring to cluster on the outside of the hive, and in some instances will swarm with ample storage room, and when such is the case the beekeeper must resort to some method of compelling them to go above and get to work. This can often be accomplished by the use of bait sections, that are partially completed, and can either be had from some left over from the previous season, or a few can be taken from the supers of colonies that are working well, and three or four of them scattered among the empty sections in the supers on the sulking colony. It is astonishing how quickly this will set some 
HOW TO PRODUCE COMB HONEY

sulkers to work, so that in a day or so the colony will be working with vim and energy, in striking contrast to their idleness of a few days before.

If this does not work, another good plan is to give the colony a good smoking, driving almost the entire force up into the supers, and often this will accomplish the desired result, but should this not succeed, then there is one plan more that can be worked, which I have never known to fail. Lift from a good working colony, in which the bees are working in full blast on the sections, the entire super, bees and all, and place it on the sulking hive, and it will not be long before the colony will catch the fever of the force above and begin to work, and as the bees transferred will return to the hive from which they were taken, no loss of its working force will ensue. A disad vantage of smoking the bees out of the comb honey supers is that as soon as we smoke them a lot of bees are certain to uncap many cells in their endeavor to fill up before going below, 
and this will spoil the looks and sale of otherwise perfect sections.

Comb as well as extracted honey usually comes from two flows, the early or light honey, and the late or dark honey; they should be separated, as the early light clover honey is of lighter color than the late, and, being of more delicate flavor, is worth more per pound. For this reason most beekeepers take off the early surplus as soon as the flow is over, which is usually the middle of July, and, removing the honey to a safe place, give back the supers, or extracting-cases as the case may be, for the later fall flow.

Nothing is gained and much is lost by leaving all the surplus on till the fall, for in the case of the early honey the nice white combs will become travel-stained and unsightly and not bring the top-notch prices, so for this reason it is best to take the honey off as soon as it is sealed, for when it is sealed it is fully ripe and ready for use or sale.

There is really only one satisfactory way to 128 
take off comb honey, and that is by means of a bee escape board, having a Porter bee escape in it that escapes all the bees into the brood nest below, thus enabling us to take off the surplus without having to smoke the bees below, and getting a lot of stings.

The bee escape boards are furnished by the supply houses, and are used in the following manner :

First lift all the supers from the hive and slip the bee escape board on top of the brood nest, and place the supers on top of the escape board. In twenty-four hours all of the bees will have passed out below, and, being unable to get back again through the trap, the supers will be completely emptied without the aid of smoke and no uncapping of cells. The best time to put on the bee escape board will be late in the afternoon after the bees have ceased flying, and by the following evening the supers free of bees will be ready to come off.

These supers with their section boxes should be stored in a warm room secure from the 
HOW TO KEEP BEES FOR PROFIT

bees, for should the bees find them, they will steal the honey, and carry it back to their hives in short order. For this reason see that it is stored in a safe place until you are ready to take the sections of honey from the supers and pack in shipping-cases.

When you are ready to put your comb honey in marketable shape, it will be necessary to take the sections out and with the blade of a sharp knife, scrape from the wood of the section boxes the propolis or bee glue, more or less of which will be on the boxes, but be careful and not jab the combs.

At best, there will always be some unfinished sections on hand, but their number can be greatly reduced by a little care.

As we stated above, nothing is gained by leaving the combs on the hive after they have been sealed, but the having a number of unfinished sections can be avoided by waiting until nearly all the combs are sealed, and when this condition is reached, the supers should be taken off by aid of the bee escape board 
and the fully sealed or finished sections removed from them. If the bees are working nicely, there will be very few of the unfinished sections on a hive, and these can be separated from the finished ones, and be placed in supers by themselves, and returned to the bees immediately, and if the flow lasts a few days longer, they will practically all be finished.

There are several different sizes of sections that are used, some with the bee-way cut in them and perfectly square, while others are plain, without the bee-way and are taller than their width. Though the latter contain no more honey than the perfectly square ones, yet they appear to, and sell more quickly, and these things have led an increasing number of beekeepers to adopt them. A perusal of the catalogues of the various supply houses will enable the beginner to make such selection as suits his fancy, as tastes differ.

The fall flow of comb honey is harvested the same as the early flow, and should be taken off as soon as finished, or when the 
HOW TO KEEP BEES FOR PROFIT weather indications point to a cessation of the flow.

In the production of comb honey there will be a greater likelihood of swarming than in the production of the extracted; but giving the hives shadeboards, and open entrances full depth and width, and, last, treating each hive according to the "shook swarm" plan, will reduce it to a minimum and lessen the work and worry of the beeman.

The proper way to prepare the sections for market will be treated fully in the chapter on "Marketing the Honey Crop." 


\section{CHAPTER XI}

HOW TO PRODUCE EXTRACTED HONEY

THE method of producing extracted honey 1 differs so materially from that employed for comb honey that we treat it under a separate chapter.

When the colonies are run for comb honey it becomes almost a necessity to resort to the "shook swarm" plan to keep down swarming, and this compels us to handle the brood body of the hive in an entirely different manner.

The matter of swarm control becomes easy when we run our colonies for extracted honey, as we can extract from time to time and thus keep the bees from feeling crowded, with the consequent swarming.

The extracting supers differ from the comb honey super cases in that, instead of being 
shallow and filled with little section boxes, the bodies are full depth, and have in them the same size of frames as the brood nest.

When the colonies are strong and the tops of the combs in the brood nest show the presence of newly gathered honey, we are ready for the extracting bodies. When the honey flow comes on with a rush, happy is the man who is the possessor of a lot of surplus combs, as this means the immediate storage of the surplus, and does away with the attendant waste and delay when frames with but full sheets of foundation are at hand. This, however, is not a serious matter, and only prevails for the first season, as at the end of the season after the surplus is gathered, the fully drawn combs are in hand for the next season's crop, and for a number of seasons, for that matter, as these combs are capable of being used for a period of years. Many beekeepers make it a point never to use in the extracting supers combs that have ever been used in the brood nest, as they claim that such combs invariably 
result in a somewhat darker honey, owing to the darker color of the brood combs; but in my experience $I$ have found that it makes but little difference, and a host of beekeepers use their frames interchangeably with the brood body and the supers.

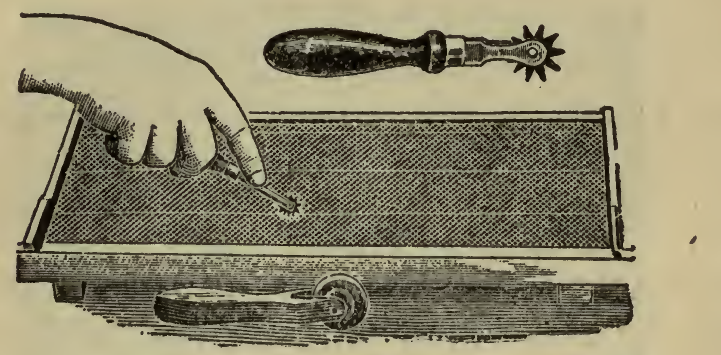

Imbedding the wire.

One thing, however, is an absolute necessity, and should not be overlooked, and that is to see that the foundations in the extracting combs are properly wired in, full directions for doing which come with the hives from the manufacturers, as this prevents the combs from becoming broken as they are rapidly whirled around in the extractors, a breakage that is . almost sure to occur in the case of new combs. 
HOW TO KEEP BEES FOR PROFIT

When the flow comes on, and the colony is strong, lift off the lid of the colony's hive and place on top of the hive a queen-excluding board, so that the queen cannot have access to the extracting supers, for if she is allowed to enter, the presence of her eggs and brood

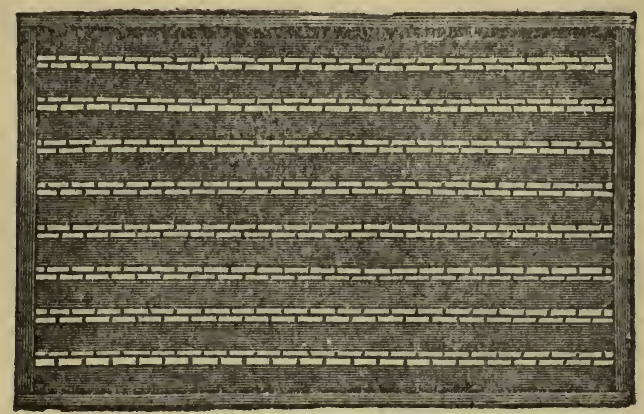

Zinc honey-board.

will seriously interfere with extracting, more or less of the brood being thrown out.

For many years these excluders were nothing more or less than sheets of zinc to fit over the brood body, and were perforated with oblong holes just large enough for the workers to get through, but small enough to keep the queen below. 
Even at their best the edges of the perforated holes were more or less rough and to a certain extent impeded the workers, but they were the best we could get, and there was no choice in the matter.

With the advent of the Root wire excluder, the results in increased production of honey were marked, as the bees seem readily to slip through the polished edges of the wires, and are not interfered with in the least, while the queen is fully secured below as under the old method of stamped zinc excluders. These excluders are bound with wood, and with care should last a number of years.

It has been a mooted question for years as to the proper size of hive to use in the production of extracted honey, and the tendency of late has been toward a large hive, certainly of no less than ten frames, which has become the standard, though there is an ever increasing number of extracted honey men who have made special hives of twelve and fourteen-frame size, claiming that swarming 
HOW TO KEEP BEES FOR PROFIT

is more easily controlled, and that the queen has ample laying-room.

The beginner had better adopt the regulation ten-frame size hive, as the expense will be considerably less, as these goods are always carried in stock by the supply houses; and as experience is gained, the larger hives can be tried out according to one's own ideas, but these experiments should be very carefully made, for it is a waste of time and money to try out hives of one's own invention when the very ideas may have been tried and found wanting many years ago.

Now that you have the queen-excluder in place, proceed to put on top of it a full-sized body filled with extracting combs, and, if combs are not at hand, then use frames with full sheets of foundation wired in. The extracting super will of course be of the same size as the hive body, but it will be best not to crowd the former with its full capacity of frames, as experience has proved that it is best to use but eight frames in a ten-frame ex- 
tracting super, pulling them a little apart from each other so that the bees' will have ample space to cluster while storing their surplus and working on the combs.

I cannot tell why, though I know from experience, that a colony likes to build a certain amount of comb, and this may have a great deal to do with their desire to swarm, as by swarming they have ample opportunity to build new combs in their new homes, and by spacing the frames apart it enables them to satisfy this propensity by building the combs in the super out to a point where they are decidedly fat and bulky, thus holding swarming in restraint.

When filled with honey these fat combs are not an encumbrance when it comes to extracting, but on the contrary they render their uncapping particularly easy, as the capping knife can be sunk deep into the comb, and when the honey has drained from the cappings that are thrown into the uncapping boxes, it can be drawn off, and a fine lot of wax thus secured each season. 
HOW TO KEEP BEES FOR PROFIT

Now that you have your super in position place on it its covering board, replacing the lid, and treat in like manner all colonies that are ready for supers.

If the flow is good, an examination of the super body will tell how rapidly the bees are filling it, and if you find that about twothirds of each comb is filled and capped over, the frames are ready for extracting.

Some beekeepers never use more than one extracting super for each colony, and by frequent extracting, keep the colony from being crowded for room, but there is another class who prefer to tier up, and in some cases as many as three or four supers are used.

Where tiering up is to be resorted to, it requires that the beekeeper, as soon as he finds that the first super is nearly filled, shall gently lift it and place between it and the hive brood body another super with eight frames of combs or frames of wired foundation sheets, leaving the excluder still over the brood body. When the second body is nearly filled, and the indi- 
PRODUCING EXTRACTED HONEY

cations point to a continuance of the flow, a third body may be added under the second, and all left in place until the flow is ended and operations for extracting begin.

Running the bees for extracted honey has this advantage over the production of comb honey, namely, there is no risk of having a lot of unfinished sections on hand if the flow should suddenly cease, as it often does, for in producing extracted honey it matters not at all if a lot of cells should be uncapped if the bees have possession of the combs long enough to thoroughly ripen it.

Whether the extracting is done frequently with the use of but one super, or done all at once about the last of July, it is a waste of money not to extract the early white honey and keep it by itself, as it is sure to be more or less mixed with the inferior and cheaper fall honey that comes from the fall flow if the supers are left on from spring till fall. For this reason it is wiser to extract during or at the close of the flow from clover, basswood, and 
early bloom, and give the empty combs back to the bees for the later flow.

When your supers are ready to extract, it becomes necessary to free the combs of the bees, and, as it makes little difference if a few combs should be uncapped by the bees when we smoke them down, we need not use bee escape boards as in the case of comb honey, for in the matter of comb honey there would be a noticeable loss in the appearance and salability of the combs if the bees should in their fright at being smoked at the time of emptying the supers, uncap many cells on what would otherwise be perfect sections.

To get rid of the bees on the extracting frames, open the hive and smoke them until they run down into the body below; what few bees remain can be shaken from the frames in front of their hives and the frames of honey placed in an empty hive body on a wheelbarrow handy for the purpose.

To prevent robbing, cover the body on the wheelbarrow with a large cloth thoroughly 
PRODUCING EXTRACTED HONEY

wet, for the robbers are very chary about crawling up under a wet cloth, and as soon as the carrying body is full, cover it immediately. When two or more bodies are filled, take them to the extracting room for extracting. Do your extracting in a room the doors and windows of which are securely screened, and in the top corner of the screen door or window screen have a bee escape, so that any stray bees that may be carried into the extracting-room may escape without possibility of returning.

There are a good many extractors and uncapping knives on the market, and the novice, after reading the various catalogues, will have to make his choice, but there are certain principles that go to make up an effective extractor, and these should not be overlooked. By all means secure an extractor that is reversible; this will save much work and trouble in the matter of extracting, as it is a nuisance to have to take out each frame after one side of the comb has been extracted, and turn it 


\section{HOW TO KEEP BEES FOR PROFIT}

around by hand to put it into the extractor again.

There are extractors on the market that reverse automatically by a lever pressure, so that when one side of the combs is emptied, they are, at the will of the operator, reversed in a second, and the opposite sides emptied also.

While the two-frame extractors will perhaps do for the novice having a half dozen hives, yet the four-frame extractor is decidedly preferable, as it can be used just as effectively in a small apiary, and as the number of colonies increase, it is ample for the increased output.

There are a few beekeepers, whose colonies are numbered by the hundreds and whose surplus runs up into the thousands of pounds, who use an extractor of eight-frame capacity, and have it geared to a small gasolene engine. Where the size of the apiary warrants it, this is a decided saving in time and labor, but where no more than one hundred colonies 
are kept, the four-frame hand-power extractor will meet all the requirements, and it is astonishing how much honey can be extracted in a day with them.

The Bingham improved uncapping knife is about the best that can be used, as its square wooden handle and projecting metal shoulder on the blade enable the operator to secure a firmer grip than with the old style round handle knife. A small oil or alcohol stove is a positive necessity, and on it should be a pan filled with water kept hot, so that while one knife is being used, the other is resting in the hot water, being heated and cleansed of adhering honey and particles of wax. Personally I use an alcohol stove of special construction, and thus avoid all danger of spoiling the delicate flavor of the honey by the fumes of an oil stove. As one knife becomes cool it is placed in the pan of hot water, and the other used until it cools. The constant heating of the uncapping knives makes all the difference in the world, and renders uncapping a compar- 
HOW TO KEEP BEES FOR PROFIT

atively easy task. Another necessary fixture is an uncapping can or tank, and it is unwise to attempt to make one, for the homemade affairs are sticky and unsatisfactory at best, and the patented ones are more effective and not expensive.

We will suppose that everything is now ready, that all the adhering bees have been shaken and brushed off the combs in front of their hives, and the combs in the extractingroom ready for the extractor.

Lift up one of the combs and rest its end on the bar of the uncapping can, and with the knife proceed to cut just under the cappings with a backward and forward motion, like sawing, from the bottom upward; don't be afraid to cut deeply, as any damage to the combs, if not too great, will be repaired by the bees when the combs are returned to them. Do not be afraid to cut well under the cappings and make the comb nearly its normal thickness, and as the cappings fall into the uncapping can, scrape the blade of the knife 
across the rack for the purpose and clean it of honey and wax that are sure to adhere to some extent. Now reverse the frame of honey and uncap the opposite side, and when it is all uncapped, place it in one of the wire baskets of the extractor, and proceed to uncap another and place it in another of the baskets. When the four baskets are filled, extract by turning the handle of the extractor, and don't be afraid to get up considerable speed, for there is little danger to the combs if the original foundation was wired in. If you have widely spaced your combs in the extracting supers, you will find uncapping a pleasure. As the baskets whirl about, the honey is thrown out by centrifugal force, and there is no more pleasant sound than the rain of well-ripened honey against the sides of the extractor.

The extractor should be elevated at least a foot above the floor of the extracting-room, and two feet would be better, so as to permit the placing of some vessel to catch the honey as it runs from the honey gate on the extractor. 
A piece of cheesecloth made into a bag about six inches long can be tied to the honey out. let gate of the extractor, and as the honey runs out it is strained of all sediment or dirt, and is in first-class condition for putting into cans, kegs, or vats, as the case may be. Some large beekeepers, like Mr. Alexander of Delanson, New York, place the extractor on the floor, running a large tin funnel through the floor and permitting the honey as fast as extracted to run through the funnel into a pipe that conveys it to a vat in the room below. At the end of the pipe just over the vat is hung a pail made of wire cloth; the honey is strained through the pail into the vat holding about five thousand pounds, and when one vat is filled, another section of pipe is slipped on and the honey carried to another vat.

Where the output does not run over five thousand pounds, it is just as well to elevate the extractor, using the cheesecloth, and run the honey into pails from which it can be poured into whatever vessels are to be used to 
store or market it, or it can be run directly into the vessels in which it is to be sold.

We have seen a good many receptacles used for storing extracted honey, from old milk cans to stone crocks, but there is nothing so satisfactory as the square five-gallon tin cans made for the purpose, two of which come packed in a reshipping case.

These cans, if new, - and second-hand cans should never be used, - are the very best receptacles, as there is no danger of contaminating the honey, and no fear of leakage. Moreover, when put up in this shape they are just right for the buyer who bottles honey, as honey, which is almost sure to granulate, can be conveniently liquefied by simply placing the cans in hot water. Where the honey is so packed, it often brings a considerably greater price than honey run into kegs and barrels, which has to be scooped and shovelled out to be liquefied. Again, honey in these cans can be packed in storage compactly, and when the caps are screwed on, there is no leakage 
HOW TO KEEP BEES FOR PROFIT

or danger of robbing being started by the bees.

Shall we return the extracted combs to the bees as soon as they are emptied? That will depend upon the chances of robbing being started by the bees getting at the empty combs. If the flow is well on and care is exercised, it will do no harm to return them at once, but there are a number of beekeepers who prefer to wait till toward evening, when the bees have stopped flying, and return them all at once. Local conditions will guide the beginner as to which method he had best pursue.

When all of the early light-colored honey has been extracted, the empty combs can be allowed to remain on the hives until the late flow in late summer and fall has been gathered, when the same methods of taking the surplus that were used for the early flow should be followed as soon as the late flowers cease to secrete nectar. After the late flow has been extracted, the combs may be set outdoors in 


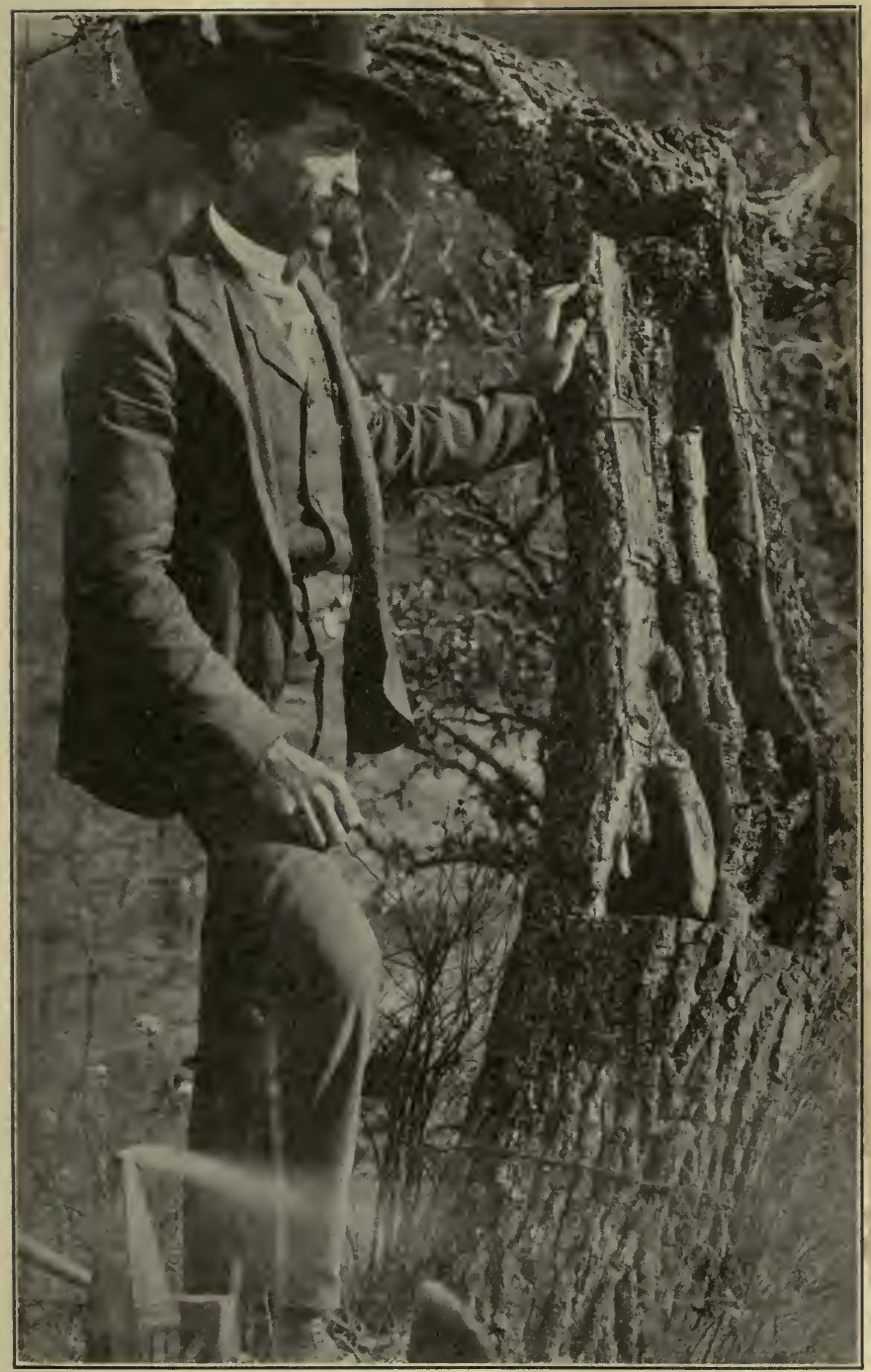

A Dissected Bee-tree. 


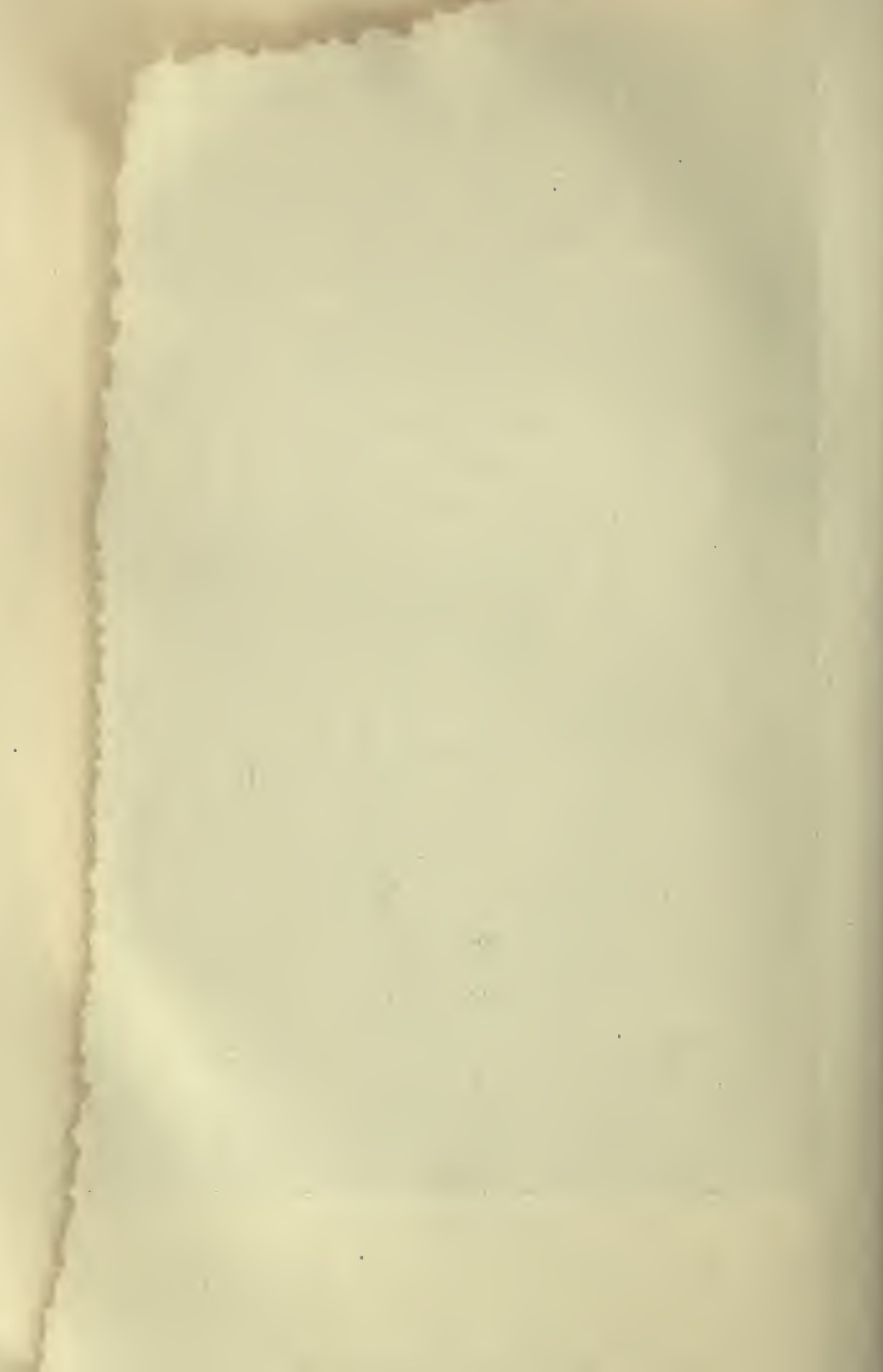


their bodies and the bees permitted to have access to them to clean them up, and then they should be set away in a safe place where mice or rats cannot destroy them, as they are an important asset for the coming season.

My plan is to fill each super body with its full quota of combs and to pile them five or six high on the barn floor, closing them securely at the top with extra lids and placing a weight upon each lid; and if the nights are frosty, there is no danger from the ravages of the wax moth. 


\section{CHAPTER XII}

\section{HOW TO MAKE INCREASE}

NWARMING is nature's method of in$N$ crease, but it is so uncertain and this with the possible loss of swarms emerging during the beekeeper's absence, has led professional beekeepers to adopt artificial methods of increase that are absolutely under the control of the operator. Generally speaking, natural swarming is a very uncertain dependence for increase, as there are many years when it will hardly more than make up for winter losses, and he who would increase his colonies materially must adopt methods of division that will give him the desired number of extra colonies.

When it comes to a matter of simply doubling the number of colonies, division is comparatively easy and safe even in the hands of 
an amateur, but when the increase is rapid, involving a splitting up of a ten-frame colony into five or ten little colonies, great care should be used or failure is sure to follow.

The late Mr. E. W. Alexander of Delanson, New York (than whom there was no better beekeeper in the world), had a method of doubling his colonies for increase, by which he did away with all possibility of loss of brood, and was still able to secure a good surplus at the same time, whereas under most of the methods followed, increase was carried on at the expense of the honey crop, for it is almost an axiom with beekeepers, "The greater the increase, the less honey for that year."

It can be readily seen that in the splitting up of colonies for increase there would be no surplus gathered, as each of the divisions would require the entire season to draw the frames of foundation out to full combs, and get strong for winter quarters.

While in rapid increase there is an entire 
HOW TO KEEP BEES FOR PROFIT

loss of the honey crop, yet the increase of one colony to five or even ten would represent an increased equipment many times the value of the surplus that would have been gathered by the colony had it been run for honey. There is, therefore, a gain and not a loss, though the gain is in bees and not in honey.

Mr. Alexander's method of course meant the increase of but one more colony for each strong colony in hand, but as it carried with it the assurance of a surplus at the same time, it is a most excellent plan to follow where a rapid increase is not desired.

In "Gleanings in Bee Culture," an illustrated bee journal published by the A. I. Root Co. of Medina, Ohio, we find in the issue of one of the months of 1906 , page 423, the method outlined as follows:-

"When your colonies are strong enough to swarm naturally, and you wish to divide them so as to make two from one, go to the colony you wish to divide; lift it from its 
stand and put in its place a hive containing frames of comb or foundation, the same as you would put the swarm in providing it had just swarmed. Now remove the centre comb from your new hive, and put in its place a frame of brood, either from the hive you wish to divide or some other colony that can spare one, and be sure you find the queen and put her on this frame of brood in the new hive; also look it over very carefully to see that it contains no eggs or larvæ in any queen cells. If it does, destroy them. Now put a queenexcluding honey-board on top of this new hive that contains the queen and frame of brood with their empty combs, then set your full queenless colony on top of the excluder; put the empty comb or frame of foundation into the body from which you took the frame of brood; and close the upper hive except the entrance they have through the excluder into the hive below. Leave them in this way about five days, then look over the combs carefully, and destroy any larvæ you may 
find in the queen cells in ihe top body, un. less they are of a good strain of bees that you care to breed from, for they frequently start the rearing of queens above the excluder very soon after their queen has been placed below the excluder. If so, you had better separate them at once; but if they have not started any queen cells above, then leave them together ten or eleven days, during which time the queen will get a fine lot of brood started in the lower hive, and every egg and particle of larva that was in the old hive on top will have matured, so it will be capped over and saved; then separate them, putting the old hive on a new stand. It will then be full of young bees mostly, and capped brood, and in about twenty-four hours they will accept a ripe cell, a virgin, or laying queen, as they will then realize that they are hopelessly queenless. I would advise you to give them a laying queen, as I never like to keep my full colonies for even a day longer without a laying queen than I can help. In 
this way you have two strong colonies from one, as you have not lost a particle of brood nor checked the laying of your queen; and with me it almost wholly prevents swarming. This is the way we have made our increase for several years, and we like it much better than any other way we have ever tried. In doing so you keep all your colonies strong during the whole summer, and it is the strong colonies that count in giving us our surplus.

The mere fact of having a large number of colonies does not amount to much unless they are strong in bees and are well cared for at all times. This is a fact that many have sadly overlooked; and when the season comes to a close, giving them a small surplus, they feel disappointed and lay the fault on many things that have had but little to do with their failure.

In making your increase in the above way, your new swarm on the old stand is in fine shape for a clamp of sections, as it has a large working force backed up by having its hive 
HOW TO KEEP BEES FOR PROFIT nearly full of brood, and but little honey, as the bees have been in the habit of storing their honey in the old hive that was on top. They will soon go to work in the sections, with no intention of swarming. Then the old hive that has been set away can usually spare fifteen or twenty pounds of honey, which can be taken with the extractor, giving its new queen plenty of room to lay, and in a short time will be one of your best colonies, with no desire to swarm.

Now, if you have done your duty by your bees since taking them from their winter quarters, as I have recommended above, keeping them snug and warm, and feeding them a little thin warm syrup nearly every day for the first thirty days after they have begun to fly, you can have two good strong colonies in the place of one, ready to commence work on your clover harvest, which will probably come about June $\mathbf{1 5}$.

From an extensive experience along this line I find I can get nearly twice the amount 
of surplus by dividing as above stated, over what I was able to acquire either by letting them go undivided or dividing in a way that caused the loss of a greater part of their brood. This losing of brood we must guard against at all times if we expect to secure a fine surplus. It costs both time and honey to produce it, and it is the principal factor in obtaining those strong colonies that give us tons of honey.

Far too many beekeepers think that the value of their apiary consists in the number of colonies they keep. This is so only to a certain extent; for if you had one thousand colonies and they were all weak in bees, so they would give you no surplus, they would not be worth as much as one good strong colony that would give you two hundred or three hundred pounds of honey.

Several years ago one of my sons bought nine colonies of bees in common box hives, about the first of June. He brought them home and transferred them at once to movableframe hives, and in about three weeks divided 
them, making twenty colonies of the nine he bought, using some queen cells I had on hand for his surplus colonies. He then attended to those twenty colonies so they were all strong at the commencement of our buckwheat harvest. I then loaned him twenty hives of empty combs to put on top of his colonies to extract from. He took two thousand eight hundred and forty-nine pounds of extracted honey from those nine colonies and their increase, and left them in good condition so that every one came out the next spring in fine order.

Another son, the same season, took one colony, divided into three, and received three hundred and forty-seven pounds of extracted honey. They also came through the following winter in good condition. I speak of these cases simply to show that it is not necessary to keep hundreds of colonies in order to get a little honey. If you will keep only strong colonies and give them the best of care, you will soon find both pleasure and profit in bee-keeping. 
Now, in regard to the criticism on this way of making our increase, which has been published in "Gleanings." I find that nearly all who have made a failure of the method have taken colonies that had already made some preparations for swarming by having eggs or larvæ in their queen cells, as did J. D. Ronan, of Chesterville, Mississippi, and also Don Mills, of Highland, Michigan.

During the summer $I$ received a few letters from persons who had made a failure of this method in much the same way. Some had taken colonies that had capped queen cells in their hives at the time they put the queen in the under hive, and, of course, they swarmed in a day or two. I cannot see that these failures are any proof of fault in the method. When we work with our bees we must always use some discretion in such matters. If a colony is very strong in bees, it certainly requires different management from that given to one rather weak.

The above plan is a most excellent one; 
HOW TO KEEP BEES FOR PROFIT

I have used it with unfailing success, and the beginner will make no mistake in adopting it where a rapid increase is not desired; it will result in a doukling of the colonies and a goodly surplus at the same time.

There are other times, however, when the beekeeper desires to increase his colonies several fold, and if great care is exercised, it is possible to increase the number of colonies to ten times the original number in one season; but one had better wait a season or two for experience before going in for a wholesale multiplication of colonies. Personally, I was able in one season to increase ten colonies up to one hundred, and, by a little feeding which will be described later on, succeeded in building the one hundred colonies up to strong swarms for winter quarters, and the following spring had one hundred prime colonies ready for the honey flow, all made from but ten colonies the season before. The increased value of the apiary was from $\$ 100$ to $\$ 1000$, and though there was no honey surplus gath- 
ered by the increase the season the division took place, yet the increased value of the apiary was many times what the surplus from the original ten colonies would have amounted to had they not been divided.

Let us suppose that you have a good strong ten-frame colony of bees, strong in bees and brood, and you wish to increase it to five colonies by division so that the apiary at the close of the season will be five times its original size.

About the last of April, if the colony is strong, and the weather permits, and honey is coming in rapidly, have on hand five extra hives all complete with full sheets of foundation wired in the frames, and above all four extra queens in their mailing cages that have been secured in advance from some breeder. You are now ready for the division.

Toward evening after all the bees are in, open the strong colony, and when you have found the frame with the queen, lift it gently from its hive and place it in one of 
HOW TO KEEP BEES FOR PROFIT

the empty hives, removing two of the frames of foundation from the empty hive, in order to make room.

Then lift another frame of bees and brood from the strong colony with all adhering, bees and place it in the new hive beside the frame that has the queen, and when they are in place, put on the lid, and close the entrance with a strip of wood nailed on. The new swarm, or nucleus, is now ready to be carried and placed on the stand it is to permanently occupy.

This new hive will contain two frames of bees and brood with queen and eight frames of full sheets of foundation.

Now take another empty hive and set aside two of its frames of foundation, and in their place put two more frames of brood and bees from the strong colony. As these two frames of brood and bees and all others taken will be without queens, take one of the little cages having a queen, and, tearing off the piece of cardboard from the end of the cage holding 
the feed, insert the little cage with the queen, the feed end down, between the frames of brood and bees in the new hive; push the frames close together, and, closing the entrance of the hive, place it on the stand it is to occupy. In about two days the imprisoned bees will eat a passageway through the feed to liberate the queen, and by the time she is liberated she will have acquired the odor of the colony and be accepted, whereas if she had been liberated at once at time of division, the bees would have perceived her to be a stranger and killed her. Treat the remaining empty hives the same way, and when all have two frames of bees and brood with a new queen you will have five little colonies all ready to get to work as soon as we take away the strip of wood from their entrances.

The original hive that was divided should be left on its old stand with the last two frames of bees and brood and the cage containing the queen. (See chapter on "Queen Rearing" in reference to introducing queens.) 
In three days you can remove the block from each entrance, and, using the same entrance strip, so tack it to the entrance of the hives, that there will be a small outlet about a half inch wide. Place a piece of board slanting from the top of the hive to the ground so that the bees when coming out will mark their new location and not return to the old stand they occupied before the division.

If this rapid increase is done early in the season, - and it should be done early to give the little colonies the entire season in which to build up, - the weather will be sufficiently cool, and the number of bees in each hive so few that there will be no danger of the bees smothering while imprisoned, which certainly would occur if a strong colony were so imprisoned during warm weather.

In about a week the little colonies can be opened and the cages taken out, and if you find the queen, or even eggs a day or so old, you can know that she has been accepted. There may be rare cases where the queen will 
be destroyed, but this will not occur more than in one case out of a hundred, and when her loss is discovered, a new queen should be introduced at once by the method described.

Of course it is understood that a caged queen is not to be given to the first division that was made, as that nucleus has the original queen given to them when the division was made.

If you desire to increase one colony up to ten, the method of procedure is identically the same, and differs only in that you give each empty hive but one frame of bees and brood instead of two.

A few days after the division has been made it is well to examine each nucleus, and when it is found that the bees have begun to work on the frame of foundation next to their frame of bees and brood, it can be lifted out and inserted between the two frames of brood, as this will facilitate its rapid completion. In this way the completed combs can be spread every few days until all the sheets of foundation are drawn out to full combs. 
If the honey flow should cease before the sheets of foundation are fully drawn out, each little colony should be fed daily about a half pint of syrup made from mixing equal parts of good granulated sugar and boiling water, as this has the same effect upon them as though the natural flow continued, and will force them to work out of season, build good combs, and rear a numerous brood.

A good feeder for this purpose is the Boardman entrance feeder, which has a quart jar with perforated cap inserted in a block of wood which can be placed at the entrance safe from robber bees, and the glass jar enables the operator to tell at a glance how rapidly the feed is being taken up. Other feeders will be described in the chapter on "Feeding."

The danger attending very rapid increase is that the operator will either make his divisions before the colony is strong, or else will defer it so late in the season that the little colony will not have time in which to build up 
before cold weather. Personally I have made divisions as late as August 1, but this necessitated constant feeding and great care, and the addition to the nucleus of an occasional frame of sealed brood from some strong colony. Late increase, however, is only successful in the hands of an expert; the course of wisdom for the beginner is to make the increase early, and as the season progresses, if there are other strong colonies in the apiary that have not been divided, it is an excellent thing to encourage the struggling nuclei by giving them a frame of sealed brood every once in a while from one of the strong colonies. Be sure that you do not give them the queen from the strong hive, or you will make your strong hive queenless and possibly sacrifice a good queen, as the little swarm will be sure to kill any additional queen that may be accidentally given them.

The empty space in the strong colony from which the frame of sealed brood is taken can be filled by a frame of foundation taken from the little swarm, after all adhering bees have 
been shaken in front of the hive to which they belong.

The reason we give the little colony sealed brood is because such sealed brood does not require attention and feeding by the bees, for if we gave the weak nucleus unsealed brood, there might not be sufficient bees present to properly care for it, with a consequent loss of brood and bees. When the brood is once sealed over, all that it requires is the proper temperature of about ninety-eight degrees to insure its hatching, and when these frames hatch in the little colony, it is astonishing what a multitude of bees will result to the colony to which the frames were given.

The above methods are the very best, and have proved their worth over and over, but, as has been said, the Alexander plan is the best for the novice. As experience is gained, rapid increase can be resorted to; but in any case keep your eyes on the increase, and give them all the encouragement possible in the matter of slight stimulative feeding, and an 


\section{HOW TO MAKE INCREASE}

occasional frame of sealed brood if conditions demand it.

If the increase is started early, and the flow of honey prolonged, it is possible to make rapid increase without either feeding, or addition of sealed brood, but at all events watch the colonies closely, and meet any emergency that may arise. 


\section{CHAPTER XIII}

LOCATION OF THE APIARY - OUT APIARIES MOVING BEES

T OCATION is of a twofold character, and 1 has to do first with the possibilities of the flora of any given section of the country where bees are to be kept, and secondly with the position of the hives in the apiary.

As we stated in the first chapter, in any section of the country where agricultural pursuits are successfully carried on bees are sure to be a source of profit to their keepers, and even in suburban towns where the farming districts are remote, there is more or less forage for the bees, so that one is not compelled to seek an isolated country district in order to make a success of the venture. In fact, there are wild regions, such as the Middle West, where there is an abundant natural 


\section{LOCATION OF THE APIARY}

growth of clover, basswood, and wild raspberries, where some of the greatest crops are secured, so that we can see that the bees adapt themselves to almost any environment. While the buckwheat sections of New York state, the alfalfa districts of Utah, Colorado, and California, are particularly favorable for large returns, nevertheless in almost every section of the country bees are able to extract a goodly surplus for their owners.

Where the nectar-secreting flowers are more or less restricted, there is danger of overstocking, and this has led a good many eastern beekeepers to resort to a system of out apiaries.

Instead of placing five hundred colonies in the home yard, a thing that is possible in the regions referred to above, it will be best in an average location to place not more than seventyfive colonies in the home yard, and then at distances of say three to five miles from each other, place additional apiaries of like number. In this way a large number of colonies may be kept in sections of the country that are 
HOW TO KEEP BEES FOR PROFIT

often only of an average character. The management of these apiaries is identically the same as the home yard, the only difference being that the operation of the out-yards requires a trip to them by the operator, which can be easily accomplished with horse and buggy, bicycle, motor cycle, or automobile.

Whether there be many or one yard, it is essential that the home yard be placed in a favorable or safe position so that the neighbors shall not be annoyed, or the keeper's family be constantly stung. This should also be the rule in the location of the out-yards.

In the matter of the out apiaries, a purchase of land for their location is not at all necessary, for a farmer or other person having a little land will usually be glad to rent it for from $\$ 5$ to $\$ 10$ a year, as an apiary of considerable size occupies but a small space.

If horses or other stock are at hand, the apiary should be placed a sufficient distance away from them to avoid annoyance, and the exercise of a little judgment will enable the 


\section{LOCATION OF THE APIARY}

beekeeper to adjust himself to local conditions. Formerly an orchard was advocated as the best place in which to locate an apiary, but experience has proved that the bees do better if their hives are placed so that the sun can shine on them, and, during very hot weather, a little extra ventilation and the use of a shade

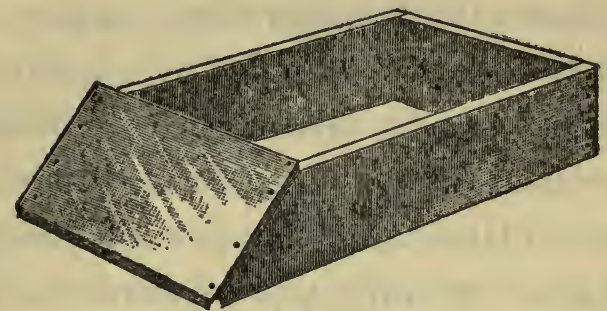

Hive stand.

board on top of the hives will offset the disadvantages of the hot spells. There is no doubt but that a back yard or open field is the very best place in the world for the bees, as the sun's rays in spring aid very materially in the rearing of brood, and even during the winter months it is a decided help to the bees.

A good plan is to arrange the hives in groups of four or five, as this renders manipulation 
much easier, and by equalizing things in the matter of distributing brood and honey, each group forms a convenient unit by itself. A stand of some sort for each hive is a necessity, as it keeps the hive from contact with the moist earth, and adds to the life of the hive, for rotting of wood is not likely to occur, and when stormy and winter days come on its protection is important.

Some beekeepers make concrete stands for each hive while others buy stands ready made, but both of these are an unnecessary expense, as any man can with a few boards, saw, and hatchet, make his own, and though such stands may be more or less crude, they are nevertheless just as useful as the expensive ones. All that is necessary is to get some rough hemlock boards and cut two lengths about a foot longer than the width of the bottom board of the hive; then cut two shorter lengths about six inches longer than the length of the bottom board of the hive and using each of the shorter lengths for 
the ends, nail the longer pieces on top of the shorter ones, and the stand is complete. The advantage of these low stands over the taller ones is that the bees when coming in from the fields heavily loaded will not fall to the ground a foot or more from the entrance of the hive, but get into their homes at once.

When it comes to operating an out apiary, the methods and fixtures are the same as in the case of the home apiary. To avoid carrying back and forth the necessary implements, it is well to have a small building, or even a large box covered with heavy waterproofed paper, with a door that can be locked, and in this little building keep the smokers, hive tools, veils, fuel, and such other little articles that are necessary for the work to be done. These things are inexpensive, and much trouble is saved by having located at each yard the necessary tools, etc. The extra hive bodies, and comb and extracting supers, can be stored in the barn or other such buildings that may be at hand by the owner of the land from 
which it is rented, or else they can be brought over as needed.

When extracting at the out yard, the extracting supers can be taken off late in the afternoon and be carted back to the home yard, extracted in the place set apart for this work, and be returned to the bees in the morning. If this is too much trouble, a wooden frame extracting cage about ten feet square, covered with wire cloth, and when set up secured by hooks and eyes, can be carried to the yard and the extracting done on the spot. As these large cages are inexpensive, and when taken down can be easily carried in a small wagon, an increasing number of bee-keepers who have a system of out yards are using them.

If the bees at the out yards are to be wintered outdoors with winter cases, there will be no carting of the bees to the home cellar in the fall and carting them back to their yards in the spring, and this is an important item in favor of outdoor wintering, which will be considered in the chapter on "How to Winter. 
Bees Successfully." If, however, the bees are to be carted back home in the fall to be placed in the cellar, great care should be used in preparing and carting them.

To prepare the bees properly for carting to the home for cellar wintering the following is a most excellent plan: For each hive to be moved, take some wooden strips about an inch wide and about seven-eighths of an inch thick, and make frames just the size of the top and bottom of the hive; over these frames tack securely some ordinary mosquito wirenetting, and after all the bees are in their hives nail one of these frames to both the top and the bottom of the hive, and it is ready for moving either by wagon or train. As an extra precaution against smothering the bees, it is well to tack or nail an extra strip of wood on the front ends of the bottom screen to elevate it above the floor of the wagon or car, as this will give a free circulation of air for the colony and insure their better condition when arriving at their destination. Some of the 
supply houses have in the making of their screens overlooked this extra bottom cleat, so that when the hive of bees is set on the floor, they might as well be entirely without the bottom screen. The lids and bottom boards that were removed from the hives to be moved can be sent or carried separately.

When bees have been bought in the oldfashioned box hives, all that is necessary is to turn the hive upside down and tack some wire net over the bottom, and ship the hive in this position.

When a quantity of bees are to be shipped a considerable distance by rail it will be a good thing for their owners to accompany them, and give them in warm weather an occasional sprinkling of cold water to cool and keep them quiet.

If horses and wagon are employed, by all means unhitch the horses before the bees are loaded on the wagon and take them a safe distance from the bees until the wagon is loaded, and, when the other bees have stopped flying, 


\section{LOCATION OF THE APIARY}

hitch up again, and there will be no risk of the horses being stung.

In some sections of the country, migratory bee-keeping is practised, the bees being moved from place to place to take advantage of the flow that may come in districts remote from the yards already located; though this has been tried in Florida and other parts of the country, the results have not warranted the extra trouble, save in some parts of Europe, where it is carried on quite extensively. The better plan is to locate the bees where the forage is abundant, and leave them there permanently.

In shipping full colonies of bees, or two- or three-frame nuclei, the screens referred to above are all that is needed, and in the case of nuclei, small boxes made from old boxes secured at some store with a piece of screen tacked over the top and the bottom, with the frames firmly secured by small nails, fully answer the purpose. Be sure in every case to see that the wire screens are properly ad- 
HOW TO KEEP BEES FOR PROFIT

justed to the hives to prevent the escape of the bees, or otherwise most of them will escape in transit, and the colony become almost entirely depopulated by the time it arrives at its destination.

If a shipment of a large number of hives is to go a long distance, it is essential that some one accompany them, and if the bees are found to be clustering on the upper screens, some water, which can be carried in five-gallon honey cans, can be sprinkled on them with a small hand sprinkler, or whisk broom, and after sprinkling, the bees will return to their combs, with the result that there is greater ventilation and air for the colony. In warm weather especially, it is a mistake to ship a very strong colony, for they are almost certain to smother, as I know by some sad experiences. For this reason it is best to screen and pack the colony about noon, when a large number of bees are in the field, and on the stand from which the colony was taken there should be placed an empty hive with frames of full 
foundation, with a frame of unsealed brood in its centre, which will take care of the returning bees. A queen can be given to them, and in an incredibly short time the hive will build up to a strong colony.

This method, however, should not be adopted, unless the colony so divided is unusually strong. It is no detriment to the colony shipped, for by the time it reaches its destination, enough new bees will have hatched out to fill it full, and it has this advantage to the buyer, that the bees in the colony will be largely young bees, and their gentleness will be a decided gain to him, as he can handle them with greater confidence.

Some years ago beekeepers advocated migratory bee-keeping, believing that the colonies could be located in the far South at the opening of the early flows there, and be gradually moved north to take advantage of the continuing flows, and a gigantic crop secured; but few have tried it, and those who have declare that the results do not warrant 
the effort. I have not heard of any phenomenal crops being gathered by this method. The majority of beekeepers are content to leave their home and out apiaries in their permanent locations, and where a section is found to be unusually good, an out apiary is established at that point. This has proved to be the most satisfactory and profitable plan.

Before closing this chapter, a few words concerning out apiaries seem necessary. It is the fear of overstocking a given location that has led to the adoption of out apiaries, but after all is said, the danger of overstocking is more imaginary than real, if a little care is exercised.

There are few locations that will not support as many as one hundred colonies, and add a goodly surplus at that, and if one hundred colonies are the limit, it will be better to keep them all at the home yard than to go to the extra trouble of establishing an out yard. 


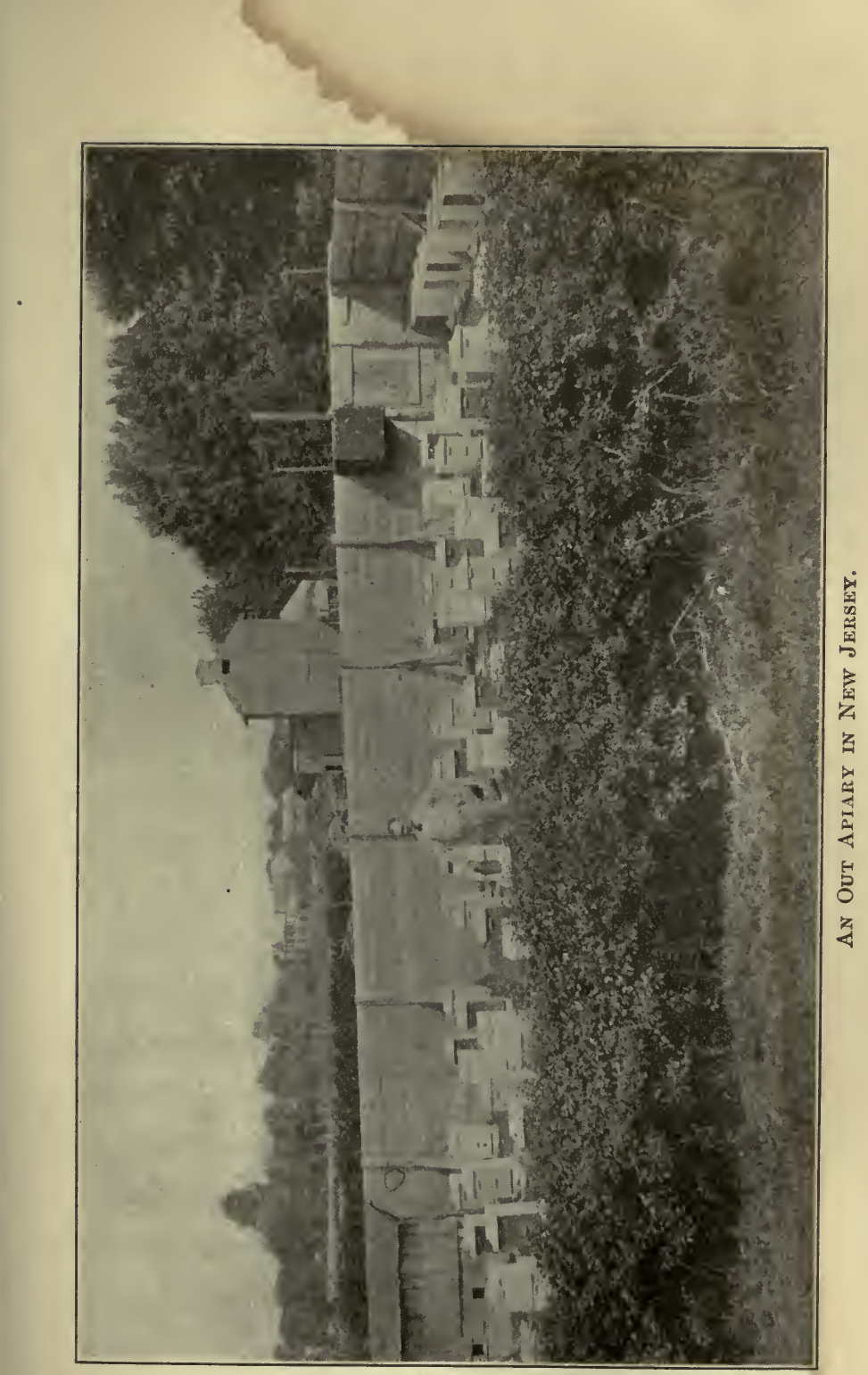





\section{LOCATION OF THE APIARY}

If one hundred and fifty or several hun. dred colonies are to be kept, then it becomes an absolute necessity to establish some out yards, and if one hundred and fifty are to be kept it will be best to put, say, seventy-five hives in the home yard, and seventy-five in an out yard, say from three to five miles from home; and these out yards can be so located along the line of trolley and railroad as to be of easy access by their operator.

It is a disputed question how far bees will travel from their homes in quest of nectar; some authorities go so far as to say that bees will travel a distance of five miles or more, but, generally speaking, three miles will be their limit, and even if the apiaries are located but three miles from each other (though five miles would be better), there is not a great deal of danger in the matter of crowding, as many experiments have proved.

There are some beekeepers fortunately located, notably the late Mr. Alexander of Delanson, who is in the midst of the buckwheat country of 
HOW TO KEEP BEES FOR PROFIT

New York state, who kept all of his hives, some eight hundred, located in the one home yard, and during favorable years produced in the neighborhood of eighty thousand pounds of extracted honey, principally buckwheat. This, however, is an exceptional case, and the average location will demand the keeping of not more than one hundred hives in one yard; in case a large number of colonies are kept, a system of out apiaries is absolutely essential to success.

The novice will be wise to go slowly in the matter of out apiaries, until he has the necessary experience to make it a success. 


\section{CHAPTER XIV}

\section{DISEASES AND ENEMIES OF BEES}

BEES, like all other stock, may be subject to disease, and other enemies that will ravage them if the conditions are favorable, but as a matter of fact the danger is very remote if the bees are given the proper care they demand. In my many years of experience, I have never had a case of disease among my bees, and the predations of natural enemies such as birds, skunks, snakes, and mice have been of such rare occurrence as to be infinitesimal factors in all the years that have passed. It is well, however, to describe some of the diseases to which bees are prone, and to point out preventive and curative measures for any possible condition that may arise.

Foul Brood is the most dreaded of diseases. It is of two varieties, the American and the 
HOW TO KEEP BEES FOR PROFIT

European, and, unless speedily cured, will in a short time ravish and destroy an entire apiary.

It is primarily a bacterial disease of the larva, and when once a spore of the disease takes possession of a larva, it spreads with wonderful rapidity.

It is usually transmitted to a healthy colony in one of two ways : either by the introduction of a new queen that may have come from some section of the country where the disease is prevalent, or by the bees of a healthy colony robbing honey from an infected hive, and the spores carried in the honey that was robbed. This danger has led a great many beekeepers to kill all of the attendant bees that accompany the queen in her journey through the mails, and reserve only the queen for introduction; and this is a most excellent precautionary measure to adopt.

Beginners are very liable to confuse chilled dead brood, or pickled brood, with foul brood, and become needlessly alarmed; but when 
DISEASES AND ENEMIES OF BEES

once the real thing has taken possession of a colony, the condition of the brood, and the terrible stench, will enable him to detect its presence at once. The American foul brood is easily distinguished from the European foul or black brood by its sticky or ropy nature, as a very easy test will prove. One of its first symptoms is that some of the brood will fail to hatch, and the cappings of the cells will assume a sunken appearance, and if a match or wooden toothpick is inserted into the cell and gently pulled out, a foul-smelling mucilaginous substance will adhere to it. The larva soon loses its shape, and becomes a sticky mass, smelling very much like ordinary glue. The offensive odor is not very pronounced in its early stages, but as the disease advances, it becomes more and more noticeable.

The larvæ that are attacked are usually sealed over by the bees, but this is not always the case, as it frequently happens that the unsealed brood is destroyed, especially if the 189 
HOW TO KEEP BEES FOR PROFIT

infection is well under way, and the bacteria fully at work. The color of the sticky mass is like strong coffee with milk added, but since these conditions prevail to a certain extent in the cases of chilled and pickled brood, we cannot be sure it is the real foul brood unless we test it with a toothpick or match as outlined above; if it adheres to the match, and can be drawn out to a distance of onehalf or one inch, we can then be reasonably certain that we have a case of real foul brood on hand.

The progress of this disease is very rapid, as all the combs of the hive are more or less certain to be infected, the honey included, and when the queen lays new eggs the honey that is fed to the larvæ will contain a lot of spores, and the new larvæ will in turn become diseased.

After a time the bacteria are so prevalent in the hive that no brood can be reared, and as the old bees die off the colony becomes so weak that it becomes an easy prey to robber 


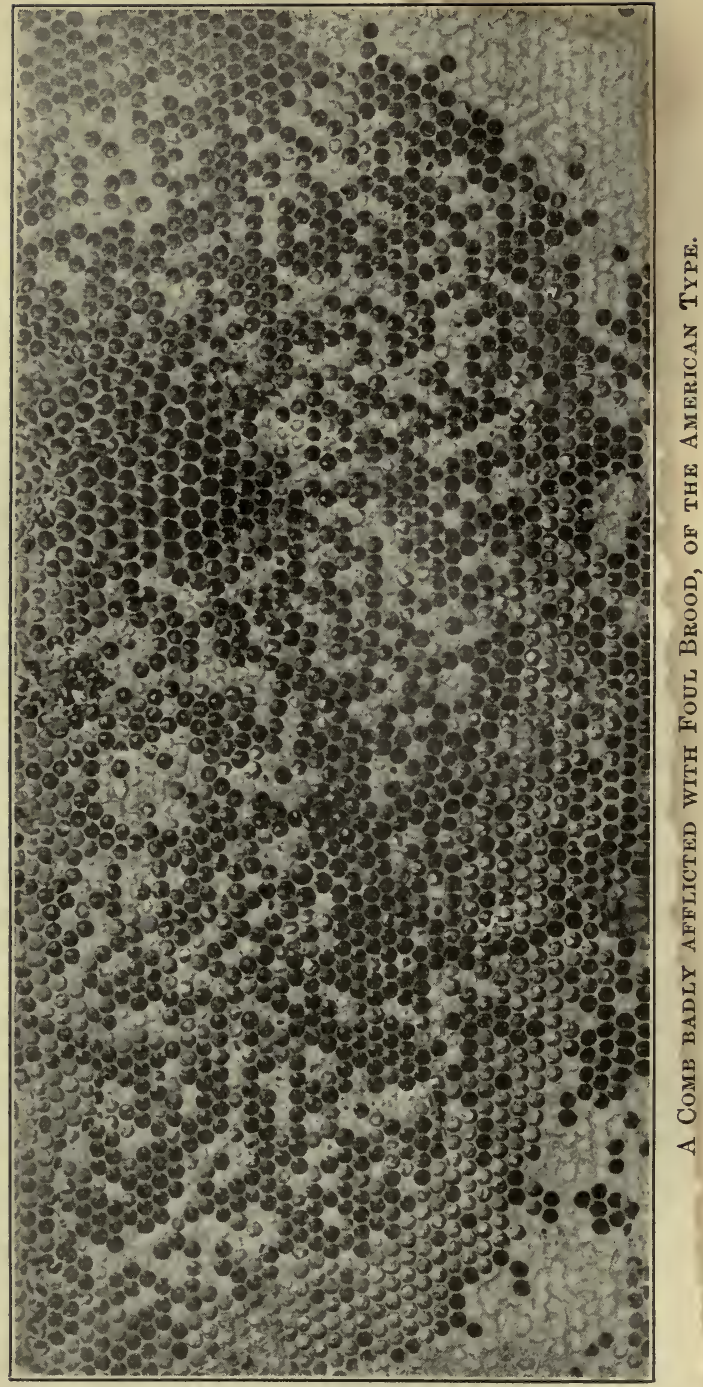



DISEASES AND ENEMIES OF BEES

bees, who will in turn carry its infected honey to healthy colonies, and in this way the disease will spread with alarming rapidity.

Sometimes a beginner will imagine he has a case of foul brood because the bees in warm weather will sometimes leave the cappings of brood they are sealing in an unfinished shape, so that there will be a small pinhole opening in the centre of the cell, but if the larvæ are nice and white, there is no occasion for alarm. In the case of foul brood the perforation will not be regular and rounded, but will have ragged edges, and this is due to the fact that the bees seem to have an instinct that something is wrong with the brood, since it fails to hatch, and they tear away a part of the cappings to determine what is the matter.

The best preventive measure is to take such good care of every colony that it is always strong, for bees are like human beings, the stronger are better able to resist disease in every form; and as a rule a strong colony is seldorn affected unless the spores are directly 
introduced by the bees from some already infected source.

After the treatment of a diseased colony, it is absolutely essential that all tools and implements that have been used shall be kept from the other bees till they have been thoroughly boiled and sterilized, if they are to be used again on a healthy colony. Even the clothing that was worn while treating a dis. eased colony is a perfect means of transmission, and there have been cases where careless inspectors of foul brood have gone from a diseased apiary to a healthy one without change or fumigation of their wearing apparel, and rendered the infection of the healthy apiary almost a foregone conclusion. The entrance to the hive of a diseased colony should be made smaller to prevent the possibility of robbing, and all manipulation should be done late in the day after the bees have ceased to fly, or serious consequences will follow. A great many curative methods have been tried in the past, using salicylic acid, phenol, carbolic 
DISEASES AND ENEMIES OF BEES acid, and formaldehyde, but the results were in no sense satisfactory.

William McEvoy of Woodburn, Ontario, Canada, claims to have had great success in the treatment of thousands of colonies, and he puts them back into the hives out of which they came; but there have been a large number of cases where the disease has appeared again in the hives whose bodies and fixtures were not disinfected. His plan is to take the infected colony in the height of the honey season, and in the evening shake the bees from their infected combs into their old hive, giving them frames with foundation starters, and let them work on them for four days. The bees will in that time have worked out some comb, and have stored in it all the diseased honey they carried in their sacs from the diseased combs, and then in the evening of the fourth day, he takes the new combs out and shakes the bees on new frames of foundation; and he claims that the cure will be complete as all the infected combs with their 
HOW TO KEEP BEES FOR PROFIT

honey will be removed from the hive. $\mathrm{He}$ does not advocate the disinfection of the old hive, but a little extra work in this respect will save worry and possible return of the disease, and for one's peace of mind it will be well to pour a strong solution of boiling water and carbolic acid over the hive body, lid, and bottom, letting it soak in all sides and run into every crevice.

A good plan for disinfection of the hive body is to pour some gasolene all over it and touch a match to it and let it burn off, and if too much is not used, and the blaze carefully watched, no harm will result to the hive. The old combs should be burned over a good fire and the ashes buried, this work being done at night; but if the combs are filled with honey, the honey can be extracted and boiled, and used for feed, but there is always the possibility of infected honey, with its fearful consequences, remaining in the extractor.

European foul or black brood differs in many ways from the American foul brood, and 
DISEASES AND ENEMIES OF BEES

first made its appearance in this country in New York state. Many an apiary was devastated by it, and it has been only in recent years that we seem to have found a cure.

While this form of foul brood in some respects is similar to the American kind, yet there are several respects in which it very materially differs. In the first place, it is very rarely ropy in its consistency, and the dead larva seldom loses its shape and becomes a sticky mass, but on the contrary, it assumes a watery consistency, and confines itself to the grub itself, which in time turns a dark brown. I have seen it a coffee black in some hives that were infected. Only in its latter stages does it become offensive like American foul brood, but even then it is hardly as foulsmelling.

Mr. E. F. Phillips, Ph.D., in charge of the Department of Apiculture at Washington, D.C., is one of the leading experts on bee diseases and will gladly render a report on any specimen that may be sent to him in a tightly 
sealed tin box; so that any beekeeper may determine beyond the shadow of a doubt just what disease he has to contend with.

The usual treatment for black brood up to a short time ago was identically the same as that used for American foul brood, but during recent years the late $\mathbf{M r}$. Alexander, of Delanson, New York, experimented for a considerable period and finally discovered a treatment that seems to be effective in every case. His plan was to remove from every diseased colony its queen, and by cutting out all queen cells already started, leave the colony in a hopelessly queenless condition for at least three weeks, during which period no new brood developed. During this time all of the healthy brood in the hive will hatch, and the colony, in anticipation of a new queen, will, as all queenless colonies do, clean out and polish every cell for the new eggs; this cleaning and polishing process seems to eradicate the disease completely. Some beekeepers were not very successful in following this method, 
DISEASES AND ENEMIES OF BEES

but in the hands of Mr. Alexander it was a pronounced success, and a personal examination of some colonies that were treated the season before failed to reveal to me any indication of the presence of foul brood in any form.

It might be said that during a good honey flow a strong colony runs little chance of becoming diseased. Do all the work with a diseased colony in the evening, and prevent even a single bee from another colony getting access to any of the diseased honey or implements, for one bee carrying even the minutest drop of infected honey to a healthy hive can spread the germs as effectively as a thousand.

Bee Paralysis is another disease that is sometimes found in warm climates, but is rarely known in the North, and, as a whole colony is seldom affected by it, it is not a cause for alarm.

An occasional bee with its abdomen greatly distended will be found crawling along the alighting-board evidently in an effort to get away from the hive to die; and this is about the 
HOW TO KEEP BEES FOR PROFIT extent of its ravages in the North; though the ravages of the disease in warm climates have been known to clean out an entire apiary, and is as dreaded as foul brood. Sometimes the removal and killing of the queen will work a cure, and would seem to indicate that the disease was inherited from the queen, but some experiments have proved that dequeening fails to accomplish the desired result. Perhaps the best way to cure it is to remove from the diseased hive all of its frames of brood and give them without their bees to a strong colony for a day or more, and giving a liberal sprinkling of powdered sulphur to the bees remaining in the affected colony; thus a cure is generally accomplished.

Spring dwindling of a colony is not a disease, but rather a condition, and is usually the result of a cold spell following the removal of bees from their winter cellars. Uniting such colonies has not proved the best plan, and a much better one is to place a queen-excluding zinc on top of a strong colony and on it set the 


\section{DISEASES AND ENEMIES OF BEES}

dwindled one, queen, bees, combs, and all, and when it has built up to fair strength, put it back on its stand.

There are a number of enemies that prey upon the bees, and as some of them are hard to reach, and as the results of their predations are minor, it is one of the phases of bee-keeping where the beekeeper has to take a chance, as it were. There are certain insectivorous birds that catch and eat bees while in flight, and many a good virgin queen in her matrimonial flight has been gobbled up, but this is a chance we have to take, and I know no means of stopping it. In warm climates the dragon flies kill a large number of virgin queens when in flight, and in certain sections they are so numerous that commercial queen-rearing is well nigh an impossibility.

Frogs will often in the cool of the evening place themselves at the entrance of a hive of bees, and many a luckless bee has been ensnared in their long tongues to make a tasty morsel for them. Field mice and small 
HOW TO KEEP BEES FOR PROFIT

snakes will often invade a hive, and if the colony is weak will work havoc with the combs, but, with the exception of mice, the setting of the hive upon a stand a foot or so above the ground will prevent their ravages.

An apiary is very likely to be the lurkingplace of skunks, who seem to have a fondness for bees, and the little rascals will, in the shadow of night, scratch on the alightingboard of a hive to lure the sentinels out for investigation, only to be gobbled up by their odoriferous enemies. A few traps baited with the proper bait will soon rid the yard of these pests; but care should be used in their handling if they are still alive when trapped.

In some sections of the country, the fondness of bears for honey has led them to topple over the hives and work much damage, but a little watchfulness on the part of the beekeeper, with the aid of a good rifle, will result in breaking it up.

Sometimes a mouse or small snake will invade a strong colony and be stung to death, 


\section{DISEASES AND ENEMIES OF BEES}

and when the bees find that they are unable to remove the carcass, they will proceed to propolize or mummify it and glue it securely to the bottom board of the hive. In lifting hives, with their bottom boards, I have frequently found a live snake, or nest of mice, enticed there no doubt by the warmth of the hive and the possibilities of a rich repast; but as these are things of but rare occurrence, no serious harm is likely to occur. 


\section{CHAPTER XV}

MARKETING THE HONEY CROP

A FTER the surplus honey has been A gathered, whether it be comb or extracted, its proper grading, packing, and marketing is an important factor, as these things added to the quality of the crop will with a little attention mean the securing of a better price for the output, and whether the crop be large or small, is an item worth considering.

Where the apiary is of moderate size, there is no better place to sell the crop than right at home or in a near-by town, as the reputation of the beekeeper, supplemented by a high-grade article, will result in high prices. The honey package should be attractive whether it be wholesaled or retailed, and a package a little more attractive than that of the other dealers means increased revenue. 
If the crop is extracted and is intended for the commission trade or the wholesale bottler, there is no better package than new five-gallon cans, two of which come in a wooden case. Being in cans, it is more easily handled by the commission merchant and the bottler, and in this shape will bring a little higher price than if sent in wooden kegs with the attendant labor of scooping it out for liquefying.

Use nothing but new, clean cans, and have the early light honey separate from the later dark honey; and be sure of the honesty of the commission merchant, for thereby hangs many a sad tale.

It will be far more profitable to bottle your extracted honey in an attractive bottle and work up a trade among the retail grocery houses, as it means securing about fifteen cents a pound net profit as against about seven cents a pound net profit when sold wholesale.

The standard package for the retail is a glass jar holding just one pound, and a nicely 
printed label with a half-tone cut of the apiary and a statement of the purity of the honey will make for it a very ready sale. These jars can be procured from the manufacturers, and as they come in reshipping cases holding two dozen, each can be shipped very handily when filled.

By the time you are ready to bottle your honey it will in all probability be granulated, which in itself is a test of its purity; and to return it to its liquid state it will be necessary to heat it to about one hundred and fifty degrees and hold it there for about three hours; but do not under any circumstances heat it above one hundred and sixty degrees, or you will spoil its delicate aroma and reduce its value. A large tin boiler or galvanized square can can be made at slight cost; it should be eighteen inches deep, and in this boiler over a gasolene or cook stove, with a block of wood underneath each can of honey, one or two of the sixty-pound cans can be placed, with their caps removed, and the boiler filled 204 
nearly full of water. When the water heats to the desired point, it should be kept there for about three hours, and when the honey. in the cans is nice and clear, which it will be if it was properly strained at time of extracting, the little one-pound jars should be filled with the hot honey and capped at once, when they are ready for the stores to which they are to be sent.

A most excellent jar for this purpose is the Hazel Atlas Simplex, a jar with a glass cap and a waxed ring, and attractive to the eye. Another good package for the home trade, if a house-to-house canvass is to be made, is the ordinary quart preserve or canning-jar, and as the housewife can make use of this jar after it is emptied, this style of package will appeal to her.

The county fairs held in the fall form an excellent medium for the sale of honey, as the beekeeper can have a booth and an observation hive at hand with live bees in it, and such an exhibit will always attract a crowd. 
Sometimes it is a good thing to take the extracting cage referred to in another part of this book, and in it have a hive of live bees. The operator can then go through an interesting performance that will astonish the natives, and secure a large sale of his honey.

Other beekeepers take a little cage of live bees under their arms and visit the business offices of our large cities, taking orders for honey in gallon cans at $\$ 2$ a gallon to be sent by express C. O. D. at the expense of the buyer; in this way a profitable employment is secured for the beekeeper during the entire winter months, with a larger profit for his honey than if it were sent to the city wholesale.

Where the output runs up into many tons, it will be more satisfactory for the producer to send it to the cities in bulk, but even in this case there is no reason why the producer should not dispose of a large amount of his output to the grocery trade in bottles, and 


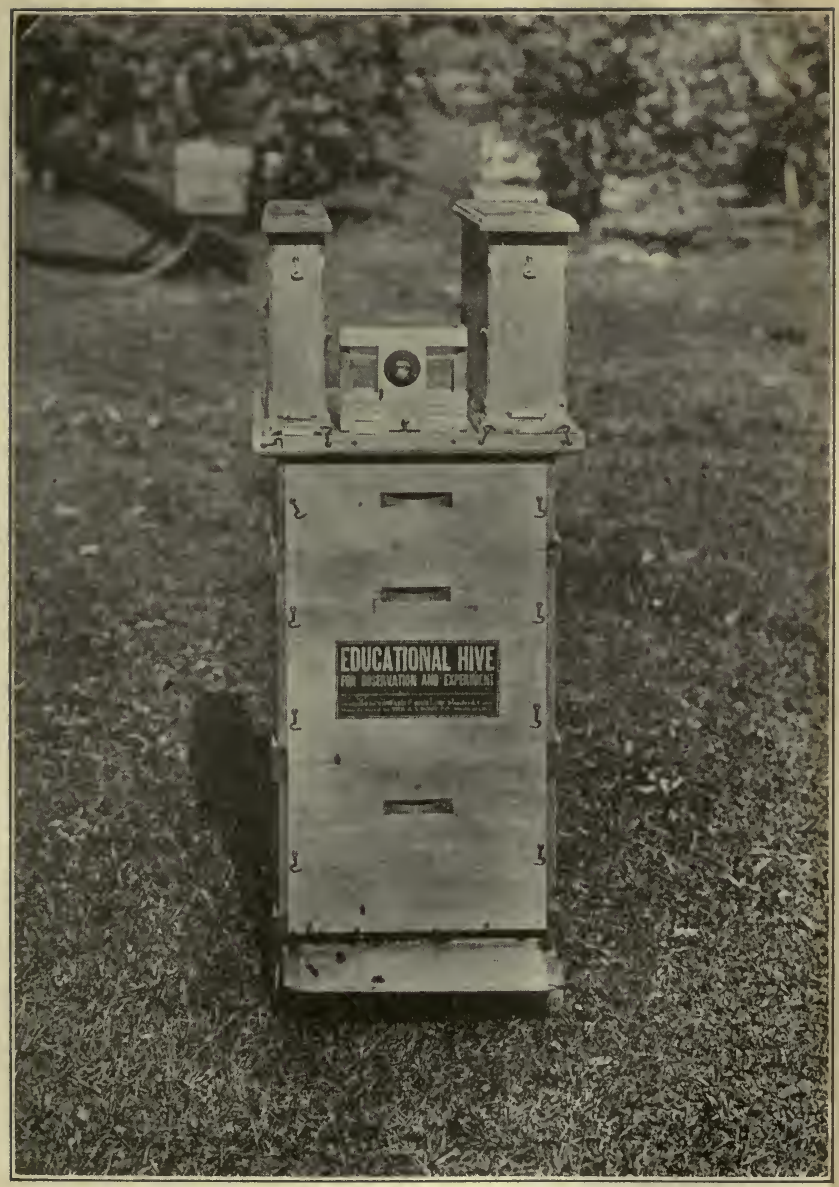

An Observation Hive affords much Pleasure in studying THE HABITS OF BEES. 
MARKETING THE HONEY CROP

reap the benefits of the increased price secured.

Generally speaking, there is seldom more than one beekeeper in business on an extensive scale in a given place, and he will have little difficulty in disposing of his crop at home and in near-by towns to both stores and families. This will necessitate the use of a horse and wagon, but the greater profit will make this plan advisable, and it is followed by hundreds of beekeepers every year. I know an old man seventy years of age, who puts his honey up in quart jars, and visits the factories and shops at the noon hour, giving a little talk on bees, who has sold as much as $\$ 2000$ worth of honey in a single year. He gets fifty cents a quart for his honey.

Sometimes in a large city a vacant store on a busy thoroughfare can be rented for a month, and a display of live bees and honey will result in large sales at fancy prices, as bees are a source of interest to city folk. Depart- 
ment stores are good customers and are glad to have an exhibit of live bees in observation hives together with a nice display of honey, as such exhibits draw a crowd and result in business in all departments.

With the new pure food laws in operation, the beekeeper is having his day, as he no longer has to compete with mixtures of honey and glucose masquerading under the name of pure honey, as was formerly the case. In the matter of honey these laws are rigidly enforced, and adulterated honey is required to have a statement on every package, stating just what the adulterant is and in what proportions. Few people will buy such stuff when they can secure the real thing at a moderate price.

Comb honey has to be prepared in an entirely different way to be placed on the market, and unless great caution is exercised in the matter of packing, serious breakage of the combs will follow. Each section should be carefully scraped of all particles of propolis, 208 


\section{MARKETING THE HONEY CROP}

and the honey according to its appearance carefully graded and marked. The ordinary shipping-cases with glass on one side and corrugated paper in the bottom, and holding twenty-four sections, is the best all-round package that can be used, and these cases

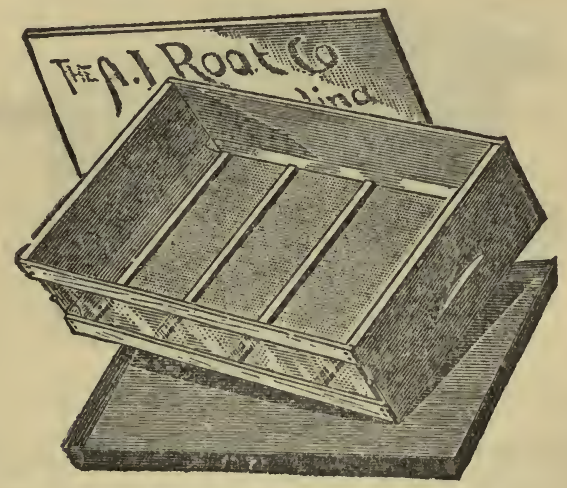

No-Drip Shipping-Case:

can be purchased at moderate cost from any of the supply houses that make them especially for the comb honey producers.

Under no circumstances should these cases be shipped individually. A number of them should be packed in a crate with projecting strips for handles, and the bottom of the 209 


\section{HOW TO KEEP BEES FOR PROFIT}

crate filled with at least six inches of hay or straw to act as a cushion for the honey and prevent its breakage in transit.

It is the poorest of policies to face the glass end of each case with the best sections, and put the poorer ones at the back, as the trick will

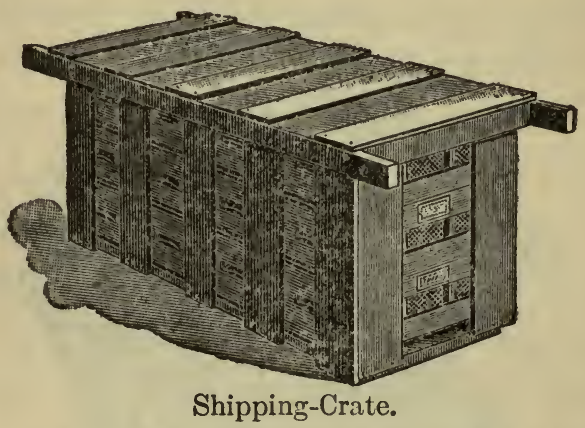

sooner or later be discovered to the detriment of the shipper. A better plan is to select and grade all the best sections and put them in cases by themselves, and crate the poorer ones by themselves; the additional price of the first grade will average the price in a satisfactory manner.

In scraping the propolis from the sections nothing is better than a broad-bladed butcher 
MARKETING THE HONEY CROP

knife. Unless you are careful, there will be more or less gashing of the surfaces of the sections with its resulting drippings, which will make them sticky and unsightly, and greatly reduce their value. Though there is no reason why there should not be a universal rule for grading comb honey, certain rules prevail of a twofold character, known as "Rules for Western Beekeepers," and "Rules for Eastern Beekeepers."

The Eastern Grading Rules read as follows :-

FANCY. - All sections well filled: combs straight, firmly attached to all four sides; combs unsoiled by travel stain or otherwise; all the cells sealed except an occasional one; the outside surface of the wood well scraped of propolis.

A No. 1. - All sections well filled except the row of cells next to the wood; combs straight; one-eighth part of the comb surface soiled, or the entire surface slightly soiled; the outside surface of the wood well scraped of propolis.

No. 1. - All sections well filled except the 
row of cells next to the wood; combs comparatively even; one-eighth part of the comb surface soiled, or the entire surface slightly soiled.

No. 2. - Three-fourths of the total surface must be filled and sealed.

No. 3. - Must weigh at least half as much as a full-weight section.

In addition the honey must be classified according to color, using the terms white, amber, and dark; that is, there will be, "Fancy White," "No. 1 dark," etc.

These are the result of the action of the National Beekeepers' Association in convention in Washington, D.C., in December, 1892.

The Colorado Beekeepers' Association adopted the following rules, which prevail west of the Mississippi:-

NEW COMB-HONEY GRADING-RULES ADOPTED BY THE COLORADO STATE BEEKEEPERS' ASSOCIATION

No. 1 Whiтe. - Sections to be well filled and evenly capped except the outside row, 212 


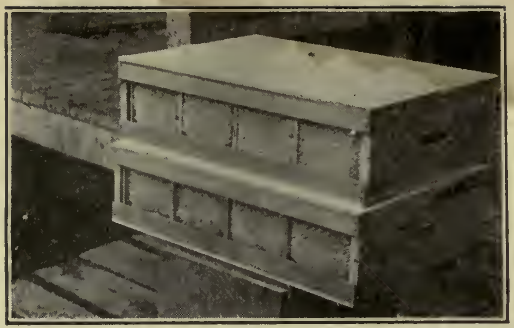

Shipping-cases with Beeway and Plain Sections.

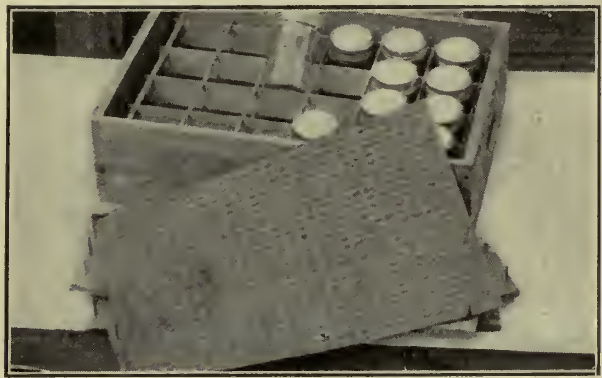

How the No. 25 JaR is PaCked.

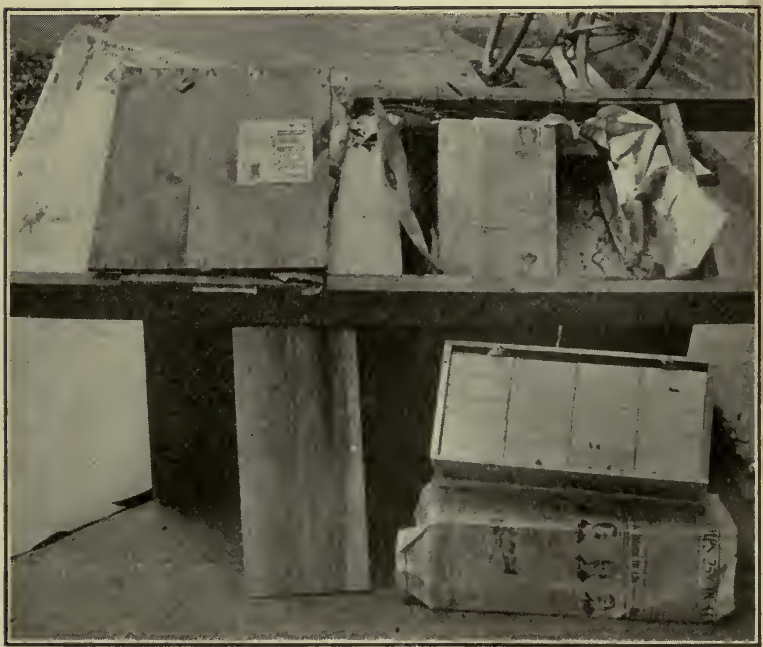

A Shipping Crate of Comb-Honex. 

MARKETING THE HONEY CROP

next to the wood; honey white or slightly amber, comb and cappings white, and not projecting beyond the wood; wood to be well cleaned; cases of separatored honey to average 21 pounds net per case of 24 sections, no section in this grade to weigh less than $13 \frac{1}{2}$ ounces.

Cases of half-separatored honey to average not less than 22 pounds net per case of 24 sections.

Cases of unseparatored honey to average not less than 23 pounds net per case of 24 sections.

No. 1 Light Amber. - Sections to be well filled and evenly capped, except the outside row, next to the wood; honey white or light amber; comb and cappings from white to off color, but not dark; comb not projecting beyond the wood; wood to be well cleaned.

Cases of separatored honey to average 21 pounds net per case of 24 sections; no section in this grade to weigh less than $13 \frac{1}{2}$ ounces.

Cases of half-separatored honey to average 213 
HOW TO KEEP BEES FOR PROFIT not less than 22 pounds net per case of 24 sections.

Cases of unseparatored honey to average not less than 23 pounds net per case of 24 sections.

No. 2. - This includes all white honey, and amber honey not included in the above grades; sections to be fairly well filled and capped, no more than 25 uncapped cells, exclusive of outside row, permitted in this grade, wood to be well cleaned, no section in this grade to weigh less than 12 ounces.

Cases of separatored honey to average not less than 19 pounds net.

Cases of half-separatored honey to average not less than 20 pounds net per case of 24 sections.

Cases of half-separatored honey to average not less than 20 pounds net per case of 24 sections.

Cases of unseparatored honey to average not less than 21 pounds net per case of 24 sections. 
It can be seen by the above that the rules for the eastern beekeepers are a little more discriminating than the western standard, and enable the buyer to form a clearer idea of just the quality of the honey bought.

When producing comb honey for market, the beekeeper has several styles and sizes of sections from which to select, though in each case the amount of honey will be nearly the same. Formerly the square section with the slotted bee-way was the only one that was used, but there is a growing demand for a plain section a little taller than wide, measuring $4 \times 5 \times 1 \frac{3}{5}$ inches, and although this section is a trifle thinner than the old style, yet it appears to have more honey, and is being adopted more and more by up-to-date beekeepers.

There is a class of trade that demands that every section when it is packed shall be glazed, with pieces of glass fitted to each side of the surface of the wooden holder, and although they are a nuisance to prepare, it pays if the 
HOW TO KEEP BEES FOR PROFIT

trade demands it, as a little higher price can be secured for the trouble, especially if a fancy paper border is used to secure the glass to the section. Where glass is not used, it is well to encase each section in a pasteboard carton, as it protects the honey and adds to the appearance of the section.

If the faces of some combs are slightly stained, they can be bleached by placing them in a box or small room and fumigating them with the fumes of burning sulphur, or else they can be exposed to the direct rays of the sun, to accomplish the same result. 


\section{CHAPTER XVI}

BEESWAX - ITS USES - HOW TO RENDER IT

T running an apiary, especially one main1 tained for extracted honey, large quantities of beeswax from cappings, old combs, and brace combs, will accumulate, and as beeswax is always in demand and sells at a good price, its proper care and rendering becomes an important item. For many, centuries, beeswax has been a much-needed commodity in almost every branch of work. Before the ingenuity of man made parchment as a medium for writing, tablets covered with beeswax were almost entirely used, and fulfilled a useful purpose. Owing to the fact that beeswax will not rot, it was used by many nations to embalm their dead, and mummies that have lain for centuries upon examination show the wax used to be in a fine state of preservation. 
The rubrics of the Catholic Church prescribe beeswax exclusively in the making of candles for solemn ceremonies, as it is secreted by a virgin insect. In the polishing of floors and furniture wax has been found a valuable adjunct, as its use adds to the beauty and life of the object polished. Sculptors, painters, dentists, and molders use large quantities of it, and in the arts and various departments of manufacture it has become so great a necessity that there is never an over-production, and the beekeeper who has a goodly supply on hand will experience no difficulty in exchanging it at the supply houses for new sheets of foundation for both his brood and super frames.

For the use of the beekeeper there has been found nothing that will take its place, although a long line of experiments with paraffin and ceresin have been made, without success, as the bees show a positive dislike for any other foundation than that made from pure beeswax. 
The making of beeswax by the bees is a very delicate and wonderful process, and if you will open a hive in the height of the honey flow when the bees are at work, a lot of the little disks will be found on the bottom board of the hive, and when examined under the microscope they are really beautiful. Before secreting wax, the bees fill themselves with honey and then hang in clusters in their hives; and by generating heat they are able to convert the honey into wax, which as small disks protrudes from the little wax scales located on the under side of the abdomen of the bee.

Pattern-makers, machinists, and manufacturers of shoe and furniture polish are ready to purchase at a good figure unlimited quantities of pure beeswax, so it can be readily seen that there is a great demand for it, and the careful beekeeper will make it \& point to save every particle, melting and rendering it into commercial form at his convenience.

It seems unfortunate that progressive meth- 
ods of beekeeping, as compared with the older methods, have restricted the production of beeswax in the apiary; but as the progress has resulted in a greater production of honey, there is no actual loss in profit. When bees were largely kept in the old-fashioned box hives the bees were brimstoned to get the honey, and as the combs were usually mashed and strained, there was of necessity a larger amount of beeswax secured each season.

With the use of the modern extractor, the honey is extracted from the combs by centrifugal force, and the combs used year after year, so that the proportion of beeswax to honey secured is not as great as formerly; the honey-producer of to-day is dependent upon the cappings from the frames extracted, old combs, brace and bur combs, but even at that the revenue from these sources is considerable. As the wax accumulates it should be kept in a cool place, so that it will not become a breeding-place for the wax moth and be ruined, and for this reason it is well 
to melt and render it before it becomes attacked.

There are many methods of rendering old wax, and the beekeeper is allowed large latitude in the matter of selection. One of the older methods was to fill a porous sack or bag with cappings, old combs, and other waxen refuse and to weigh it down in a large kettle, covering it with water and allowing it to boil until the wax began to rise, and when the water became cold a cake of wax would form at the top. At best this method was far from satisfactory, as the cake was more or less burned or water-soaked, and filled with more or less dregs of matter from the old combs from which it was rendered.

About 1862 the first solar wax extractor was invented in California, and was first used for extracting the honey from the combs, but later it was used solely for melting wax, and even to-day is extensively used in many of the largest apiaries in the world. These solar wax extractors were little more than 
large boxes covered with glass in which old combs were placed and exposed to the rays of the sun, and toward evening as the day grew cooler the wax, because of its lightness, was found in sheets on top of the honey.

Doolittle, Boardman, Rauchfuss, and others invented solar wax extractors which were more or less adopted, but in principle they were practically the same, and depended upon the sun's rays shining through glass to do the work.

While the solar wax extractor can be depended upon to do a certain amount of rendering, especially where capping and new combs are put into them, yet when it comes to getting the wax out of old dark combs, they have their limit, and compel us to resort to another method. The only satisfactory way to render wax is by some method by which the old combs can be enclosed in a sack and subjected to pressure while surrounded by steam. This method is not entirely new, though some of the appliances are, and were 
used in Germany many years ago, where it originated, but it remained for America to invent a satisfactory press, several makes of which are on the market, all capable of doing excellent work.

Some of these presses extract the wax under pressure at the time the steam is surging through the mass, as in the case of the German Wax Press and the Hershiser Wax Press, while others extract the wax under pressure after the heated sack has

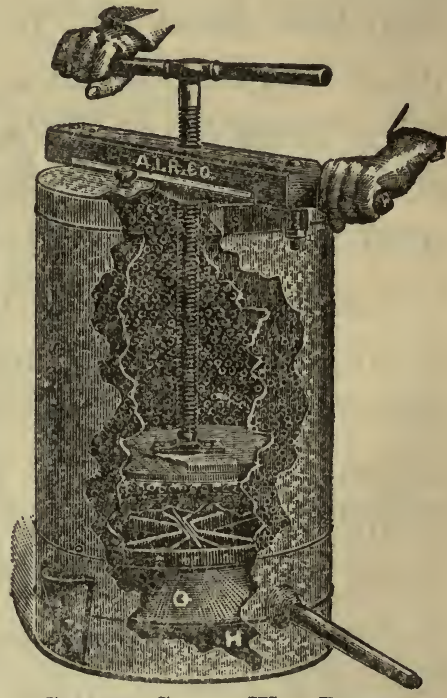

German Steam Wax Press. been taken from the steamer, and Messrs. Hatch and Gamil were successful pioneers in the perfection of the press that bears their names. The latter plan is perhaps the best, and is fast being adopted, as experience proves that there is 
less wax left in the slumgum, as the refuse is called, than under other methods.

The old combs and pieces of wax are encased in a stout bag and boiled for a few minutes, then lifted and poured out of the bag, about a gallon at a time, and, when the cloths of the press are firmly secured about it, pressure is exerted, and the water and practically all of the wax will run out of the press into the bucket or other vessel that has been put into position to receive it, and when the water is cooled the cake of wax is ready for removal. Repeating the process, using about a gallon of the mass at a time, it is surprising how much wax will be secured within a short time. An up-to-date wax press is not expensive, and as it does its work so much better than the many homemade makeshifts that are used, it is economy to buy one, as the extra amount of wax obtained from the slumgum will pay for it in a short time.

If the wax secured is intended for the manufacturers of foundation, it can be shipped 
just as it comes from the press; but if it is for general use, it should be remelted and molded in little tins, and in the melting an iron kettle should be avoided, as it has a tendency to discolor the wax and render its sale difficult.

Manufacturers of comb foundation say that hardly two lots of wax that they receive are uniform in color; this is due to the presence of more or less foreign substances, and to reduce it all to its original yellowness, it is necessary for them to treat it to a bleaching process with sulphuric acid.

The following is the method of bleaching used by the A. I. Root Co.

HOW TO REFINE WAX WITH SULPHURIC ACID

Wax cakes, as they are bought up, are usually of all grades and colors. The difference in color is due largely to the amount of impurities the wax contains. In all the years that we have been in the business we have found no practical or satisfactory way

Q 225 
of bringing the wax to a yellow color - that is, to its original state of purity, except by treating it with acid.

The method, in brief, is as follows: Fill a wooden tank or barrel a quarter full of water, and add cakes of wax until nearly full. The water is then boiled until all the wax is melted, when a quantity of commercial sulphuric acid is poured in, and the boiling continued until all is thoroughly mixed. The heat is then removed and the impurities are allowed to settle.

For a detailed account, it may be well to describe our own system of refining wax. Our tank is a little over three and one-half feet in diameter, and about five feet high. Water is run into it to a depth of twelve inches, and then fifteen hundred pounds of wax are thrown in, making it about full. The mass is then heated by means of a jet of steam from a pipe projecting down into the water from the top. When all the wax is melted, the acid is poured in. If the wax is dark, seven pints of arid are used; but if light enough to make 


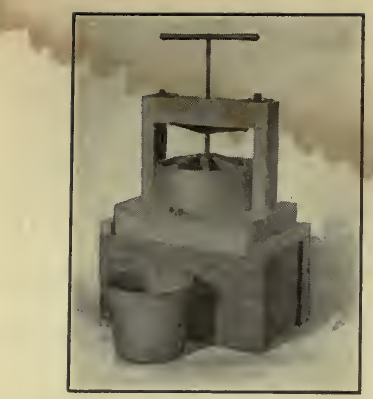

A WAX-PRESS. .

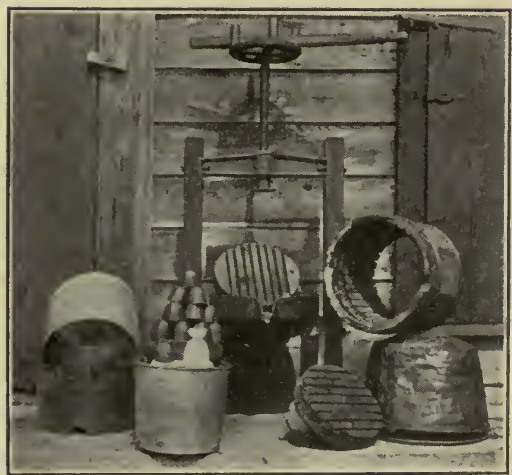

A LARD-PRESS MODIFIED FOR PRESSING WAX.

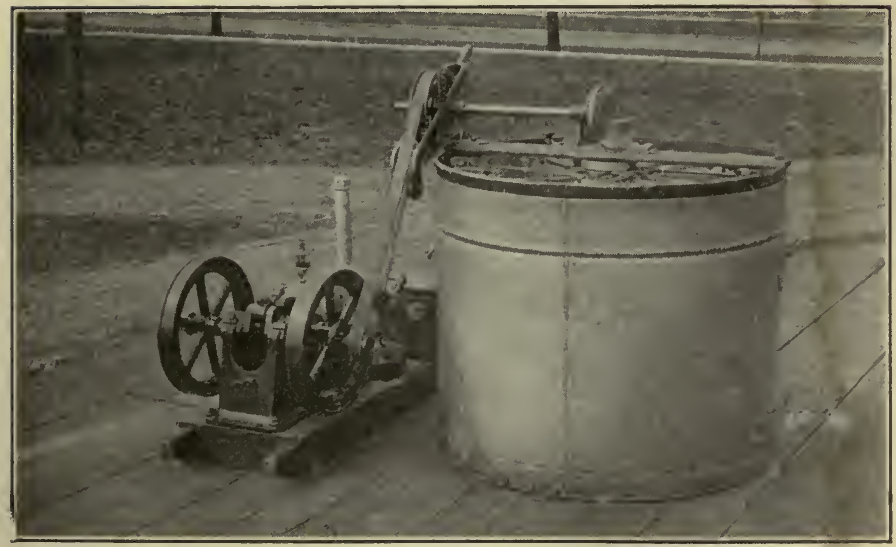

An Eight-frame Extractor connected to a One Horse Power Air-cooled Gasoline Engine. 

surplus foundation, not more than three quarts are used. If the wax is already of good quality, so small an amount as two quarts of acid will answer. On the average, therefore, we use three quarts of acid to eighty gallons of water for fifteen hundred pounds of wax. Soon after this is poured in, the color of the boiling wax will be seen to grow lighter, and, after a minute or so, the boiling is stopped.

The steam pipe is now drawn out, and the tank covered with a cloth or carpet, and allowed to stand as many hours as the wax will remain liquid, or about twenty-four hours. At the expiration of this time the water and acid will have settled to the bottom by reason of their greater specific gravity; and the acid, in turn, having a greater specific gravity than that of water, will settle to the bottom of the water; and the consequence is, that the wax itself, after being purified, is allowed to become thoroughly cleansed of any residue of acid, and the dirt accumulation will all have settled to the bottom of the wax and into the 
HOW TO KEEP BEES FOR PROFIT

water. The melted wax is now drawn off from the top, and poured into any sort of receptacles with flaring sides. When the wax is nearly to the bottom, or when it shows evidence of coming near the dirt, the rest is allowed to stand. As soon as it is caked in the tank it is lifted out, and the dirt clinging to the bottom scraped off.

Rendering wax at best is a troublesome and messy job, and it is possible to work much damage to a carpet or a suit of clothes that is of far more value than the little wax that may be secured where the beekeeper has but a few hives.

If the rendering is done in the house kitchen, spread some paper - newspapers will do - on the floor, and go about the work slowly and carefully. If at the close of the work the wax is smeared over kettles and pans, it can be removed by immersing the utensils in boiling water for a while, and rubbing them with a cloth that has been saturated with benzine. 
Muffin tins, egg cups, pails, or any receptacles of proper size may be used to pour the melted wax into for molding, first wetting the vessel with water, and when the wax has cooled into solid cakes it can be dumped out and is ready for market. Some of the supply houses make little tins for molding the wax into cakes that retail for ten cents, and these are a help where the wax is to be sold in the home town or placed with the grocery trade for sale. Little candles made of beeswax give a brilliant light and throw off a delicate perfume; the molds and wicks for making them can be had at slight cost, and their sale brings the highest prices for the wax that is used.

I know of one beekeeper who is able to make a dozen of these little candles from a pound of beeswax, and he has no difficulty in getting $\$ 1$ a dozen for them. By all means husband your old combs and cappings, as the revenue derived from them will often pay for the foundation that from time to time has to be bought for brood frames and section boxes. 


\section{CHAPTER XVII}

HONEY AS A FOOD AND MEDICINE

TONEY is being more and more recog11 nized as a necessity and not as formerly a luxury, and could its food and healthgiving qualities be better known, it would appear more often on the bill of fare than it does.

In looking over the various dictionaries I fail to find a correct scientific definition of the constituents of honey, and only succeeded in finding the following definition in Phin's Dictionary of Beekeeping:-

"Honey contains four different kinds of sugar: (1) Cane sugar (though this is not always present); (2) fruit sugar or glucose; (3) invert sugar, so-called because it turns the plane of polarization to the left, or inverts the action of the fruit sugar; (4) a sugar of 
HONEY A FOOD AND MEDICINE

which little is known, but which is evidently a distinct variety.

"Under the peculiar action of the ferment (enzyme) previously mentioned, and which is generally present, the cane sugar gradually changes to sugar of the second and third kinds; and as these are less soluble than cane sugar, the clear limpid fluid gradually becomes opaque and granular, or in other words the honey is said to granulate."

However vague the above description may be, honey in the public mind means nectar secreted by the flowers of the field and gathered by the bees and thoroughly ripened in the hive. Honey will vary in its color and flavor according to the source from which it was gathered, the clover being mild in flavor while that from buckwheat is pronounced. Notwithstanding this variation in color and flavor, the food value of all honey is practically the same, the particular flavor desired being largely a matter of choice.

Before the passage of the Hepburn Pure 231 
HOW TO KEEP BEES FOR PROFIT

Food Law in America on June 30, 1906, a great deal of adulterated honey was sold to the public, but since the passage of the above law, the public is reasonably certain of getting pure honey.

\section{Honey as Food}

The American nation consumes an enormous amount of sugar, averaging nearly eighty pounds per head, and the people of the British Isles ten pounds more. The increased consumption of sugar during the last few years has been phenomenal, and even people in moderate circumstances consume a large amount. Honey sells in some states for very little more than good cane sugar.

Honey is much superior to sugar in several respects. It has far more flavor and aroma, and for baking certain fancy cakes it has no equal; and for this reason will always command a higher price than sugar. We know fastidious people are always willing to pay high prices for foods having fine flavors, and 
all physiologists are agreed that flavor has much to do with the dietetic value of a food by inducing a free flow of saliva and promoting digestion by its palatability.

Honey is an excellent food in the prevention of fatigue, owing to the fact that, while it builds up the body, or rather makes up for the loss of tissue, it does not tax the system. The latter is not called upon to throw off or get rid of a mass of perfectly useless material, for ii is undoubtedly true that not more than one two-hundredth part of honey is actual waste. Practically the human system uses up almost every particle of honey placed in the stomach. This can be said of no other food except sugar, which must undergo a process of inversion before the system can utilize it. Honey, on the other hand, is in a state of partial digestion before being eaten; and this, in addition to the very free flow of saliva induced by the flavor, causes it to be completely used up by the digestive system without straining it in the least - so 
HOW TO KEEP BEES FOR PROFIT much so, in fact, that many invalids and infants may use honey when sugar would be prejudicial.

Honey, it is believed, after passing through the stomach, becomes glycogen by the action of the liver, and in this way is converted into heat and work. It differs from sugar in two important particulars. First, it does not require to be "inverted," or converted into natural glucose (it is that already), a process which frequently leads to diabetes, and, again, it possesses an aroma and flavor which sugar does not. Moreover, it does not contain powerful chemicals, as sugar sometimes does. It is a purely natural production, and requires no cooking or preparation.

There is almost an infinite variety of flavors in honey, so that the peculiar palate of every one may be suited. In dealing with children and delicate people this is important. In countries where the consumption of sugar is large, as in the United States, Canada, and the British Islands, Germany, Holland, and 234 
other northern lands, diabetes is quite common. This is due to the fact that the system of those afflicted is so constituted that they are unable to convert ordinary sugar into glucose. There is always a certain number of such people in every community. Diabetes bears considerable resemblance to Bright's disease of the kidneys, which is, however, due to an excess of albumen - not sugar.

Children generally crave something sweet, and this is a perfectly healthy and natural longing which ought to be satisfied in some way. This is generally done by giving confectionery and sweetmeats, which frequently are indigestible. Honey can be made to take their place with many children if it is allowed in the regular dietary. In this way the craving for sweets is very effectively met. In France and other parts of Europe the doctors recommend honey and cream, or honey and butter, in the treatment of consumptively inclined children. They say this combination is better than cod-liver-oil emulsion, 
for the reason that it is much more palatable, and more satisfactory to the patient's stomach. A fine combination for fast-growing thin children is bread, butter, and honey. In this country any mother may try this bill of fare on her well-beloved children. She may feel certain that no better menu for a child can be suggested. Honey may be very effectively used in summer drinks, and should take the precedence of sugar in this respect, more particularly where workmen are employed in hot and fatiguing work such as takes place in glass and iron factories.

Immense quantities of honey are used by bakers, both in America and Europe. In this country alone the National Biscuit Company uses an amount which seems staggering to a man unacquainted with the industry. This concern recently purchased in one lot seventy carloads of good honey, and is always in the market for honey in big lots. There are no means of knowing just how much honey the baking industry uses in this country; but 
we do know it is very large indeed. The best bakers have discovered that honey is far superior to sugar as a sweetening agent. The latter causes the cakes and bread made with it to dry up and become unpalatable in a few days; whereas honey, on the other hand, causes them to remain sweet and moist for a long period. Cases are reported of honey-jumbles remaining moist for twelve years; and in France nobody thinks it is anything very wonderful to keep honey-bread a year or eighteen months, and yet have it remain perfectly good and satisfactory. If it is hard, it is simply put into a damp place for a few days, when it returns to its original condition.

It is perfectly clear that, where bread and cakes are made in factories, they must have some "keeping" qualities; and by experience the managers have found honey is the only acceptable agent for this purpose. At Dijon, in France, from time immemorial a kind of honey-bread (pain d'épice, or Lebkuchen, as the Germans call it) has been 
made which has acquired a wide fame. It is made in other parts of Europe, but this place seems to excel in its production. The bakers there are fastidious, and cannot be induced to use any but buckwheat honey. They say they cannot risk their reputation by using any other. The honey is obtained in Brittany; and when it is used up the bakers will stop baking rather than use a substitute.

Honey-bread is now made and sold in New York, and what we have used of it here in Medina proved to be very fine eating indeed. The general opinion of it is, it would be very acceptable to dyspeptics or persons of impaired digestion, as it is very open and porous, and easily masticated.

Honey-cakes and jumbles have been consumed in steadily increasing quantities of late years, and the demand increases by leaps and bounds, showing that consumers appreciate a really delicious and satisfactory food, no matter if it seems somewhat higher priced than similar foods. 
A considerable amount of honey has also been used in confectionery. This demand is increasing; and in this connection beeswax is also used to some extent. The beeswax is used in about the same proportions that we find it in a piece of comb honey, and some actually buy comb honey for making confectionery. Honey-candies coated with chocolate are much consumed in Europe.

Honey is largely used as a medicine and as a vehicle for administering nauseous medicines. It is so soothing in its action that it is used effectively for many purposes in the sickroom. In continental Europe the doctors constantly recommend and use honey. For some unexplained reason our medical men are not so favorable to honey as their European confrères, possibly because they are afraid of its adulteration. Since the passage of the national pure-food law there need be but little fear of this, and it may be freely recommended.

Honey has an excellent effect on the skin, and for this reason is much used in soaps 
and similar preparations sought by ladies for softening the cuticle and improving the complexion. Salves are also improved by the use of honey and beeswax; in fact, the latter is considered the only proper substance for forming the base of ordinary salves.

Very many of the so-called honey cooking recipes are untested, and hence worse than none; for when the ingredients are put together and cooked the result is vile. The recipes given below have been tested, and every one is guaranteed to be good. The honey-jumble recipe, for instance, is especially good, as is the honey-cake recipe by Maria Fraser.

\section{HONEY COOKING RECIPES}

HoneY-Gems. - 2 qts. flour, 3 tablespoonfuls melted lard, $\frac{3}{4}$ pt. honey, $\frac{1}{2}$ pt. molasses, 4 heaping tablespoonfuls brown sugar, $1 \frac{1}{2}$ ievel tablespoonfuls soda, 1 level teaspoonful salt, $\frac{1}{2}$ pt. water, $\frac{1}{2}$ teaspoonful extract vanilla.

HoNEY-JUMBLes. -2 qts. flour, 3 tablespoonfuls melted lard, 1 pt. honey, $\frac{1}{4}$ pt. molasses, $1 \frac{1}{2}$ level tablespoonfuls soda, 1 level teaspoonful salt, $\frac{1}{4}$ pt. water, $\frac{1}{2}$ teaspoonful vanilla. 


\section{HONEY A FOOD AND MEDICINE}

These jumbles and the gems immediately preceding are from recipes used by bakeries and confectioneries on a large scale, one firm in Wisconsin alone using ten tons of honey annually in their manufacture.

HoNEY-CAKe or Cookies without sugar or molasses. 2 cups honey; one cup butter; four eggs (mix well); one cup buttermilk (mix); one good qt. flour; one level teaspoonful soda or saleratus. If it is too thin, stir in a little more flour. If too thin it will fall. It does not need to be as thin as sugar-cake. I use very thick honey. Be sure to use the same cup for measure. Be sure to mix the honey, butter, and eggs well together. You can make it richer if you wish by using clabbered cream instead of buttermilk. Bake in a rather slow oven, as it burns very easily. To make cookies, use a little more flour, so that they will roll out well without sticking to the board. Any kind of flavoring will do. I use ground orange-peel mixed soft. It makes a very nice gingerbread.

Maria Fraser.

Howell Honey-Cake. - (It is a hard cake.) Take 6 lbs. flour, 3 lbs. honey, $1 \frac{1}{2}$ lbs. sugar, $1 \frac{1}{2}$ lbs. butter, 6 eggs, $\frac{1}{2}$ oz. saleratus; ginger to your taste. Directions for mixing. Have the flour in a pan or tray. Pack a cavity in the centre. Beat the honey and yolks of eggs together well. Beat the butter and sugar to cream, and put into the cavity in the flour; then add the honey and yolks of the eggs. Mix well with the hand, adding a little at a time, during the mixing, the $\frac{1}{2} \mathrm{oz}$. 
saleratus dissolved in boiling water until it is all in. Add the ginger, and finally add the whites of the 6 eggs, well beaten. Mix well with the hand to a smooth dough. Divide the dough into 7 equal parts, and roll out like gingerbread. Bake in ordinary square pans made for pies, from $10 \times 14$ tin. After putting into the pans, mark off the top in $\frac{1}{2}$-inch strips with something sharp. Bake an hour in a moderate oven. Be careful not to burn, but bake well. Dissolve sugar to glaze over top of cake. To keep the cake, stand on end in an oak tub, tin can, or stone crock - crock is best. Stand the cards up so the flat sides will not touch each other. Cover tight. Keep in a cool dry place. Don't use until three months old at least. The cake improves with age, and will keep good as long as you will let it. I find any cake sweetened with honey does not dry out like sugar or molasses cake, and age improves or develops the honey flavor.

E. D. Howell.

Aikin's Honey-cookies. -1 teacupful extracted honey, 1 pt. sour cream, scant teaspoonful soda, flavoring if desired, flour to make a soft dough.

SoFT Honex-CAKe. -1 cup butter, 2 cups honey, 2 eggs, 1 cup sour milk, 2 teaspoonfuls soda, 1 teaspoonful ginger, 1 teaspoonful cinnamon, 4 cups flour. Chalon Fowls.

Ginger Honex-cake. -1 cup honey, $\frac{1}{2}$ cup butter, or drippings, 1 tablespoonful boiled cider, in half a cup of hot water (or $\frac{1}{2}$ cup sour milk will do instead). Warm these ingredients together, and then add 1 tablespoonful ginger 


\section{HONEY A FOOD AND MEDICINE}

and 1 teaspoonful soda sifted in with flour enough to make a soft batter. Bake in a flat pan. Chalon Fowls.

Fowls' Honey FrutT-Cake. $-\frac{1}{2}$ cup butter, $\frac{3}{4}$ cup honey, 5 cup apple jelly or boiled cider, 2 eggs well beaten, 1 teaspoonful soda, 1 teaspoonful each of cinnamon, cloves, and nutmeg, 1 teacupful each of raisins and dried currants. Warm the butter, honey, and apple jelly slightly, add the beaten eggs, then the soda dissolved in a little warm water; add spices and flour enough to make a stiff batter, then stir in the fruit and bake in a slow oven. Keep in a covered jar several weeks before using.

Muth's Honey-CaKes. - 1 gal. honey (dark honey is best), 15 eggs, 3 lbs. sugar (a little more honey in its place may be better), $1 \frac{1}{2} \mathrm{oz}$. baking-soda, $2 \mathrm{oz}$. ammonia, 2 lbs. almonds chopped up, 2 lbs. citron, 4 oz. cinnamon, 2 oz. cloves, 2 oz. mace, $18 \mathrm{lbs}$. flour. Let the honey come almost to a boil; then let it cool off, and add the other ingredients. Cut out and bake. The cakes are to be frosted afterward with sugar and white of eggs.

Fowls' Honey Layer-Cake. $-\frac{2}{3}$ cup butter, 1 cup honey, 3 eggs beaten, $\frac{1}{2}$ cup milk. Cream the honey and butter together, then add the eggs and milk. Then add 2 cups flour containing $1 \frac{1}{2}$ teaspoonfuls baking-powder previously stirred in. Then stir in flour to make a stiff batter. Bake in jelly-tins. When the cakes are cold, take finely flavored candied honey, and after creaming it spread between layers 


\section{HOW TO KEEP BEES FOR PROFIT}

Fowls' Honey-cookies. -3 teaspoonfuls soda dissolved in 2 cups warm honey, 1 cup shortening containing salt, 2 teaspoonfuls ginger, 1 cup hot water, flour sufficient to roll.

Honey Nut-Cakes. -8 cups sugar, 2 cups honey, 4 cups milk or water, $1 \mathrm{lb}$. almonds, $1 \mathrm{lb}$. English walnuts, 3 cents' worth each of candied lemon and orange peel, 5 cents' worth citron (the last three cut fine), 2 large tablespoonfuls soda, 2 teaspoonfuls cinnamon, 2 teaspoonfuls ground cloves. Put the milk, sugar, and honey on the stove, to boil 15 minutes; skim off the scum, and take from the stove. Put in the nuts, spices, and candied fruit. Stir in as much flour as can be done without making the dough too stiff. Set away to cool, then mix in the soda. Cover up and let stand over night, then work in flour enough to make a stiff dough. Bake when you get ready. It is well to let it stand a few days, as it will not stick so badly. Roll out a little thicker than a common cooky; cut in any shape you like.

This recipe originated in Gernany, is old and tried, and the cake will keep a year or more.

Mrs. E. Smith.

Honey Drop-Cakes. -1 cup honey, $\frac{1}{2}$ cup sugar, $\frac{1}{2}$ cup butter or lard, $\frac{1}{2}$ cup sour milk, 1 egg, $\frac{1}{2}$ tablespoonful soda, 4 cups sifted flour.

Honey Shortcakę. - 3 cups flour, 2 teaspoonfuls baking-powder, 1 teaspoonful salt, $\frac{1}{2}$ cup shortening, $1 \frac{1}{2}$ cups sweet milk. Roll quickly, and bake in a hot oven. When 


\section{HONEY A FOOD AND MEDICINE}

done, split the cake and spread the lower half thinly with butter, and the upper half with $\frac{1}{2} \mathrm{lb}$. of the best-flavored honey. (Candied honey is preferred. If too hard to spread well it should be slightly warmed or creamed with a knife.) Let it stand a few minutes, and the honey will melt gradually and the flavor will permeate all through the cake. To be eaten with milk.

Honey TeA-Cake. -1 cup honey, $\frac{1}{2}$ cup sour cream, 2 eggs, $\frac{1}{2}$ cup butter, 2 cups flour, scant $\frac{1}{2}$ teaspoonful soda, 1 tablespoonful cream of tartar. Bake thirty minutes in a moderate oven.

Miss M. Candler.

Honey Gingersnaps. -1 pt. honey, $\frac{3}{4} \mathrm{lb}$. butter, 2 teaspoonfuls ginger. Boil together a few minutes, and when nearly cold put in flour until it is stiff. Roll out thin, and bake quickly.

Honey Fruit-Cake. - $1 \frac{1}{2}$ cups honey, $\frac{2}{3}$ cup butter, $\frac{1}{2}$ cup sweet milk, 2 eggs well beaten, 3 cups flour, 2 teaspoonfuls baking-powder, 2 cups raisins, 1 teaspoonful each of cloves and cinnamon.

Honey Popcorn-Balls. - Take 1 pt. extracted honey; put it into an iron frying-pan, and boil until very thick; then stir in freshly popped corn, and when cold, mold into balls. These will specially delight the children.

Honex-Caramels. - 1 cup extracted honey of best flavor, 1 cup granulated sugar, 3 tablespoonfuls sweet cream or milk 


\section{HOW TO KEEP BEES FOR PROFIT}

Boil to "soft crack," or until it hardens when dropped into cold water, but not too brittle - just so it will form into a soft ball when taken in the fingers. Pour into a greased dish, stirring in a teaspoonful extract of vanilla just before taking off. Let it be $\frac{1}{2}$ or $\frac{3}{4}$ inch deep in the dish; and as it cools cut in squares and wrap each square in paraffin paper, such as grocers wrap butter in. To make chocolate caramels, add to the foregoing 1 tablespoonful melted chocolate, just before taking off the stove, stirring it in well. For chocolate caramels it is not so important that the honey be of best quality.

C. C. Miller.

Honey Apple-Butter. - 1 gal. good cooking apples, 1 qt. honey, 1 qt. honey vinegar, 1 heaping teaspoonful ground cinnamon. Cook several hours, stirring often to prevent burning. If the vinegar is very strong, use part water.

Mrs. R. C. Aikin.

Honey and Tar Codgh-cure. - Put 1 tablespoonful liquid tar into a shallow tin dish and place it in boiling water until the tar is hot. To this add a pint of extracted honey and stir well for half an hour, adding to it a level teaspoonful pulverized borax. Keep well corked in a bottle. Dose, teaspoonful every one, two, or three hours, according to severity of cough.

Summer Honey-Drink. - 1 spoonful fruit juice and 1 spoonful honey in $\frac{1}{2}$ glass water; stir in as much soda as will 


\section{HONEY A FOOD AND MEDICINE}

lie on a silver dime, and then stir in half as much tartaric acid, and drink at once.

Honey Cereal Cofree. - Fresh wheat bran, 5 lbs.; mix with $2 \mathrm{lbs}$. of rye flour $2 \mathrm{lbs}$. of alfalfa honey. Mix the honey with 3 pts. of boiling water. After the honey and water have come to a boil, pour into the bran mixture. Stir thoroughly, and knead to a very stiff dough. Put them through a domestic meat-grinder to separate them. Dry in a warm oven. Brown the same as coffee. For a coffee flavor, add 2 lbs. best Mocha and Java. Have it all ground and put in air-tight cans for future use.

W. L. Porter.

HoNEY-TAFFY. - Boil extracted honey until it hardens in cold water. Pull until white. Any quantity may be used. One pound requires about twenty minutes' steady boiling. Mary C. Porter.

Dyspepsia Remedy. - Dr. McLean, San Francisco, California, recommends this for the cure of dyspepsia. Mix a drink of honey and water to suit the taste, then add a small quantity of myrrh (just a few drops), and drink every morning on rising.

Honey-paste to put Labels on Tin. - Take two spoonfuls of wheat flour and one of honey. Mix the flour and honey, and add boiling water to make $i$; the r.ght thiskners. This is fine for labels or wall paper where parer wi'l not $\cdot x=k$ with ordinary paste. W, L. Porter. 


\section{FOREIGN HONEY RECIPES}

Alsatian Gingerbread. - $1 \mathrm{lb}$. honey, $1 \mathrm{lb}$. flour, ginger to suit, $2 \frac{1}{2}$ drams bicarbonate soda. The honey is first brought to a boil, preferably in a double boiler. It is then removed from the fire, and the flour well stirred into it, and then the soda (or baking-powder); bake. If sweet gingerbread is wanted, add the white of an egg, well whipped, and more honey. The above will keep well for a year if kept in a cellar.

Swiss Cookies. - Prepare some dough as for the gingerbread, and mix with it $\frac{1}{3} \mathrm{lb}$. crushed almonds, orange and lemon juice, and cinnamon; and, if desired, cloves to suit the taste.

Honey Fruit-cakes. -4 eggs, 5 teacups flour, 2 teacups honey, 1 teacup butter, 1 teacup sweet milk, 3 teaspoonfuls baking-powder, $1 \mathrm{lb}$. raisins, $1 \mathrm{lb}$. currants, 1 teaspoonful cloves, 1 teaspoonful cinnamon, 1 teaspoonful nutmeg. Then bake in slow oven. The above will keep moist for months.

Honey Brown Bread. -1 cup corn meal, 1 cup rye meal, 1 cup sour milk, $\frac{1}{2}$ (or less) cup honey, 1 teaspoonful salt, 1 teaspoonful soda. Steam 4 hours, then dry in the oven 15 minutes. This bread should be kept in an air-tight box, where it will keep fresh for a long time. 


\section{HONEY A FOODAND MEDICINE}

French Honey-muffins. $-1 \frac{1}{2}$ pts. flour, 1 cup honey. $\frac{1}{2}$ teaspoonful salt, two teaspoonfuls baking-powder, 2 tablespoonfuls butter, 3 eggs, and a little over half a pint of milk or thin cream. Sift together the flour, salt, and powder; rub in the butter cold; add beaten eggs, milk, and honey. Mix smoothly in batter as for pound cake; about half fill spongecake tins, cold and fully greased, and bake bread in good steady oven for eight minutes.

Remedy for Constipation. - Dr. Vogel, of the University of Dorpat, one of the greatest authorities on the subject of children's diseases, recommends giving the juice of well-stewed prunes, sweetened with honey, to very small children, instead of castor oil or other remedies. This is also a remedy which can be used by adults with good results. Try it.

HonEY-TAFFY. - Boil honey until it hardens when dropped into cold water. Pull until it becomes white. Any quantity may be used. A pound requires 20 minutes' boiling and stirring. Great care must be exercised not to burn the honey. It makes very fine taffy.

HoNEY-Drops. - Blend $\frac{1}{3}$ cup honey, 1 teaspoonful butter, 1 egg well beaten, $\frac{2}{3}$ cup flour, sifted with half a teaspoonful of baking-powder and a pinch of salt. Drop by teaspoonfuls on a tin, and bake in a quick oven. These proportions will make about 20 cakes. 


\section{HOW TO KEEP BEES FOR PROFIT}

Pickled Grapes in Honey. - 7 lbs. good grapes (wine grapes if possible). The stalks must be left, and carefully packed in a jar without bruising any of them. Make a syrup of $4 \mathrm{lbs}$. of honey, a pint of good vinegar with cloves, etc., to suit the taste. Then boil the syrup, carefully skimming it, for 20 minutes. While boiling hot, pour the syrup over the grapes and seal up. This will keep perfectly for years, as the honey is a preservative.

Honey Cold Cream. -1 cup of honey; $\frac{3}{4}$ of a cup of beeswax; 1 cup of cottolene. Melt all, take off the fire, and stir till it is cool; rose or violet perfume may be added. It should be well protected from the air. The blending should be well done. This is fine for chapped or rough hands, which should be slightly wetted before applying.

Honey-cakes (Pain d'épice or Lebkuchen). - The following recipe will be much appreciated by cake-makers. The cakes are excellent, and will keep indefinitely. If they get dry, simply put them for a few days into a bread-tin. Use $3 \mathrm{lbs}$. of honey, $3 \mathrm{lbs}$. of flour, 1 oz. powdered ammonia, a small teacupful of ground cinnamon, half-teaspoonful of ground cloves, $6 \mathrm{oz}$. orange peel (or citron) cut very fine; $4 \mathrm{oz}$. sweet almonds cut very small. (The ammonia evaporates in baking.) Directions. - Pour the honey in a graniteware or copper saucepan, and set on the stove. When it boils, draw it aside and remove the scum (as honey boils and burns very quickly, great care must be used). Then pour the honey into the vessel in which the paste is to be made; leave it to cool; 


\section{HONEY A FOOD AND MEDICINE}

then add flour and other ingredients, except the ammonia which latter must not be added till the flour and honey have been mixed up and the paste has become cold. In preparing for use, place the ammonia in a cup; pour on a few drops of cold water, and stir it well, so as to form a thick paste, then mix it up with the rest. Then take a piece of the paste, roll it out into a cake not over $\frac{1}{4}$ inch thick, and cut up into convenient sizes. Put these on a flat tin and bake in a hot oven 12 to 15 minutes. The above is made by the monks of Buckfast Abbey, England.

Honey Vinegar. - The best vinegar produced anywhere is made from honey. Any one who understands how to make cider vinegar can easily make honey vinegar, only substituting water sweetened with honey for the apple juice.

Bar-Le-Duc Preserves. - These preserves are believed to be the finest of their kind, and have hitherto been imported at extravagant prices. Other fruits besides currants may be treated in this way, as honey is of itself a preservative. These preserves do not require to be kept absolutely airtight.

Take selected red or white currants of large size, one by one; carefully make an incision in the skin $\frac{1}{4}$ of an inch deep with tiny embroidery scissors. Through this slit remove the seeds with the aid of a sharp needle; remove the seeds separately, preserving the shape of the fruit. Take the weight of the currants in honey, and when this has been 
heated add the currants. Let it simmer a minute or two, and then seal as for jelly. The currants retain their shape, are of a beautiful color, and melt in the mouth. Care should be exercised not to scorch the honey, then you will have fine preserves.

Honey-Paste for Chapped Hands. - An excellent paste for chapped hands is made as follows: The white of one egg, one teaspoon of glycerine, one ounce of honey, and sufficient barley flour to compose a paste. It may not be generally known that honey is a prime ingredient of cosmetics; for its action on the skin is always agreeable.

Honey for Cleaning the Hands. - Honey is an excellent cleanser of the skin, though few are aware of the fact. Try this: Rub a little honey on the dry skin; moisten a little, and rub again; use more water, and rub. Wash thoroughly, when it will be found the hands are as clean as the most powerful soap can make them.

Honey Tooth-PAste. $-8 \mathrm{oz}$. precipitated chalk, $4 \mathrm{oz}$. powdered castile soap, $4 \mathrm{oz}$. orris-root powder, 40 drops oil of sassafras, 80 drops oil of bay, and honey to make a paste.

French Honey-candies. - In an enamelled-ware saucepan melt one part of gelatine in one part of water, stirring well. When arrived at the state of a soft paste, add 4 parts of honey previously warmed, stirring briskly. Take from the fire; add the desired flavor and color, mixing carefully, and pour into a shallow lightly greased dish. Let it dry for a few days. 


\section{HONEY A FOOD AND MEDICINE}

Honey as a Softener of the Hands. - Rub together $1 \mathrm{lb}$. of honey and the yolks of $8 \mathrm{eggs}$; gradually add $1 \mathrm{lb}$. oil of sweet almond during constant stirring; work in $\frac{1}{2} \mathrm{lb}$. bitter almonds, and perfume with 2 drams each of attar of bergamot and attar of cloves. Of course, the quantities may be reduced if necessary.

Honey for Freckles. - Half a pound of honey, $2 \mathrm{oz}$. glycerine, 2 oz. alcohol, 6 drams citric acid, 15 drops ambergris. Apply night and morning.

Honey-Chocolate. - Chocolate sweetened with honey rather than with sugar is excellent. This is how it is made: Melt $1 \mathrm{lb}$. of gelatine in a pint of water; add $10 \mathrm{lb}$. of honey, thoroughly warming the same, and then add $4 \mathrm{lbs}$. of cocoa. Flavor with vanilla when taken off the fire, and then pour into greased dishes or molds.

Honey Brown Bread. - One cup corn meal, 1 cup rye meal, 1 cup sour milk, $\frac{1}{2}$ cup or less of honey, a teaspoonful of salt and a teaspoonful of soda. Steam four hours, and then dry in the oven fifteen minutes. It may be added that most of the molasses now sold is not fit to eat, and in any case honey is much better.

It can be seen from the foregoing recipes that honey has a multitude of uses in the home, and its free use as a spread for bread is far preferable for children to much of the cheap candies that they buy. 
We cannot close this chapter better than by giving the advice of the Scriptures, found in Proverbs xxiv: 13: "Eat honey because it is good." Not only as a food has honey a great value, but in medicine it has a large place, especially in the treatment of colds and diseases of the lungs, and forms a valuable ingredient in many of the excellent cough remedies that are made and sold.

The following uses of honey as a medicine are given by permission of the A. I. Root Company:

Covghs, Colds, Whooping Covgh, etc. - Fill a bellmetal kettle with horehound leaves and soft water, letting it boil until the liquor becomes strong - then strain through a muslin cloth, adding as much honey as desired - then cook it in the same kettle until the water evaporates, when the candy may be poured into shallow vessels and remain until needed, or pulled like molasses candy until white.

Dr. Kneipp's HoneY-SALve. - This is recommended as an excellent dressing for sores and boils. Take equal parts of honey and flour, add a little water and stir it thoroughly. Don't make too thin.

Honey and Cream for Freckles. - Have you tried a mixture of honey and cream - half and half - for freckles ? 


\section{HONEY A FOOD AND MEDICINE}

Well, it's a good thing. If on the hands, wear gloves on going to bed.

Honey Croup Remedy. - This is the best known to the medical profession, and is an infallible remedy in all cases of mucous and spasmodic croup: Raw linseed oil, 2 oz.; tincture of blood root, 2 drams; tincture of lobelia, 2 drams; tincture of aconite, $\frac{1}{2}$ dram; honey, four oz. Mix. Dose, $\frac{1}{2}$ to 1 teaspoonful every 15 to 20 minutes, according to the urgency of the case. It is also excellent in all throat and lung troubles originating from a cold. This is an excellent remedy in lung trouble: Make a strong decoction of horehound herb and sweeten with honey. Take a tablespoonful four or five times a day.

Honey for Dyspersia. - A young man who was troubled with dyspepsia was advised to try honey and graham gems for breakfast. He did so, and commenced to gain, and now enjoys as good health as the average man; and he does not take medicine. Honey is the only food taken into the stomach that leaves no residue; it requires no action of the stomach whatever to digest it, as it is merely absorbed and taken up into the system by the action of the blood. Honey is the natural foe to dyspepsia and indigestion, as well as a food for the human system.

Honey as a Laxative. - In olden time the good effects of honey as a remedial agent were well known, but of late little use is made thereof. A great mistake surely. Notably 
is honey valuable in constipation. Not as an immediate cure, like some medicines which momentarily give relief, only to leave the case worse than ever afterward, but by its persistent daily use, bringing about a healthy condition of the bowels, enabling them properly to perform their functions. Many suffer daily from an irritable condition, believing thernselves nervous, not realizing that constipation is at the root of the matter, and that a faithful daily use of honey would restore cheerfulness of mind and health to the body.

Honey for Old People's Coughs. - Old people's coughs are as distinct as the coughs of children, and require remedies especially adapted to them. They are known by the constant tickling in the pit of the throat - just where the Adam's apple projects - and are caused by phlegm that accumulates there, which, owing to their weakened condition, they are unable to expectorate.

Take a fair-sized onion - a good, strong one - and let it simmer in a quart of honey for several hours, after which strain and take a teaspoonful frequently. It eases the cough wonderfully, though it may not cure.

Honey for Stomach Cough. - All mothers know that a stomach cough is caused by an irritation of that organ, frequently attended with indigestion. The child often vomits after coughing.

Dig down to the roots of a wild cherry tree, and peel off a handful of the bark, put it into a pint of water, and boil down to a teacupful. Put this tea into a quart of honey, and 


\section{HONEY A FOOD AND MEDICINE}

give a teaspoonful every hour or two. It is pleasant, and if the child should also have worms, which often happens, they are pretty apt to be disposed of, as they have no love for the wild-cherry flavor.

Honey and Tar Cough Candy. - Put a double handful of green horehound into two quarts of water, boil down to one quart; strain, and add to this tea two cupfuls of extracted honey and a tablespoonful each of lard and tar. Boil down to a candy, but not enough to make it brittle. Begin to eat this, increase from a piece the size of a pea to as much as can be relished. It is an excellent cough candy, and always gives relief in a short time.

Honey and Tar Cough Cure. - Put one tablespoonful liquid tar into a shallow tin dish, and place it in boiling water until the tar is hot. To this add a pint of extracted honey, and stir well for half an hour, adding to it a level teaspoonful pulverized borax. Keep well corked in a bottle. Dose, one teaspoonful every one, two, or three hours, according to severity of cough. 


\section{CHAPTER XVIII}

ROBBER BEES - HOW TO PREVENT ROBBING

THE energy that bees will display in rob1 bing each other, also the alacrity with which they will pounce upon any honey or other sweets if left within their reach, is not after all an unmixed evil, as it shows their industry; and a few preventive measures will result in keeping it within bounds and prevent any serious consequences.

This tendency to rob prevails in all races of bees, especially if no honey is coming in from the fields, and is more pronounced in some races than in others.

The Italian bees especially are given to robbing, but be it said to their credit that they are more easily discouraged from it when attempts are made to break it up.

The main danger when extensive robbing is under way, is that the robbers 258 
after cleaning up any honey that may have been left carelessly about, will proceed to pounce upon one weak colony after another, and will often clean them out completely, to say nothing of the viciousness of their tempers when robbing.

When a single bee has succeeded in stealing a load of honey from some weak hive, it seems to have some means of communicating that fact to the other members of its colony, for when it rushes out for another load it is invariably accompanied by some of its comrades, until literally thousands of bees are engaged in robbing.

With the bees no question of ethics is involved in robbing, as they seem to regard as legitimate prey any and all honey that is in their reach, and they will keep on stealing until means are taken by their keepers to stop it.

When honey is coming in from the fields there is little danger of the bees robbing, and extracting can be carried on in the open field 


\section{HOW TO KEEP BEES FOR PROFIT}

without any precaution whatever; but as soon as the flow ceases the little rascals are ready to gobble anything at hand, urged thereto no doubt by the fact that they are in a state of enforced idleness and want to lay up as much honey for wintering as possible.

Until a case of robbing is well under way, it will often be difficult for the novice to detect it, as the little thieves will act in many ways similar to young bees taking a play spell flying before their hives; but when the thing is in full operation, it is easy to recognize it at once, as the hive being robbed will have a large number of bees busily flying before it like a new swarm coming out, and the terrific fight going on on its alighting-board with the dead bees that have been killed in the fighting - often as many as a quart - will tell its own tale even to the novice.

Another method of detecting robbing is to watch the actions of the bees coming out of the hive suspected of being robbed; as the robber comes out it does not act in the 
leisurely manner of a bee getting ready to fly to the fields, but rushes out in a great hurry, and the distention of its abdomen will indicate that it is heavily loaded, whereas in the case of a bee coming out for its flight to the field, the abdomen is empty and slim in appearance.

It is a good plan as soon as the flow of honey is over, and the weather not too warm, to contract the entrances of all hives; this is not so necessary in the case of strong colonies, but where they are weak it is absolutely essential and should not be neglected. Be careful about opening hives out of season, and keep their lids off only so long as is necessary; above all, do not leave any honey or feed syrup about, for this will be only an invitation to robbing.

Where queen-rearing is carried on, there is great danger of robbing, as the little mating nuclei are not strong enough to repel the invaders unless the entrances are small, and what is true of nuclei is also true of all weak colonies. 
Frequent cases of robbing are started in the most innocent way imaginable by people's making preserves in the neighborhood without proper screens for the windows of the room in which the preserving is done; I know of one occasion when the bees drove a woman from the room and swarmed upon the sugar and syrup until it was all cleaned up, and it was not until night that the woman could get back. On the following morning thousands of the little thieves were on hand to complete the work and were only prevented from continued robbing because every window had been screened with mosquito netting during the night. As it was, many bees lingered about the windows all day, wondering why their rich repast had been interfered with.

I knew of another case where a good housewife was candying some peaches; the candied peaches were placed on a large tray on a shed to harden in the sun, and in a few hours some bees from a neighboring apiary had discovered them. Before night they had licked all the 262 
sugar from the peaches, leaving them as clean as they were before being coated with sugar syrup. The bees could hardly be blamed; if anywhere, the blame rested upon the housewife for not protecting the fruit with a screen, for common sense would have told her that there must be some bees in the vicinity that would take advantage of their opportunity.

If the robbing is confined to one or two colonies, it will be a good thing to carry the colonies being robbed into the cellar in the dark, leaving them there until the following afternoon, when they can be set out again, and, with their entrances contracted, the damage can be stopped.

If the robbing is general in the apiary, or even if a single colony is being robbed, it can often be stopped by throwing an armful of brush at the entrance of the hive being robbed, for the robbers are a bit wary about working their way through the tangled mass, as they always want a rapid way of retreat. In this way the colony being robbed will be able to 
get over their demoralization, and can marshal and organize their scattered forces for a good resistance; and if toward evening the entrance to the hive is contracted it will have spent its course as far as that hive individually is concerned. Sprinkling the brush with cold water has a good effect upon the robbers, and they will often give up at once rather than run the risk of getting wet and being placed hors de combat. Frequently I have broken up a case of robbing by squirting kerosene oil on the front and on the alighting-board of the hive being robbed, and this has proved effective, because the robbers at once become suspicious of the strange odor. It must be remembered that a bee that is robbing is on the lookout continually for some trap to catch him in his piratical career, and their actions indicate the fear of being killed.

Sometimes a colony will be so completely cleaned out of its stores that it will be a wise thing to let the robbers finish their work at that hive rather than give their attention to 
others. At nightfall the cleaned-out hive can be examined, and if the queen is uninjured, and a fair amount of bees present, its entrance can be contracted so that only a bee or two can pass out at a time, and in a couple of days it can be built up with bees and sealed brood from strong colonies and no serious damage will have resulted.

A plain pane of glass laid in a slanting position in front of a hive that is being robbed will so confuse the robbers that they will give up in despair, but the kerosene, squirted on the front of the hive or on some brush or dried grass thrown in front of the hive entrance, is the best thing of which I know, and again and again $I$ have nipped in the bud what promised to develop into a first-class case of embezzlement. Turpentine, or a weak solution of carbolic acid water, will work equally as well, and, when the robbed colony have a chance to rest over night, and recover from their panic, it is astonishing what a fight they will be prepared to put up the following day. 
HOW TO KEEP BEES FOR PROFIT

When bees are in full swing of robbing they are liable not only to pounce upon a weak hive, but in all likelihood will sting everything and everybody in sight, including stock, and for this, if for no other reason, it is important to prevent robbing entirely, and if it is under way to break it up at once. If we were sure that the robbers were entirely our own bees, it might not be a great loss in honey, as the honey that was robbed will be transferred to other hives in the yard, but in all probability the robbers are from any and all hives within a radius of three miles, and no one cares to enrich the yards of a neighbor at one's own expense.

It is sometimes the course of wisdom to fight fire with fire, and to divert the robbers from the hive that is being robbed by exposing some combs of honey a little distance from the apiary, and the robbers will leave the hive they are robbing and devote their time to the exposed combs, as there are no bees to fight them. While they are robbing these combs, the hives in the yard can be attended 
to, and at night the combs can be carried into the house. In the morning it is amusing to see the clouds of bees hovering over the spot where the combs were given them the day before and wondering what on earth has become of their "Klondike."

If it were possible to do all our work among the bees during a honey flow, we should have no trouble from robbing, but unfortunately we have to do much work at other times, especially if we are rearing queens; but this difficulty can be overcome by using a small tent, made for the purpose of laths and mosquito netting, which can be set over the hive to be worked, and, as it is large enough to permit the operator to do his work, all operations can be carried on in safety. These tents are inexpensive and exceedingly light, and are a positive necessity in a well-regulated apiary of even moderate size, and the excellent results they accomplish, added to the peace of mind of the beekeeper, more than warrant the expenditure for them. 
It must not be supposed from the foregoing that robbing is a terrible bugbear and a fatal thing to bee-keeping, for I can safely say that by the exercise of a little caution and the adoption of the preventive measures referred to I have not for ten years had a serious case of robbing in any of my yards, and a pound of prevention is worth a load of cure. Be careful when working out of the honey flow, and, when feeding the bees, not to let any of the honey or feed lie about, and in all probability you will never have a case of robbing that will amount to anything. 


\section{CHAPTER XIX}

\section{FEEDING}

W ${ }^{\text {HEN we speak of feeding bees we would }}$ not be understood as advocating the feeding of bees with sugar syrup in order to have it stored in the combs and sold as honey, as such a practice is dishonest, and certain to bring the honey-producer into conflict with the pure food laws; but rather that feeding which from time to time is necessary, such as feeding the bees to supply them with sufficient stores to carry them over the winter, or to stimulate brood-rearing in the early spring, or when given to a hive to encourage them to rear queens outside of the season of the natural honey flow; and under these conditions feeding is both legitimate and important.

Sometimes in the early spring, a colony or two will be found to have come out of winter quarters in a much-depleted condition, and 
HOW TO KEEP BEES FOR PROFIT

in order to encourage it to rear a lot of brood, which it generally will not do until the natural flow comes on, we feed it about a half pint of syrup each day with remarkable results.

Some of the most successful beekeepers even advocate feeding all colonies in the spring for brood-rearing, but this is not at all necessary - the better plan is to see that each colony goes into winter quarters with abundant stores, more or less of which will be present in the hive with the coming of spring, as such stores are the best for early brood-rearing without resorting to stimulative methods.

Whether the feeding is to be done for early brood-rearing, or for raising queens, or even given in large quantities in the fall for winter stores, the syrup should be the same, and is made by thoroughly mixing equal parts of pure granulated sugar and boiling water. If a large quantity is to be made, it can be mixed up in the extractor, first putting the boiling water in, and pouring the sugar in while the baskets are being whirled about. 
It is possible to make the stimulating syrup with a smaller proportion of sugar, but this is no advantage, as the surplus water has to be thrown off by evaporation, and by using equal parts of sugar and water, we save the bees that much extra work. Moreover, experiments have proved to me that they seem to prefer the thicker syrup at all times. In every case the syrup should be given them while it is hot, as they take it up more quickly. Under no conditions should the mixture be boiled on a stove, as there is danger of scorching it, and this will work serious damage to the bees in promoting dysentery and other intestinal diseases, particularly where such syrup is fed for winter stores.

There is no class of men given to invention as much as are beekeepers. In regard to feeders, especially, the number that has appeared from time to time is enormous, and it is the purpose of this chapter to call attention only to a few that have stood the test of time.

A good feeder for stimulative feeding in 271 
HOW TO KEEP BEES FOR PROFIT the spring is the Simplicity feeder. This is nothing more than a long block of wood, preferably basswood, that has been grooved out to hold the feed; it is placed in an empty super on the quilt or cloth that covers the frames, and is of easy access to the bees providing one corner of the cushion or cloth is turned up for the purpose. The principal things in favor of this feeder are that it is cheap and puts the feed where the bees are most likely to go for it - overhead; but it has the objection that it necessitates the lifting of the cover from the tops of the frames, with more or less loss of warmth from the brood nest, and this at the time of the year that it is most needed. It might be said, however, that a large number of beekeepers have used and continue to use it.

Another good feeder is the Alexander feeder. This is built somewhat on the plan of the Simplicity, but has the decided advantage of being placed directly under the rear end of the hive with a block covering the end 
that projects beyond the hive, which is lifted for filling, and, when put back, the little block shuts off all entrance for robber bees. Another thing in favor of the Alexander feeder is that it does not require the opening of the hive for filling, or the lifting up of the cushion or cloth for the bees to get at the syrup, and does away with loss of heat from the brood nest.

The most serious objections to the Alexander feeder are, first, that to use it requires that the hive body shall be pushed back from its entrance, and in stormy weather rain is sure to run down the sides of the hive and dilute the syrup, causing the feeder to overflow on the ground and start up a first-class case of robbing at the most unfavorable season of the year.

Still another feeder is the Boardman, which is nothing more than an ordinary quart jar, filled with syrup, to which has been fitted a perforated metal cap, fitting down securely in a hollowed block of wood. This is shoved 
in at one side of the hive entrance, and gives the bees of the hive access to the feed, at the same time excluding bees from other colonies that show an inclination to rob. One thing in favor of this feeder is that, the jar being of glass and being in position outside of the hive, the beekeeper can tell at a glance just how rapidly the colony is taking the feed, and will thus know how much to give daily to each individual colony.

Experience has proved again and again that an ideal feeder is one which places the feed right over the cluster where it is naturally found by a colony, and which does not permit the escape of heat. There is no feeder on the market that meets this requirement except the Lyon feeder, invented by the author. The following directions show how it should be made.

Take two boards, $\frac{7}{8}$ inch thick, and cut them so that the two will just cover the brood body of the hive. To secure the two boards, tack some cleats, $\frac{7}{8}$ inch thick and as long as 
required, to the top ends of the boards and along its top sides, so that when all is nailed you have a wooden cover that fits flush with the outside sides of the hive.

Fill with syrup a one-quart or a two-quart Hazel Atlas, or ordinary preserving-jar, and cover it with a perforated metal cap with rubber ring, procured from the bee supply house, and it is ready to be placed in the boarded cover. Place the metal cap in the centre of the board top, and mark around it with a lead pencil; then with a compass saw, saw a round piece of wood out of the wooden cover. Nail a square piece of wood, not over $\frac{7}{8}$ inch thick, to the round piece that was cut out, having the square block projecting an inch beyond the round block to prevent its dropping through the hole upon the frames when the jar is not being used.

When you are ready to feed, remove the lid from the hive and place the feeding-board over the brood nest. In the hole place the inverted feeding-jar with metal cap screwed 
HOW TO KEEP BEES FOR PROFIT

tightly on, and on top of the feeding-board place an empty hive body, and on top of this place the lid of the hive.

When the jar needs refilling, it can be lifted out of its hole and taken to the house, the round wooden piece of wood being put back in the hole, to prevent the bees from coming up while the jar is being refilled, and when filled the jar can be set in place again. A little time can be saved by filling another jar and placing it immediately in the hole at the time the empty o=e is taken out, and when the feeding is all over, whether for stimulating brood or for giving winter stores, the wooden block can be placed in the hole, and the feeder board left where it is as a permanent cover to the brood frames, the extra body removed, and the lid of the hive placed upon the feeder board.

These feeder boards have the advantage of being used as a permanent cover underneath the hive lid the year round, and whenever the colony needs feeding it can be changed to a 
feeding-board in a second by simply removing the round block from its hole, and inserting the jar in its place. This does away with many extra fixtures, and permits feeding in small or large amounts without escape of heat from the colony, or opening of the brood nest either above or below.

I prefer a half-gallon Hazel Atlas jar, as a little feed can be given in them for early broodrearing, and when it comes to heavy feeding for winter, a large quantity can be given each time with the use of but one jar. I have used these feeders for years. They never fail to serve the purpose. They are better than any feeders that $I$ have seen, and are readily made out of old boards, boxes, or other material at hand.

The Doolittle Division board feeder is made the size of a brood frame and is placed in the centre or at one side of the brood nest, but as the use of this feeder necessitates the opening of the hive every time it is filled, and when filled many bees are likely to be drowned, 
I, personally, have never found it so satisfactory as some others.

Whatever feeder is used, the colony fed for early brood-rearing should be given toward evening about half a pint of hot syrup, and if the amount given is more than the bees will take up during the night, the quantity should be accordingly reduced. The feeding should be discontinued as soon as a regular flow begins to come in from natural sources, and the feeders stored away, though in the case of the Lyon feeder only the glass jars are taken away, as the feeding-board remains as a cover for the frames beneath the hive lid.

In feeding for winter stores the standard feeder for years was the Miller feeder, a large water-tight box with two compartments so arranged that the bees have access to the feed through a wire screen and are thus in no serious danger of being drowned. This feeder will hold as much as twenty-five pounds of syrup, and is placed in an empty comb honey super on top of the brood frames. 


\section{F E E D I N G}

Honesty compels me to say the Lyon feeder is equally as effective, though it may require the refilling of the half-gallon jars a couple of times, to give the required amount for winter stores; and, unlike others, there is no pouring and splashing of feed outdoors, and no bees can possibly crowd up around the feeder and get drowned in the syrup as hundreds of bees often do in other feeders in spite of careful packing of cloths around them.

It is generally conceded that September is the best time to feed for winter stores, as the bees will take the feed much quicker than later on; but if there is a prolonged flow from the late fall bloom, we often sacrifice a lot of syrup in feeding, as many a light colony will secure from late flowers, even after September, sufficient honey for successful wintering. Bees will seldom take down feed in bitter cold weather when other feeders are used, and in this respect the Lyon feeder excels them all. 
HOW TO KEEP BEES FOR PROFIT

Even in freezing weather it is possible to place a Lyon feeder in place and fill the super brood body around it with planer shavings. The feed will keep warm a surprisingly long time, and even through the winter can, from time to time, be replenished, as the packing will keep it from getting too cold. Being right over the brood nest, the bees can get it without leaving the cluster, and will go through the winter depending on it entirely, whereas with other feeders they will starve with chilled feed near them.

Every colony to be wintered in the cellar should have at least fifteen pounds of stores, and if honey to this amount is not present, it should be supplemented to that quantity by syrup.

Where bees are to be wintered outdoors there should be about twenty-five pounds of stores present. One can, by lifting the back end of the hive tell by the weight of it, if it is well supplied with winter stores; and even though a colony is short, there will be more or 
less honey present, and only a little additional syrup will be necessary.

Feeding is only necessary where we have used the extractor too freely or where the colony has not gathered enough, and there are many seasons when the bees do so well that feeding will not be required. Be careful in feeding not to splash any feed about, or robbers may defeat the very end you have in view in feeding; so, for this reason, it is best to defer feeding until late in the day, and to contract the entrances of the hives being fed. I would not advocate the open outdoor method as tried by some, which consists in pouring a large quantity of feed in an open trough, as it is open to the objections that robbing is likely to be encouraged; hives that do not need feeding will get a goodly share of it; you may be feeding bees from hives not your own; and, to say the least, it is an expensive and uncertain method.

Better give to each colony individual treatment, and then you will have the satisfac- 
HOW TO KEEP BEES FOR PROFIT tion of knowing that it is getting just the amount it requires, and there will be no danger of feeding all the bees in the neigh. borhood. 


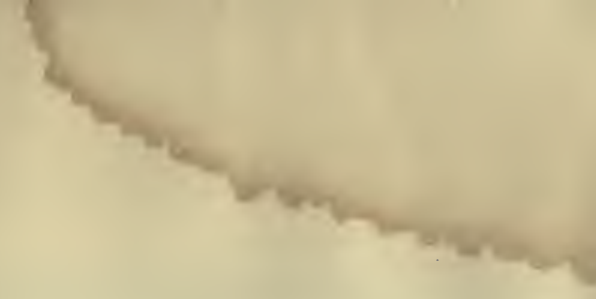




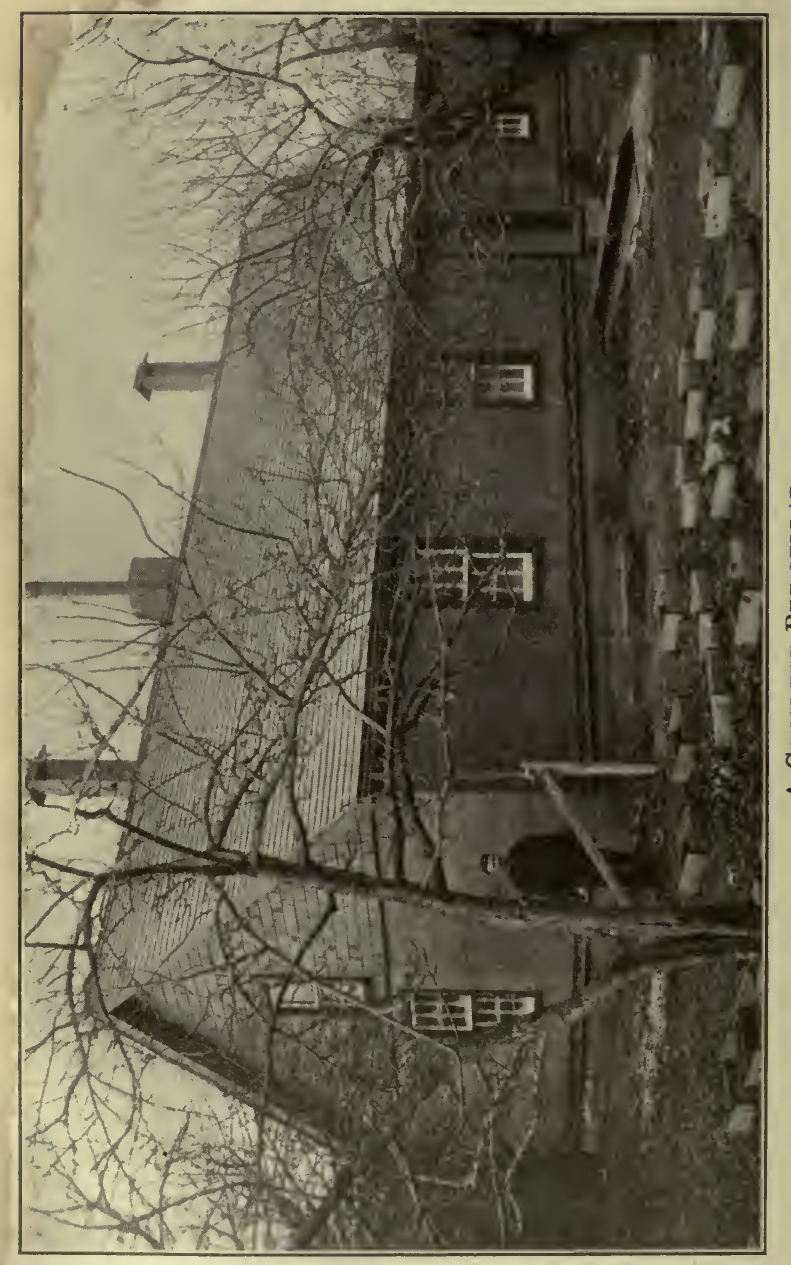




\section{CHAPTER XX}

HOW TO WINTER BEES SUCCESSFULLY

GENERALLY speaking, there are two ways in which bees are wintered, outdoors, and in cellars or special repositories, and the methods of treating the colonies vary according to the plan followed.

For many years there have been discussions among beekeepers as to which plan is the better, and there is a great deal to be said in favor of both, but it is conceded by eminent authorities that the outdoor plan is preferable if the conditions of successful outdoor wintering are followed, and the bees provided with the proper packing and shelter. Personally I believe that outdoor wintering is best even in cold climates; but outdoor wintering in such sections demands great care in the matter of extra packing, in order to bring the bees 
through their long winter's sleep in good condition, with the coming of spring.

In favor of indoor wintering in cellars and special repositories, it is said that it requires less stores to winter bees indoors, which is a distinct saving in honey and offsets the extra work of moving them in and out, and the beekeeper has no worry from the possibility of their freezing if left outdoors, if the weather goes down below zero and remains there for weeks at a time. I shall show, however, that if properly packed for extreme coldness the fear of loss from freezing is groundless. Of course it costs a great deal more for winter cases for outdoor wintering, but the first cost is the principal one, and the added benefits derived more than offset the matter of expense, and the added strength in spring of colonies wintered outdoors as compared with those wintered indoors means a larger surplus from the early flow.

Bees wintered indoors cannot take advantage of occasional warm days during winter 
for cleansing flights, and if the winter is prolonged, are subject to dysentery, whereas the outdoor bees have had several opportunities in which to relieve themselves, and seldom suffer from it. Again, bees wintered indoors require constant care in the matter of receiving proper ventilation and regulation in the matter of temperature, and when set outdoors in the spring suffer from spring dwindling, in case a cold spell should come on after they are set out. They are even destroyed, while bees that were wintered outdoors do not feel the change, as they are in their winter packing and are used to the cold.

To offset spring dwindling, many a beekeeper places some extra protection around his bees when he sets them out in spring, and while this is a help, the bees nevertheless suffer from the contrast when placed outdoors, and spring dwindling is the rule rather than the exception.

If the truth were known, the real reason why so many beekeepers keep a large number of 285 
HOW TO KEEP BEES FOR PROFIT

colonies wintered indoors is because they hesitate about going to the extra expense and trouble of providing winter cases for each hive, and having to pack them. The trouble of packing is no greater than that of having to move the bees in and out each year.

As outdoor wintering is the simpler and easier method, especially for the beginner, we will describe it first.

Whether bees are to be wintered outdoors or in the cellar, every colony should be gone over carefully in September and care exercised to see that each colony is strong in bees and stores. If there are a number of weak colonies, it is best to unite several of them and make strong ones, as these weak colonies are almost sure to perish, and it is a waste of time to try to winter them separately. Supposing that every colony is in good condition, we will in following the outdoor plan leave every colony on its summer stand, and as cold weather becomes settled, about the middle of November, we will now get ready to pack them. 


\section{HOW TO WINTER BEES}

Some beekeepers use nothing but chaft hives, and where these hives are used, it is a very simple matter to get them ready. All that we have to do is to put the chaff tray filled with planer shavings on the hive, over the board that covers the frames, and when it is in place slip the large telescoping cover over all and the hive is prepared. In sections of the country where the winters are moderately mild with an occasional zero day, these hives fulfil every requirement, but in the extreme north, where zero weather prevails for weeks at a time, a thicker packing than that of the ordinary chaff hive will be necessary. The extra cost of the chaff hives has stood in the way of their general adoption by the majority of beekeepers who winter out of doors, and this has led to other methods for providing winter protection which, to say the least, are far from what they should be. Better put the bees in the cellar a thousand times than to leave them outdoors once without proper cas ing. Beekeepers of this class usually plar 
over every hive an empty section super, in which is stuffed a bag containing old leaves, cut hay, wheat chaff, or even rags, and with the lid over this, the hives are left for the winter. We would not say that such packing is of no benefit, but it does fall far short in giving the extra warmth that goes to make up successful outdoor wintering.

Still another class of beekeepers resort to old newspapers, and where about an inch of these is placed on top of the board covering the brood nest, the lid being previously removed, and about a dozen thicknesses of paper tied around the four sides of the hive, and a deep wooden telescope case pressed down over the same, leaving of course the entrance of the hive open, this will, in the majority of cases where moderate winters prevail, winter the bees in fairly good shape.

Other beekeepers make large tenement boxes in which they place several hives side by side and pack the large case with some absorbent packing, covering the case with a 288 
HOW TO WINTER BEES

good waterproof paper, and in many cases the bees winter remarkably well, but if you want to be absolutely certain of wintering your bees successfully, even in Canada, adopt the following plan used by the author, who tried and discarded long ago as unsatisfactory most of the methods referred to above.

For each hive, I have a large winter case or nearly square box made of $\frac{1}{2}$ inch board, which is by inside measurement five inches wider all around than the hive body, and six inches deeper. This is a perfectly plain box without bottom or lid, but at its bottom edges I have some $\frac{1}{2}$ inch thick strips that run in at all sides at right angles from the sides and which permit of the case being slid down over the body of the hive with about $\frac{1}{4}$ inch space all around. The lid of the hive must be removed to permit of this case going down around the hive. On each side of the bottom board of the hive I have a cleat running its entire length from front to back, to act as a rest for the winter 


\section{HOW TO KEEP BEES FOR PROFIT}

case, which rests on both sides on the strips that run in at right angles, and prevent the winter case from slipping down over the entrance of the hive. These cleats, which are one inch thick, are left as a permanent part of the bottom board and are nailed on just a trifle below the edge of where the bottom board comes in contact with the bottom edge of the hive body, so that the winter case when packed will cover the crack completely and keep out wind and water. The winter case projecting beyond the hive body all around prevents completely the clogging of the hive entrance with snow, and keeps out the rain. When the winter case is in place and the feeder or cover board is over the frames, a barrel of planer shavings is dumped into it and packed tightly around the sides and ends, and about eight inches of loose planer shavings are put over the top of the hive body. Over this winter case is slipped a telescope lid that is five inches deep and has a tin roof, and by this means perfect conditions prevail, as 
HOW TO WINTER BEES

the colony has for protection, first its hive body $\frac{7}{8}$ inch thick on all sides, then five inches of planer shavings all around with eight inches on top, and a waterproof telescope case over this. The lid to this winter case can be covered with a good heavy paper such as Rubberoid, and will not cost as much to make as the one with the sheet iron covering. In these perfect cases, the bees are comfortable, and even in the extreme north will winter in fine shape.

The metal-covered cap is used all through the summer season as a lid for the hive over the board cover over the brood nest; and as it projects some ten inches all around, it acts as a perfect sun shade; when the time comes for winter packing it is made to fulfil a twofold purpose by covering the winter case. Any one can make these cases, and, as they are the result of many years' experiment, they are the best in the world.

When wintering bees in a cellar, the preparation of the colonies is about the same as 
far as strength is concerned, with the possible exception that not quite so much honey needs to be present in the hive, and the proper time to place the bees in the cellar is after cold weather has come, - generally speaking this is about the 20th of November. The best time is after two or three warm days following a cold spell, so that the bees may have a final cleansing flight, and when the cold days come on again the colonies are ready for moving into their winter quarters. Any good dry cellar will do for this purpose, but all the windows should be darkened, for the bees are to winter in absolute darkness, and if the entire cellar cannot be devoted to them, a part of it should be partitioned off with shingling-laths and building-paper so that it can be kept absolutely dark.

One by one, toward the close of day, the hives on their bottom boards with lids in place should be carried in and placed in rows against the wall, and when the entire floor space is occupied, leaving an aisle down the middle, 
other hives may be piled on top of those on the floor and on up to the ceiling, leaving every hive with a full opening at its entrance.

When once the bees are placed in their winter quarters, the only things to be looked after are ventilation, and the maintenance of the proper temperature, which may vary between forty and sixty degrees, though the nearer forty-five it can be kept the better. If the temperature should rise on mild days, and the bees show signs of restlessness, it will be necessary to open the door of the cellar or a window after dark and leave them open all night, but be sure to close them before daybreak lest the bees be lured out by the light.

Even though the winter may be severe outside and the bees are not restless, it is an excellent thing to ventilate the cellar occasionally. The ideal plan is first to open a part of the cellar most distant from the bees and allow fresh air to enter it, and then close the outer door, and allow the fresh air to be- 
HOW TO KEEP BEES FOR PROFIT

come tempered as it were, and then open the door that leads into the part of the cellar where the bees are stored, and let the tempered air into them. By following this method, the bees are not disturbed as they would be if the cold air were turned in on them directly from outdoors.

Do not be alarmed if during the winter some dead bees should accumulate on the cellar floor, for this does not indicate any injury, but they are merely old bees that have died off from natural causes and that have crawled out of the hive to keep from dying within their homes. If the bottoms of the hives are fitted with reasonably deep bottom boards, it will not be advisable to try to scrape out the dead bees with a piece of wire, as some beekeepers advocate, as all such poking has a tendency to annoy the bees and disturb their slumbers. The less we trouble them, the better it will be for all concerned. Where house apiaries are used, the packing can be done inside the house around the hives, but 



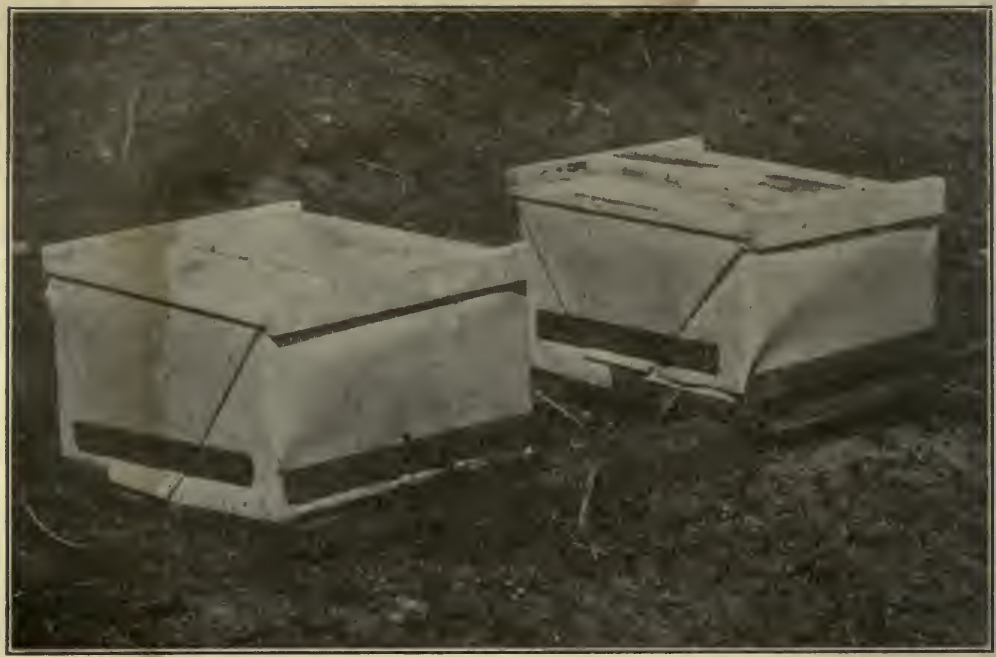

A Good Method of protecting Hives AFter setting THEM OUT IN THE SPRING.

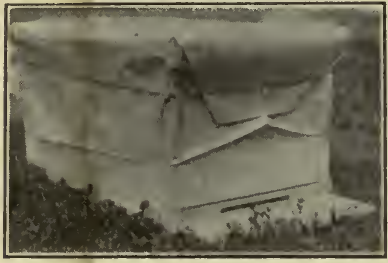

Right WAY OF PUTting THE PAPER ON.

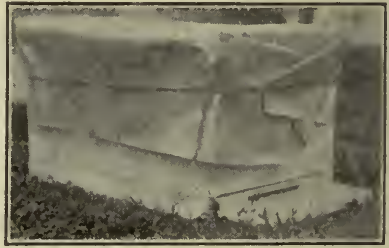

WroNg WAY OF PUTTING THE PAPER ON.

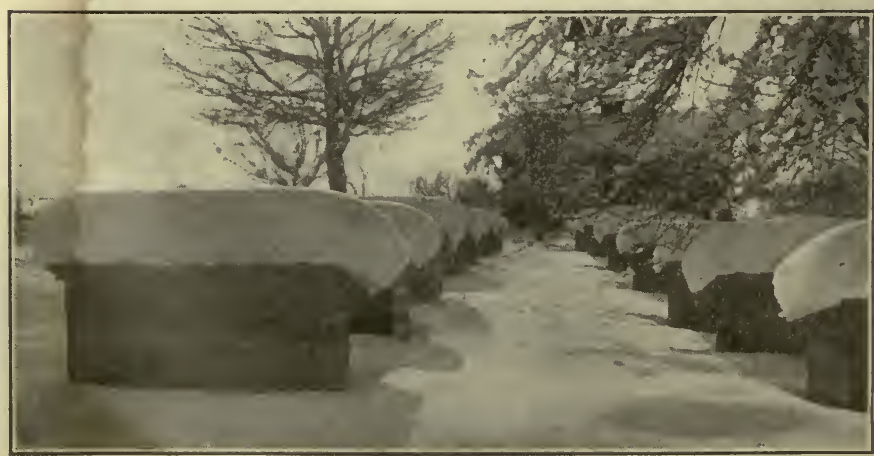

Wintering Bees out of Doors. 


\section{HOW TO WINTER BEES}

house apiaries have long since been discarded by progressive beekeepers, as the bees are always getting on the floor during the working season, to say nothing of other annoyances, that led to their rejection years ago.

The individual beekeeper must be the best judge as to the proper time to place his bees outdoors in the spring, but, generally speaking, the latter part of March, or, better still, when the pussy-willows are in bloom, or when settled, mild weather prevails, and a little added protection in the way of packing-paper placed about each hive as it is set out will help to keep down spring dwindling. The planer shavings, packing, and cases can be left on the hives of the bees wintered outdoors until fruit bloom, and will go a great way toward encouraging early brood-rearing, and here we have another advantage in favor of outdoor wintering with proper packing. In some of the northern states some beekeepers bury their bees for winter in long trenches or clamps, and cover them with branches and leaves and 
HOW TO KEEP BEES FOR PROFIT

a foot or so of earth, but we would not ad. vise such a plan, especially for the beginner.

A great deal more might be written about the wintering of bees and other plans discussed, but as we have given the best two, we need not add explanation concerning methods that have been discarded, as it will only be unprofitable and confusing. By all means winter out of doors, and by giving the proper protection for the hives in the winter cases fully described, you will have a plan which is ideal and that will help toward success in a hundred ways. 



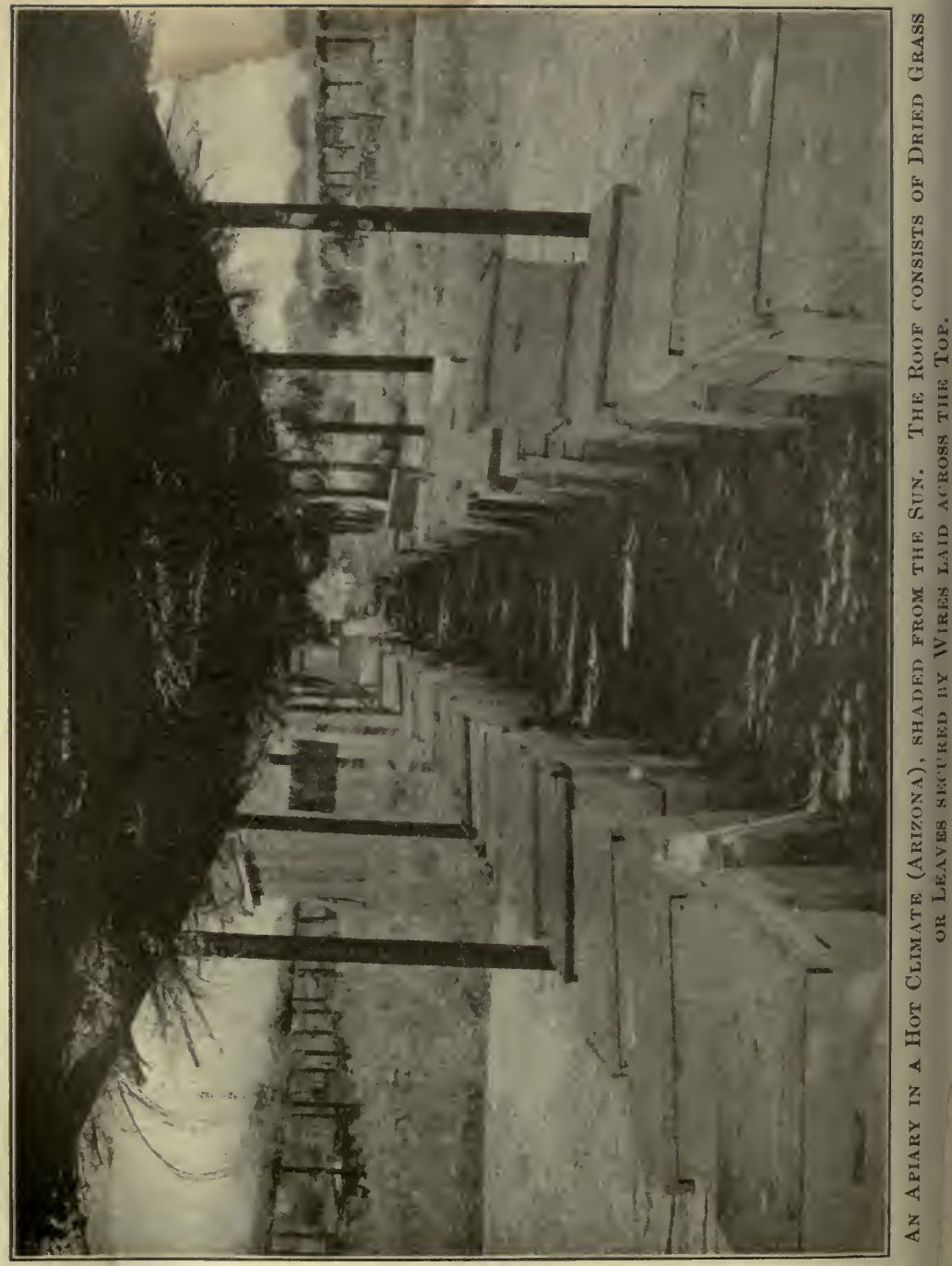




\section{CHAPTER XXI}

SOURCES OF HONEY

THE sources from which bees gather 1 their honey are many and unexpected, and often in a locality that would be considered unfavorable, they gather a surplus that is simply surprising. It is not even necessary to locate in a section where the presence of honey-secreting blossoms are noticeably abundant, for there are many plants seldom observed that yield to the beekeeper a goodly supply of honey.

Not every flower that blooms produces honey, and many a humble blossom likely to be overlooked will upon careful examination prove to be a most prolific source of revenue. Nor is it advisable to plant special crops such as alsike, clover, buckwheat, and other plants primarily for the honey they will 
HOW TO KEEP BEES FOR PROFIT

produce, but rather depend upon the bloom that is always present in greater or less quantity.

We would not gainsay the fact that the beekeeper is favored who is located in sections where honey-producing plants are cultivated, but, even so, a close scrutiny of the flora of any locality will reveal the presence of many a source upon which the busy bees will levy a handsome tribute.

Study your locality. The following list taken from a United States Department of Agriculture Bulletin will give some idea of the many sources of supply. The larger the type, the more important the plant:-

\section{NORTH AND NORTHEAST}

NAME [Above $40^{\circ} \mathrm{N}$.] TIME OF BLOOM

Red or Soft Maple (Acer rubrum) . . . April.

Alders (Alnus) . . . . . . April.

Elm (Ulmus) . . . . . . . . April.

Willows (Salix) . . . . . Apr-May.

Dandelion (Taraxacum taraxacum $=T$. offi-

cinale of Gray's Manual) . . . . Apr.-May.

Sugar, Rock, or Hard Maple (Acer saccharum

= A. saccharinim of Gray's Manual) . . Apr.-May. 298 


\section{SOURCES OF HONEY}

Juneberry, or Service Berry (Amelanchier canadensis) . . . . . . . May.

Wild Crab Apples (Pyrus) . . . . May.

Gooseberry and Currant (Ribes) . . May.

Peach, Cherry, and Plum (Prunus) - . May.

Pear and Apple (Pyrus) . . . . . . May.

Huckleberries and Blueberries (Gaylussacia

and Vaccinium) . . . . . . May-June

Common, Black, or Yellow Locust (Robinia

pseudacacia) . . . . . . May-June.

European Horse-chestnut (Essculus hippocasianum

Common Barberry (Berberis vulgaris) . .

May-June.

Tulip Tree, or "Whitewood" (Liriodendron

tulipifera ) . . . . . . . May-June.

Grapevines (Vitis) . . . . . . May-June.

Rape (Brassica napus) . . . . . . May-June.

White Mustard and Black Mustard (Brassica

$a l b a$ and B. nigra) . . . . . June.

RASPBERRY (Rubus) . . . . J June,

WHITE CLOVER (Trifolium repens) . . June-July.

ALSIKE CLOVER (Trifolium hybridum) . June-July.

Edible Chestnut (Castanea dentata $=$ C. sativa

var. americana of Gray's Manual) . . June-July.

Alfalfa, or Lucern (Medicago sativa) • . June-July.

LINDEN, or BASSWOOD (Tilia americana) July.

Smooth Sumac (Rhus glabra) . . . . . July.

Buttonbush (Cephalanthus occidentalis) . . . July. 


\section{HOW TO KEEP BEES FOR PROFIT}

Melilot, Bokhara, or Sweet Clover (Meli-

lotus alba) . . . . . . . . July-Aug.

Indian Corn (Zea mays) . . . . . . July-Aug.

Melon, Cucumber, Squash, Pumpkin (Citrul-

lus, Cucumis, and Cucurbita) . . . July-Aug.

Fireweed (Erechthites hieracifolia) . . . July-Sept.

Chicory (Cichorium intybus) . . . . . July-Sept.

KNotweeds (Polygonum, especially $P$. penn-

sylvanicum and $P$. persicaria) . . . . Aug.-Sept.

BUCKWHEAT (Fagopyrum fagopyrum $=F$.

esculentum of Gray's Manual) . . . . Aug.-Sept

Indian Currant, or Coral Berry (Symphori-

carpos symphoricarpos $=S$. vulgaris of

Gray's Manual) . . . . . . Aug.-Sept.

Great Willow-herb (Epilobium angusti-

folium) . . . . . . . Aug.-Sept.

Thoroughwort, or Boneset (Eupatorium perfoliatum) . . . . . . . . . Aug.-Sept

Burr Marigolds (Bidens, especially Spanish

Needles, Bidens bipinnata) • . . Aug.-Oct. Wild Asters (Aster) . . . . . . Aug.-Oct. Goldenrods (Solidago) . . . . . Aug.-Oct.

MIDDLE SECTION

[Between $35^{\circ}$ and $40^{\circ} \mathrm{N}$.]

Redbud (Cercis canadensis) . . . . . Mar.-Apr.

Alder (Alnus rugosa $=A$. serrulata of Gray's Manual) 
Red or Soft Maple (Acer rubrum) . . . Mar.-Apr. Elm (Ulmus) . . . . . . . . Mar.-Apr. Willows (Salix) . . . . . . . Mar.-May.

Dandelion (Taraxacum taraxacum $=T$. offcinale of Gray's Manual) . . . . Apr.-May. Apricot (Prunus armeniaca) . . . . . Apr.-May. Juneberry (Amelanchier canadensis) . . . Apr.-May. Wild Crab Apples (Pyrus) . . . . . Apr.-May. Gooseberry and Currant (Ribes) . . . . Apr.-May. Rhododendrons (Rhododendron) . . . . Apr.-May. Peach, Cherry, and Plum (Prunus) . . . A Apr.-May. Pear and Apple (Pyrus) . . . . . . Apr.-May. Crimson Clover (Trifolium incarnatum) - Apr.-May. Huckleberries and Blueberries (Gaylussacia and Vaccinium) . . . . . . May. American Holly (Ilex opaca) . . . . . May. Black Gum, Sour Gum, Tupelo or Pepperidge (Nyssa aquatica $=N$. sylvatica of Gray's Manual) . . . . . . . May. Manzanitas (Arctostaphylos) (California) . . May. Common, Black, or Yellow Locust (Robinia pseudacacia) . . . . . . . May. Barberry (Berberis canadensis) . . . . May. TULIP TREE, or "POPLAR" (Liriodendron tulipifera) . . . . . . . . . May. Mountain Laurel (Kalmia latifolia) . . May-June, Grapevines (Vitis) . . . . . . May-June. Persimmon (Diospyros virginiana) . . . May-June 
White Clover (Trifolium repens) . . . . May-June. Alsike Clover (Trifolium hybridum) . . . . May-June. Raspberry (Rubus) . . . . . . May-June. Cowpea (Vigna sinensis) . . . . . . May-Aug.

Edible Chestnut (Castanea dentata $=C$. sativa var. americana of Gray's Manual) June. Chinquapin (Castanea pumila) . . . . . June. Catalpas, or Indian Bean Trees (Catalpa) - June. Magnolia, or Sweet Bay (Magnolia Glauca) June. Linden, or "LinN" (Tilia americana) . . . June. SOURWOOD, or SORREL TREE (Oxydendrum arboreum) . . . . . . June-July. Oxeye Daisy, or Whiteweed (Chrysanthemum leucanthemum) . . . . . . June-July. Smooth Sumac (Rhus glabra) . . . . July. Buttonbush (Cephalanthus occidentalis) . . . July.

Cleome, or "Rocky Mountain Bee Plant" (Cleome serrulata $=C$. integrifolia of Gray's Manual) (West) . . . . . July-Aug.

ALFALFA (Medicago sativa) (West) . . . July-Aug.

MELILOT, BOKHARA, or SWEET CLOVER (Melilotus alba) . . . . July-Aug.

Cucumber, Melon, Squash, Pumpkin (Cucumis, Citrullus, and Cucurbita) . . . . July-Aug.

Knotweeds (Polygonum, especially $P$. pennsylvanicum and $P$. persicaria) . . . . . July-Sept.

Buckwheat (Fagopyrum fagopyrum $=\boldsymbol{F}$. esculentum of Gray's Manual) . . . Aug.-Sept. 


\section{SOURCES OF HONEY}

Wild Asters (Aster, especially Неath-Like

Aster, Aster ericoides) . . . . . . Aug.-Oct.

Thoroughwort, or Boneset (Euputorium perfoli-

atum) . . . . . . . . Aug.-Oct.

Burr Marigolds (Bidens, especially Spanish

Needles, Bidens bipinnata) . . . . Aug.-Oct. Goldenrods (Solidago) . . . . . . Aug.-Oct. Indian Corn (Zea mays) . . . . . July-Aug.

SOUTH

[Below $\left.35^{\circ} \mathrm{N}.\right]$

Redbud (Cercis canadensis) . . . . Feb.-Mar.

Alder (Alnus rugosa $=A$. serrulata of Gray's

Manual) . . . . . . . Feb.-Mar.

Red or Soft Maple (Acer rubrum) . ․ . Feb.-Mar.

Elm (Ulmus) . . . . . . . . Feb.-Mar.

Willows (Salix) . . . . . . . Feb.-Mar.

Dandelion (Taraxacum taraxacum $=T$. officinale

of Gray's Manual) . . . . . . Feb.-Mar.

Apricot (Prunus armeniaca) . . . . . Feb.-Mar.

Carolina Cherry, or Laurel Cherry (Prunus

caroliniana) . . . . . . March.

Juneberry (Amelanchier canadensis) . . March.

Orange and Lemon (Citrus) . . . . Mar.-Apr.

Cottonwoods or Poplars (Populus) . . . Mar.-Apr.

Trti (Cliftonia ligustrina) (Florida and south-

ern Georgia, westward) . . . . Mar.-Apr.

Gooseberry and Currant (Ribes) . . . Mar.-Apr. 
Peach, Cherry, and Plum (Prunus) . . . Mar.-Apr. Pear and Apple (Pyrus) . . . . . Mar.-Apr.

Huckleberries and Blueberries (Gaylussacia and Vaccinium) . . . . . . . April. Crimson Clover (Trifolium incarnatum) . . . April. Black Gum, Sour Gum, Tupelo, or PepperIDGE (Nyssa aquatica $=N$. sylvatica of Gray's Manual) . . . . . . April. BALL, or Black SAGE (Ramona stachyoides, $R$. palmeri, etc. $=$ Audibertia stachyoides, etc., of the Botany of California) (California)

Gallberry, or Holly (Ilex glabra) . . . Apr-May. Manzanitas (Arctostaphylos) (California) . . Apr.-May. Acacias (Acacia) . . . . . . . . Apr.-May.

Common, Black, or Yellow Locust (Robinia pseudacacia) . . . . . . . Apr-May. Persimmon (Diospyros virginiana) . . . Apr.-May. Edible Chestnut (Castanea dentata $=C$. sativa var. americana of Gray's Manual) . Apr.-May. Chinquapin (Castanea pumila) . . . Apr.-May. Catalpas (Catalpa) . . . . . . . Apr.-May. Magnolias (Magnolia) . . . . . . Apr.-May. Rhododendrons, Rosebays, Azaleas (Rhododendron) . . . . . . . Apr-May-June Mesquite (Prosopis juliflora) (Texas and westward) . . . . . . . Apr.-July. Cowpea (Vigna sinensis) . . . . . Apr.-Aug. 
Tulip Tree, or "Poplar" (Liriodendron

tulipifera ) . . . . . . . May.

Mountain Laurel (Kalmia latifolia) . . . May.

Grapevines (Vitis) . . . . . . . May.

Raspberry (Rubus) . . . . . . . May.

China Berry, China Tree, or Pride of India

(Melia azedarach) . . . . . . . May.

WHITE SAGE (Ramona polystachya $=$ Audi-

bertia polystachya of the Botany of California)

(California) . . . . . . May-June.

HORSEMINT (Monarda citriodora) . . . May-July.

SOURWOOD, or SORREL TREE (Oxyden-

drum arboreum) . . . . . . May-June.

SAW PALMETTO (Serenoa serrulata) (coasts

of Georgia and Florida) . . . . May-June.

Banana (Musa sapientum) . . . . . May-Sept.

Linden, or "Linn" (Tilia americana) . • . June.

Red Bay (Persea borbonia $=P$. carolinensis of

Gray's Manual) . . . . . . June.

Indian Corn (Zea mays) . . . . . June-July.

Cucumber, Melon, Squash, Pumpkin (Cucumis,

Citrullus, and Cucurbita) . . . . . June-July.

CABBAGE PALMETTO (Sabal palmetto), coasts

of South Carolina, Georgia, and Florida) June-July.

BLACK MANGROVE (Avicennia tomentosa

and A. oblongifolia) (Florida) . . . June-July.

ALFALFA (Medicago sativa) . . . June-Aug.

Cotton (Gossypium herbaceum) . . . . June-Aug. 
HOW TO KEEP BEES FOR PROFIT

Melilot, Bokhara, or Sweet Clover (Meli-

lotus alba) . . . . . . . . . . June-Aug.

Wild Pennyroyal (Hedeoma pulegioides) . June-Sept.

Blue GuM and RED GuM (Eucalyptus globulus

and E. rostrata) (California) . . . July-Oct.

Wild BucKwheat (Eriogonum fasciculatum)

(California) . . . . . . . . Aug.-Sept.

Japan or Bush Clover (Lespedeza striata) . . Aug.-Sept.

Burr Marigolds (Bidens, especially Spanish

Needles, Bidens bipinnata) . . . . Aug.-frost.

Wild Asters (Aster, especially HeATH-LiKe

Aster, Aster ericoides) . . . . . . Aug.-frost.

Goldenrods (Solidago) . . . . . Aug.-frost.

It would be well-nigh impossible to give a complete list of all the flowers that are more or less important, but in addition to the list already given we append the following, by permission of the editor of "Gleanings in Bee Culture," and the beekeeper will do well to study it carefully and familiarize himself, with the plants that are present in his immediate vicinity. He will be astonished at the varieties to which his bees have access.

Words in small capitals mean the subject 306 


\section{SOURCES OF HONEY}

is treated of in "Gleanings in Bee Culture." "See" means the subject is treated of under another name.

Acacia dealbata, or silver wattle; California, from Australia; commercially important.

Acacia decurrens, black wattle; California; similar to the above.

Acacia farnesia (huisache); along the Rio Grande; much grown in Europe as an ornamental plant.

Acacia Greggii (catclaw, or uña de gato), Southwest Texas, New Mexico, and Arizona - see Catclaw.

Actinomeris squarrosa, golden honey-plant.

Agave Americana, pulque, Century Plant; Mexico, Southern United States.

Aguinaldo (Ipomea sidafolia), Cuba - see BeLlflower. Alders (Alnus).

Alfilarila (Erodium cicutarium), or pin clover; Arizona and California; an excellent honey and forage plant from Europe - see "pin clover" under head of Clover.

Alfalfa, or lucern (Medicago sativa), see Alfalfa.

Algarroba (Inga dulsis) and other species.

Alsike or Swedish clover (Trifolium hybridum) - see Alsike Clover.

Anchusa tinctoria, dye-plant. All the anchusas are excellent bee-plants.

Antignon leptopus, Mexican rose, or coralita, California, Florida, West Indies, and Mexico; an excellent honey-plant. 


\section{HOW TO KEEP BEES FOR PROFIT}

Apple (Pyrus). The whole apple family is here meant see Frutt-BLossoms.

Apricot (Prunus Armeniaca), California.

Archas sapota, sapodilla; fruit-tree of the tropics; Florida.

Ash (Fraxinus ornus) or flowering or manna ash; planted south for its beauty.

Asters (Aster) of many species almost everywhere - see Asters.

Asparagus (Asparagus officinalis), cultivated.

Artichoke, true or globe artichoke (Cynara scolymus).

Avocada pear (Persea gratissima), Florida.

Banana (Musa sapientum and M. Cavendishii), Florida and the tropics generally.

Berberry (Berberis vulgaris).

Basil, or mountain mint (Pycnanthemum lanceolatum).

Basswood, or American linden (Tilia Americana, also T. heterophylla), Southern Kentucky, and Allegheny Mountains - see Basswood.

Beans (Phaseolus lunatus), lima beans in California; horse beans (P. nanus) in British Isles and Holland.

Bee-balm (Melissa officinalis), garden flower.

Beggar-tick, or burr marigold (Bidens frondosa), United States - see Spanish NeEdle.

Bellflower, Christmas bells, Christmas pop, aguinaldo, campanilla, etc. (Ipomea sidofolia), of Cuba, Jamaica, and other West India islands and Mexico.

Bergamot (Monarda fistulosa), a kind of mint; United States. 


\section{SOURCES OF HONEY}

Bignonia radicans, south - see NECTAR.

Blackberry (Rubus), of many species; Europe and United States.

Black gum - see Nyassa or Túpelo.

Black mangrove (Avicennia nitida); Florida and the coasts of all tropic seas; generally known as mangrove except in British Guiana, where it is known as "courida"- see MANGROVE.

Blackheart, or water smartweed (Polygonum acre), closely related to buckwheat; Illinois.

Black mustard (Brassica nigra) - see Mustard.

Black sage (Ramona stachyoides and $R$. palmeri), California - see SAGE.

Bladdernut (Staphylea trifolia), north and west.

Blue gum (Eucalyptus globulus), Tasmania and California - see Eucalyptus.

Blue thistle (Echium vulgare) viper's bugloss; a weed from Europe; Virginia and Pennsylvania.

Boneset, or thoroughwort (Eupatorium perfoliatum), a honey-plant of considerable importance.

Borage (Borago officinalis), Europe, but now well known in the United States.

Box-elder, or ash-leaved maple (Acer negundo), Northern States.

Boxwood (Buxus sempervirens), the tree box of the Balearic Islands and Turkey; produces much honey but it is very bitter; introduced into the U.S.

Buckbush (Symphoricarpus vulgaris) - see BucK BUSH. 


\section{HOW TO KEEP BEES FOR PROFIT}

Buckeye (AEsculus glabra), Ohio and similar States.

Buckthorn (Rhamnus catharticus), Southern States.

Buttercup, oxalis of Bermuda (Oxalis Bermudiana), fine for those who wish to plant for bees.

Buckwheat (Polygonum fagopyrum) - see Buckwheat.

Buckwheat, wild (Polygonum acre), also blackheart.

Burdock (Lappa major), has white pollen.

Burr marigold (Bidens frondosa), a near relative of Spanish needle, which see.

Bush honeysuckle (Diervilla Japonica), cultivated, Japan.

Button-bush (Cephalanthus occidentalis); important on the overflowed lands of the Mississippi.

Butterweed (Senecio lobatus), South and Southwest.

Cabbage (Brassica oleracea) common cabbage: see also colza, rape, turnip, charlock, white and black mustard, belonging to the Cabbage family.

Campanilla (Ipomea sidafolia), Cuba - see Bellflower.

Canada thistle (Cirsium arvense), in Canada.

Cassia (Cassia chamøecrista). Probably all cassias are honey-plants.

Cardoon (Cynara cardunculus); good where grown for seed; very common in Argentina.

Cardinal flower (Lobelia cardinalis).

Carob bean (Ceratonia siliqua) - St. John's bread for the Southwest; similar to catclaw.

Carpenter's square - see Figwort.

Catalpa (Catalpa speciosa), hardy catalpa, planted for its timber and shade. 


\section{SOURCES OF HONEY}

Catclaw (Acacia Greggii), important in the Southwest see Catclaw.

Catnip (Nepeta cataria), an important honey-plant in Europe and North America.

Ceratonia siliqua, or St. John's bread, now introduced into the United States from Europe, will probably become important.

Chaste-tree (Vitex agnus castus) introduced from Europe into parks, cemeteries, etc. This and the New Zealand species, Vitex littorales, are excellent.

Chayote (Sechium edule), grown as a vegetable around New Orleans; a good honey-plant.

Cherry (Prunus cerasus), the cultivated cherry.

Chick pea (Cicer arietinum), known in the West as coffee pea; grown very largely in Mexico - "garbanza."

Chicory (Cichorium intybus), cultivated in Europe-a common weed here.

Chinquapin (Castanea pumila), of considerable importance to the South.

Cleome integrifolia, also C. spinosa, same as Rocky Mountain bee-plant, which see.

Clovers - see article under this head; also Alfalfa, Alsike, Sainfoin, Sulla, Crimson Cl., Sweet and PeaVINE CL.

Clover, alsike (Trifolium hybridium), Swedish cloversee Clover.

Clover, crimson (Trifolium incarnatum) - see CRIMsON Clover.

Clover, red (Trifolium pratense) - see Clover. 
Clover, yellow (Trifolium procumbens), New England, Eastern and Middle States to Tennessee.

Cocoanut (Cocoa nucifera), Florida and the tropics.

Coffee (Coffea Arabica and Liberica); honey clear, but season very short; sometimes grown in Florida.

Coreopsis (Coreopsis aristosa) - see Span, NeEdle; Illi. nois and Missouri.

Corn, Indian (Zea mays); under certain conditions maize, or corn, is a good honey-plant.

Cotton (Gossypium herbaceum); south; some say it compares with clover.

Cowpea (Vigna sinensis); Southern States.

Crab apple (Pyrus coronaria), New York; west and south.

Crocus (Crocus), of many species; both spring and fall varieties are good.

Crowfoot (Ranunculus repens).

Cucumber (Cucumis sativus). In the vicinity of picklefactories this plant yields quite a harvest of honey after clover is over.

Culver's root (Veronica Virginica); north.

Currant (Ribes rubrum), from Europe; cultivated.

Cytisus prcliferous alba - tree alfalfa; grown a little in California; a great honey-plant in the Canary Islands.

Dandelion (Taraxacum officinale).

Date (Phoenix dactylifera); a great honey-plant now being planted in Arizona and California.

Duranta plumieri, or pigeon-berry, recently introduced into Florida and California; an exquisite honey-plant. 


\section{SOURCES OF HONEY}

Ebony (Zygia flexicaulis), Southwest Texas - not the true ebony.

Echinops spherocephalus, also E. ritro-excellent plants for introduction - see Chapman, H. P.

Elms (Ulmus), of various species. Where plentiful the elms are of considerable importance on account of their aid in early brood-rearing.

Eriobotrya Japonica - loquat fruit of Japan; excellent honey-plant: Florida, Gulf Coast, California, Georgia, and Arizona; known in some sections as Japan plum.

Esparcette - see SAINFoIN.

False indigo (Amorpha fructicosa), Ohio, Pennsylvania; south and west.

Figwort (Scrofularia nodosa) - see Figwort.

Fireweed, or willow-herb, which see (Epilobium angustifolium), the great fireweed of the North; Ontario, Quebec, Northern Michigan, and the Hudson Bay country.

Fog-fruit (Lippia nodiflora), California (carpet-weed); Texas and the West Indies; a great honey-plant, but little known. See Carpet Grass.

Freesia refracta alba, an exquisite honey-plant grown in California for its bulbs; also in Florida and the Gulf Coast.

Gallberry, or holly (Ilex glabra), south; important.

Genip (Melicocca bijuga), in South Florida; heavy yielder where common.

Germander, or wood-sage (Teucrium Canadense).

Giant hyssop (Lophanthus) - species, north and west. Gill-over-the-ground, or ground-ivy (Nepeta glechoma). 
Giant mignonette (Reseda grandiflora) - see Mignonetre. Golden apple (Spondias dulcis), Florida.

Golden honey-plant (Actinomeris squarrosa).

Goldenrod (Solidago), - species.

Gooseberry (Ribes grossularia).

Grape (Vitis labrusea).

Ground-ivy (Nepeta glechoma).

Heal-all, or figwort (Scrofularia nodosa) - see Figwort.

Hibiscus esculentus - okra, or gumbo, of the South.

Hibiscus sabdariffa - Jamaica sorrel of Florida.

Huajilla (Zygia brevifolia), Texas and adjacent countries. See Huajilla.

Hawthorn (Cratagus Oxycantha), Great Britain, Ireland, and North Europe; introduced here.

Hazelnut and filbert (Corylus avelana and C. Americana), valuable in early spring for pollen.

Heartsease, which see, or large smartweed (Persicaria mite), on the overflowed lands of the Mississippi River.

Heather (Erica vulgaris); a prolific source of honey in Europe and the British Isles. The honey is thick, with a rich flavor. In the same latitude on this continent its place is taken by the fireweed, which see - an excellent yielder also.

Hercules club (Aralia spinosa).

Hemp (Cannabis sativa, also $C$. Indica), ganja of the East.

Horehound (Marrubium vulgare). Good yields of honey have been reported from this plant; but it is so bitter as to be worthless except as medicine. It might improve with age. 


\section{SOURCES OF HONEY}

Hog-plum (Spondias lutea); Florida; a splendid yielder of honey. Known as hobo in Cuba.

Holly, American (Ilex opaca).

Honey-locust (Gleditschia triacanthos), also known as white locust.

Honeysuckle (Lonicera caprifolia), and some other species not so well known.

Horse-chestnut (Eculus hippocastanum), European species.

Horsemint, which see (Monarda fistula).

Hoya carnosa, or wax-plant - see Nectar.

Huisache, Mexican name for Acacia Farnesiana, a beautiful tree of the Southwest, similar to catclaw.

Indian currant, coral-berry, buckbush, which see (Symphoricarpus vulgaris).

Ironwood, or hornbeam (Carpinus Americana).

Japanese buckwheat - see BUCKWHEAT.

Japan plum; south; same as "loquat."

Japan privet (Ligustrum Japonicum), all Southern States and California; hedge-plant of the best.

Judas-tree, redbud (Cercis Canadensis).

June-berry, service-berry, shad-berry (Amelanchier Canadensis).

Knotweed, or, HEARTSEASE which see (Persicaria mite).

Lantana (L. nivea and L. mixta), Florida, Bahamas, and Bermuda.

Lemon (Citrus limonum), Florida and California.

Lentil (Ervum lens), or pulse of the East; much used in Europe to make soup. Italians grow it in this country. 


\section{HOW TO KEEP BEES FOR PROFIT}

Lime (Tilia Europea), English name for linden or basswood; now much planted as an avenue tree in the United States.

Lime (Citrus limetta); Florida, California, and the West Indies.

Limnanthes Douglasii, or marsh-flower; native of California; cultivated in England for bees.

Linden (Tilia Europea), or European basswood; famous in Berlin and other places as a street tree; now popular in the United States.

Liquidambar Styraciflua, sweet gum; very important, particularly south.

Locust, which see (Robinia pseudacacia); now being planted for its timber in Ohio and other States. See Locust.

Logwood (Hcomatoxylon Campechianum); the various states bordering on the bay of Campeche; introduced into Florida, Jamaica, West Indies, and South America. See LoGwood.

Loquat (Eriobotyra Japonica); sometimes wrongly named Japan plum; south; valuable because it flowers very late.

Lucern (Medicago sativa); the English name for the Spanish alfalfa.

Lupine (Lupinus perennis).

Madrona (Arbutus Xalapensis), southwest.

Magnolia (M. grandiflora and others); south.

Malva (M. alcea).

Mammoth red or peavine clover - see Clover.

Manzanita (Arctostaphylos), California. 


\section{SOURCES OF HONEY}

Maples (Acer), - species. The different species are of much value, yielding well for early broed-rearing.

Marigold, which see (Gailardia pulchella).

Marjoram (Origanum vulgare).

Marsh sunflower (Helianthus strumosus).

Matrimony-vine (Lycium vulgare).

Meadow-sweet, or spiræa (Spirea salicifolia).

Melilot (Melilotus alba), or honey lotus - see SwEET Clover, white and yellow.

Melons (Cucurbita melo). Melons of all kinds are valuable to apiarists.

Mesquite, which see (Prosopis pubescens and juliflora); southwest and New Mexico.

Mignonette (Reseda odorata).

Milkweed (Asclepias cornuti).

Milk-vetch (Astragolus Canadensis).

Motherwort (Leonurus cardiaca).

Mountain laurel, sheep laurel, rhododendron (Kalmia latifolia), famous for producing honey which has sickening properties - see Porsonous H. P.

Mustard (Brassica arvensis), charlock of England.

Okra, or gumbo (Hibiscus esculentus).

Onion (Allium cepa). There are reports of yields of honey from fields of onions cultivated for seed, having very strongly the peculiar onion odor, which, however, disappears after a time.

Orange (Citrus aurantium); considered valuable in some places.

Oxeye daisy (Bellis integrifolia); Kentucky and southwest. 


\section{HOW TO KEEP BEES FOR PROFIT}

Palmetto.

Parsnip (Pastinaca sativa), from the common parsmip run wild.

Partridge pea (Cassia chamcecrista).

Peach (Prunus Persica) - see Fruit-Blossoms.

Peavine, or mammoth red clover (Trifolium pratense) see Clover.

Pecans (Hicoria Pecan). Good in the South.

Pepperidge - see Tupelo.

Peppermint (Mentha vulgaris).

Pepper-tree (Schinus molle), California and Florida; fine shade-tree; excellent for honey.

Persimmon (Diospyrus Virginianum and Texana); known as "lotus" in Europe.

Phacelia tanacetifolia, a beautiful garden-plant from California.

Phormium tenax, New Zealand flax; sometimes grown south; good yielder; may become very important commercially.

Pin-clover, or alfilarila (Erodium Cicutarium Geranicœ).

Plane-tree (Platanus orientalis), also known as sycamore or buttonwood; good in Europe, and introduced here; similar to our sycamore; a fine shade-tree.

Plantain, or rib-grass (Plantago major), has white pollen.

Plantain fruit (Musa paradisica), similar to the banana, but extensively used as a vegetable in all tropic latitudes, Florida, and Porto Rico.

Pleurisy-root (Asclepias tuberosa); highly praised by James Heddon. 
Plums. All kinds of wild plums yield honey.

Poinciana regia, Florida.

Poplar, or whitewood, which see (Liriodendron tulipifera)

Poplar (Populus), south.

Prairie clover (Petalostemon candida), good in Texas.

Protea mellifera alba, South Africa; a wonderful yielder of honey. See Nectar.

Pumpkin (Cucurbita pepo); cultivated; the original, C. ovifera, runs wild in Texas.

Rape (Brassica campestris).

Raspberry (Rubus strigosus), Northern Michigan and similar localities; $R$. idosis, European raspberry, and $R$. rosafolius, Porto Rico and West Indies.

Rattan (Berchemia scandens); Texas; a heavy yielder.

Rattlesnake root, or white lettuce (Nabalus altissimus).

Rattleweed, or figwort, which see.

Redbay (Persea Carolinensis), south.

Redbud, or Judas-tree (Cercis Canadensis).

Red gum (Eucalyptus rostrata), California and native of Australia.

Rhododendron, species; rosebays, azaleas, species; and sheep laurels, or mountain laurels; important in the mountains of the South; known in England as American plants. Rhododendron pontica was the source of the honey which poisoned Xenophon's army of ten thousand.

Rocky Mountain bee-plant, which see (Cleome integrifolia).

Royal palm (Oreodoxa regia), Florida, Cuba, and Porto Rico 


\section{HOW TO KEEP BEES FOR PROFIT}

Rose apple (Eugenia jambos), Florida; very important in Cuba and Porto Rico.

Sage, black (Ramona stachyoides and $R$. palmeri); very important in California - see SAGE.

Sage, white (Ramona polystachia); Callfornia.

St. John's-wort (Hypericum), 一 species.

Sage, button, same as black sage, which see.

Sainfoin, which see (Onobrychis sativa); a great plant, similar to alfalfa.

Saw palmetto (Sabal serrulata); Georgia and Florida.

Serradella clover (Ornithopus sativus); a fine honey-plant, similar to sainfoin, which see.

Shadbush (Amelanchier Canadensis), also known as Juneberry and service-berry.

Shaddock, pomelo, or grape fruit (Citrus decumana); Florida and California.

Simpson honey-plant, same as figwort, which see.

Smartweed, same as heartsease, which see.

Sneezeweed (Helenium autumnale).

Sorrel-tree, same as sourwood, which see.

Sourwood (Oxydendron arboreum); Pennsylvania, Ohio, and south.

Spanish needle, which see (Coreopsis aristosa and C. aurea), better known as tickseed.

Spider-flower or spider-plant, which see (Cleome pungens).

Square-stalk, same as figwort, which see.

Squash (Cucurbita maxima).

Stone crop (Sedum pulchellum), south. 


\section{SOURCES OF HONEY}

Strawberry (Fragaria vesca); cultivated.

Sulla clover (Hedysarum coronarium), or Spanish sainfoin;

a good honey-plant for the Gulf States.

Sumac (Rhus venenata).

Sunflower (Helianthus major).

Sweet clover (Melilotus alba) - see Clover.

Sweet gum - see Liquidambar styraciflua.

Sweet potato (Ipomea batata).

Tea (Thea Bohea).

Thistle (Cirsium arvense), Canada.

Thyme (Thymus vulgaris). The classical honey of Mount Hymettus was from this.

Tickseed, or Spanish needle, which see.

Ti-Ti (Cliftonia monophylla); Georgia and Florida principally.

Touch-me-not, or swamp balsam (Impatiens pallida) see Pollen.

Trefoil, or clover, which see.

Tulip-tree, or whitewood, which see (Liriodendron tulipifera).

Tupelo (Nyssa multiflora), common tupelo, or sour gum; $N$. aquatica, water tupelo or gum; N. uniflora, large tupelo; $N$. capitala, Ogeechee lime; very important south.

Turnip (Brassica depressa).

Valerian (Valeriana edulus); Ohio and westward.

Varnish-tree (Alyanthus glandulosa); south from Japan; honey bad.

Vervain (Verbena officinalis). 
Viper's bugloss, or blue thistle, which see (Echium vulgare). Vetch (Vicia), - species.

Virginia creeper (Ampelopsis quinquefolia).

Vitus bipinnata, south.

Vitex agnus castus, chaste-tree in Europe and United States; introduced; $V$. littoralis, important in New Zealand.

White mustard (Brassica alba).

Whitewood, which see (Liriodendron tulipifera).

White sage (Ramona polystachya), California.

Wild buckwheat (Polygonum); produces a light-colored honey.

Wild cherry (Prunus Pennsylvanica), north.

Wild senna (Cassia chamcerista).

Wild rose (Rosa Carolina, lucida, blanda, canina, rugosa).

Wild sunflower (Helianthus), - species.

Willow (Salix). All species form an important class, coming as they do early in the season, and yielding both honey and pollen.

WiLLOW-HERB, which see (Epilobium angustifolium), northern parts of the United States and Canada.

Wistaria (Wistaria chinensis).

Yellow-wood (Virgilia lutea). Virginia. One of the finest native ornamental trees.

\section{CONCLUDING WORD}

T ET no one imagine from the foregoing 1 chapters of this work that beekeeping is a royal road to wealth, for there is a vast amount 
of experience and hard work demanded to make it a success, but it can be said in all truthfulness, that for the amount of time and application given to this most interesting department of rural life, the returns are far greater than in almost any other field of endeavor.

To be out in the great outdoors, amid the hum of these marvellously active and wonderfully intelligent creatures, is compensation enough in itself for the labor we give to them. But taking a more practical and perhaps sordid view of the subject, there is no reason in the world why any man or woman of intelligence may not, after several seasons' experience, make the bee a sole means of livelihood, and in the doing have their work confined to the most delightful months of the year. The practical work in the bee yard will be compassed between March and November, while the rest of the year may be devoted to disposing of the crop or in other avenues of congenial endeavor. 
Beekeeping has been called the poetry of agriculture, and certainly there is no more noble profession on earth, nor one in which the exercise of skill and experience will bring a more liberal income for men and women who give their time and effort to its pursuit.

As we stand amid the hives and hear the merry hum of its many thousand denizens, there will come to us again and again a feeling of contentment in the knowledge that their multiplied efforts are in our behalf; and when the season draws near for the gathering of the harvest of golden nectar, how proud we are to know that owing to our skill and direction, the busy little people have succeeded in gathering far more nectar than if left to their own inclinations. The greatest of the world's writers have written of these wonderful little creatures; how infinitely better is it to know and care for them and realize they are ours, and have wrought to make us happier and wealthier. 


\section{N D E X}

After-swarms, treatment of, 48. Age of bees, 46, 50-51.

Alexander, E. W., method of doubling colonies practised by, 153,170 ; experience of, in matter of large apiary in one yard, 185-186; treatment of bee diseases hy, 196-197.

Alexander feeder, the, 272-273.

Alfalfa as forage for bees, 173 .

Alley Method of queen-rearing, 109.

Alsatian gingerbread made with honey, 248.

American foul brood disease, 187194.

Antennæ of bees, 14.

Apiaries, system of out apiaries, $58,173 \mathrm{ff}$.; location of, and of hives in, $172 \mathrm{ff}$.; house apiaries, 294-295.

Apple-butter from honey, 246.

Artificial comb honey, impossibility of making, 31 .

Automatic hivers, fallacy of, 92.

Bakers, use of honey by ${ }_{3}$ 236-238.

Banat bees, 24.

Baskets for tools, 68 .

Basswood, fondness of bees for, 38.

Bears, damage to hives from, 200.

Bees, life of, 3; physiology of, 11-17; workers, $12,13,45,48-$ $49,52,54$; drones, $13,51,52-$ 54 ; queens, $13,26-27,41-44$, $46,48,97$ ff., $100,111,113-115$,
164-167, 199; races and varieties, 18-27; homes of, 28-39; constitution of family, 40-54; mating of, 41-43; moving of, $59-64,179-180$; handling of, 73-82; swarming of, 83-96; increasing of, 152-171; diseases of, 187-198; enemies of, 199201 ; robbers and robbing, 258268 ; feeding, 269-282; wintering of, 283-296.

Beeswax, uses of, 217-219; methods of rendering, 221-229. See Wax.

Bingham uncapping knife, 145.

Birds as bee enemies, 199.

Black bees, 18-20; resemblance of Caucasians to, 24.

Black brood disease, 189-192, 194-197.

Bleaching of wax, 225-228.

Blood of bees, 16 .

Boardman entrance feeder, 168 , 273.

Books on bees, 11, 17.

Bottling extracted honey, 204205.

Brood nest, the, 71-72.

Buckwheat, as forage for bees, 173; flavor of honey from, 231.

Candles from beeswax, 218, 229.

Candy from honey, 245, 247, 249, $252,253$.

Carniolan bees, 21-22.

Caucasian bees, 22-24.

Cellars for wintering bees, 291-294. 


\section{N D E X}

Cells, size and structure of, 33-34; of queen bees, 46 .

Chaff hives for outdoor wintering, 287.

Wothing for beekeepers, 68-70.

Clover, flavor of honey from, 231.

Color of honey, variation in, 231.

Colors, bees' choice of, 69-70.

Comb honey, shallow brood nest hives for, 71-72; production of, 117-132; marketing of, $208 \mathrm{ff}$.; grading of, 211-215; choice of sections for, 215-216.

Combs, structure and composition of, 12; method of manufacture, 32-33.

Concrete hive stands, 176.

Constipation, honey a cure for, 249, 255-256.

Cooking recipes with honey, 240253.

Cough-cures from honey, 246, 254, 256, 257.

Croup remedy from honey, 255.

Cyprian bees, 20-21.

Daisy Foundation fastener, 123.

Diseases of bees, 187-199.

Distance that bees will travel, 185.

Doolittle Division board feeder, 277.

Doolittle system of queen-rearing, 108-109.

Dragon flies as bee enemies, 199.

Dress for women beekeepers, 6869.

Drinks from honey, 246-247.

Drones, class of bees constituting, 13; fertilization of queen bees by, 44-45; rearing and development of, 51; eggs which produce, 52-53; life of, 53-54.

Dyspepsia remedies from honey, $247,255$.
Eggs, 12-13; for production of queens, 46 ; for production of worker bees, 48-49; development of, into grubs, 49 ; laying of drones' and workers', 52.

Embalming, beeswax used in, 217.

Enemies of bees, 199-201.

Escape boards, 129.

European foul brood disease, 187188, 194-197.

Excluding-boards, 136-137.

Extracted honey, defined, 117; production of, 133-151; marketing of, 203-208.

Extractors, selection of, 143-145.

Eyes of bees, 14.

Feeding and feeders, 168, 269282.

Field mice as bee enemies, 199 200.

Flavor of honey affected by its source, 37-38.

Food constituents in honey, $230 \mathrm{ff}$.

Forage for bees, 172-173, 297321.

Foul brood disease, 187-191.

Foundation, wax, 30-31; the cutting of, 122; methods of fastening to tops of section boxes, 123; importance of properly wiring in, 135; pure beeswax the only, 218 .

Frames for hives, 29-30; choice of, 72 ; question of depth of, 119.

Frogs as bee enemies, 199.

Funeral, story of bees at a, 35-36.

"Gleanings in Bee Culture," quoted, 154-157.

Gloves for working with bees, 81 . Grading comb honey, 211-215.

Hazel Atlas Simplex jars, 205.

Hearts of bees, 16 . 


\section{N D E X}

Hetherington, Captain, plan of swarm control of, 93-94.

Hives, manufacture of, 64 ; size of, 64-65; choice of, 70-72; opening of, 76-79; advantages of modern, 118-119; question of depth, 119; size of, for production of extracted honey, 137; location of, 174-175; arrangement of, in groups, 175-176; stands for, 176-177; for outdoor wintering, 287.

Hive tools, 67-68.

Homes of bees, 28-39.

Honey, amount of, produced by single hive, 7-8; not a product but the food of bees, 36-37; effect of sources on flavor, 37; sources of, 55-58, 297-321; comb honey and extracted honey, 117; receptacles for storing extracted, 149; marketing of, 202-216; food constituents in, $230 \mathrm{ff}$.; superiority of, to sugar for certain purposes, 234-237; use of, in bread, cakes, and confectionery, 237-239; as medicine, 239; in soaps and salves, 239-240; in cooking recipes, 240-253.

Honey-boards, 136-137.

Honey-bread, 237-238.

Honey sac, the, 15.

House apiaries, 294-295.

Hybrids, 20.

Implements, 65-68.

Increase, methods of artificial, 152-171.

Indoor wintering, 284-286, 291295.

Italian bees, 18, 20, 24-27; as robbers, 258.

Jars for honey, 203-205.

Jumbles, honey, 238, 240-241.
Kneipp's honey-salve recipe, 254

Knives, choice of, for uncapping, 143-146.

Langstroth, L. L., father of American bee-keeping, vii; frame hive invented by, 30 .

Larvæ, 49-50; grafting of, 104105.

Life, length of bees', 3 .

Liquefying granulated honey, 204-205.

Literature on bees, 11, 17 .

Location of apiaries, 172-175.

Lyon feeder, the, 274-276, 279280.

McEvoy, William, treatment of diseased bees by, 193-194.

Marketing of honey, 202-216.

Mating of bees, 41-44; of virgins under Swarthmore method, 109110.

Mating-boxes, 110.

Medicine, honey as, 239, 247, 249, 254-257.

Mice as bee enemies, 199-200.

Migratory bee-keeping, 181, 183184.

Miller, Dr. C. C., cited, 56.

Miller feeder, the, 278.

Mills, Don, mentioned, 161.

Moving bees, 59-64; from out apiaries to home yards, 179180.

Newspapers, use of, in preparing hives for outdoor wintering, 288.

Nurse bees, 49-50.

Odors, effect of, on bees, 70,74 ; distinctive odors of different bee colonies, 115 .

Orchards, question of locating hives in, 175.

Out apiaries, 58, 173 ff.; location 


\section{N D E X}

of, 174-175; operation of, 177179; general advisability of establishing, 184-186.

Dutdoor wintering, 283, 286-291, 295-296.

Overalls for women beekeepers, 69.

Paralysis, disease of bees, 197198.

Parthenogenesis among bees, 44 .

Paste made from honey, 247.

Phillips, E. F., bee expert, 195.

Physiology of bees, 11-17.

Plants on which bees feed, 306321.

Poison in stings, 16.

Pollen-gathering, 38-39.

Pollination of fruit blossoms by bees, 4-5.

Porter bee escape, the, 129.

Pratt, E. R., 101.

Preserves made with honey, 251.

Presses for extracting wax, 222224.

Prices of honey, 203, 206, 207.

Profits from bee-keeping, 6, 8-9, 206-207.

Propolis, bee-glue, 23, 34-35.

Purchasing swarms, 59.

Pure food laws, 208; effect on honey production, 231-232.

Queen bees, 13; choice of, in selecting Italian bees, 26-27; position of, in hives, 40-41; fertilization of, 41-44; appearance of, 44; age and powers of, 46 ; laying of eggs by, 48 ; raising of, $97 \mathrm{ff}$.; destruction of old, 100 ; tested and untested, 111; introduction of, to strange hives, $113-115,164-167$; enemies that prey on, 199 .

Queen-excluding boards, 136-137.

Queen-rearing, 97 ff.; Swarth- more system of, 101-110 danger from robber bees during 261.

Races of bees, 18-27.

Raising queen bees, 97-116.

Rauchfauss veil, the, 67 .

Recipes, honey cooking, 240-253.

Refining wax, method of, 225-228.

Reproduction, method of, 41-44, 83, 109-110.

Robbing, the matter of, 258-268.

Ronan, J. D., mentioned, 161.

Root Jumbo smoker, the, 66 .

Root twin mating-box, 110.

Root wire excluding-board, 137.

Rules for grading comb honey, 211-214.

Sale of honey, 202-216.

Sections, choice of size, 131; for marketing comb honey, 215.

Sentinel bees, 3 .

Shipping bees, 59-64, 180-183.

Shipping honey, 208-211.

Shipping-cases, 209-210.

Shook Swarm Plan, the, 90.

Simplicity feeder, the, 272 .

Skunks as bee enemies, 200 .

Smokers, 65-66.

Snakes as bee enemies, 200 .

Solar wax extractors, 221-222.

Sources of honey, 55-57, 297-321.

Spring dwindling, condition known as, 198-199; preventive measures, 285.

Stands for hives, 176-177.

Sting, the, 16.

Stings, avoidance of, 73-76; the poison of, 80 ; removal of, $80-$ 81; remedies for, 81; effect on the bee, 82 .

Sulking, treatment for, 126-127.

Super chamber, the, 71 ; insertion of, 124; for extracting honey, 133-134. 


\section{N D E X}

Superstitions concerning bees, 3536.

Swarming, reason for, 83; time of, 83-84; signs of, 84 ; method to be followed in case of, 86-87; plans to prevent, 89-96.

Swarthmore system of queenrearing, $101 \mathrm{ff}$.

Tents for use in working over hives, 267.

Tiering, process of, 125 ; in production of extracted honey, 140-141.

Time for handling bees, 76 .

Tongues of bees, 14-15.

Tools, 65-68.

Transferring bees from one hive to another, 60-63.

Transportation of bees, 59-60, 180-183.

Trouser legs, closing ends of, 68.

Uncapping, process of, 146-147.

Varieties of bees, 18-27.

Veils, 67.
Ventilation of cellars for wintering bees, 293-294.

Vinegar from honey, 251.

Virgin queens, flight and impregnation of, 199. See Queens.

Wax, method of securing, 139; uses of, 217-219; methods of rendering, 221-229; bleaching of, 225-228; use of, in confectionery, 239; as a base in salves, 240 .

Wax-building, process of, 32-33.

Wax extractors, 221-224.

Wax foundation, 30-31, 218.

Wintering bees, 283-296.

Women, as beekeepers, 6-7; proper dress for, 68-69.

Worker bees, $12,13,48-49$; socalled reverence of, for queen bees, 45; laying of eggs which produce, 52; treatment of drones by, 54 .

Young, life of the, 2; development and feeding of, 49-50; freedom from stinging by, 76 .

Zinc honey-boards, 136.

Printed in the United States of America. 



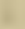

a,

$+2$

.

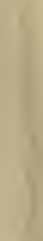

.

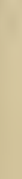

.

4 


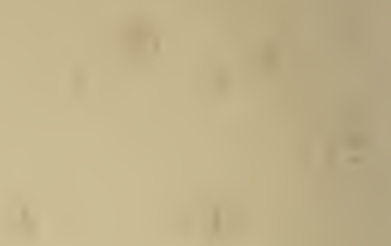

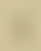

7

1

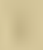
4

+

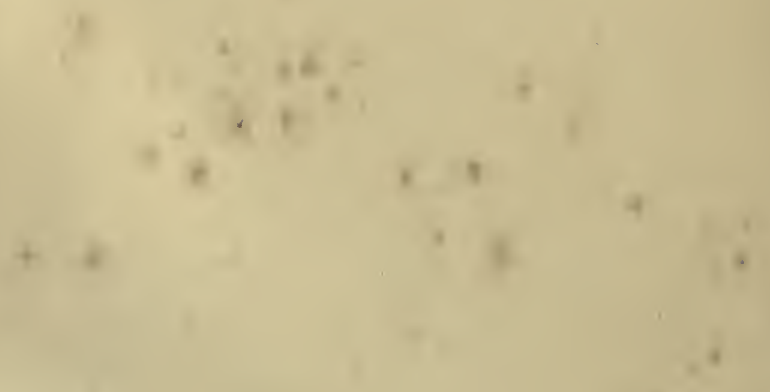





\section{THE UNIVERSITY LIBRARY UNIVERSITY OF CALIFORNIA, SANTA CRUZ}

This book is due on the last DATE stamped below.

To renew by phone, call 459-2756

Books not returned or renewed within 14 days after due date are subject to billing. 

